\title{
JULIANA CONTI
}

Teste de desempenho da função executiva: adaptação transcultural, avaliação das propriedades psicométricas e validade de constructo em indivíduos com acidente vascular cerebral

Dissertação apresentada à Faculdade de Medicina da Universidade de São Paulo para obtenção do título de Mestre em Ciências

Programa de Neurologia

Orientadora: Profa. Dra. Sônia Maria Dozzi Brucki

\section{SÃO PAULO}

2018 


\section{JULIANA CONTI}

Teste de desempenho da função executiva: adaptação transcultural, avaliação das propriedades psicométricas e validade de constructo em indivíduos com acidente vascular cerebral

Dissertação apresentada à Faculdade de Medicina da Universidade de São Paulo para obtenção do título de Mestre em Ciências

Programa de Neurologia

Orientadora: Profa. Dra. Sônia Maria Dozzi Brucki

\section{SÃO PAULO}

2018 


\section{Dados Internacionais de Catalogação na Publicação (CIP)}

Preparada pela Biblioteca da

Faculdade de Medicina da Universidade de São Paulo

Creprodução autorizada pelo autor

Conti, Juliana

Teste de desempenho da função executiva :

adaptação transcultural, avaliação das propriedades psicométricas e validade de constructo em indivíduos com acidente vascular cerebral / Juliana Conti. --

São Paulo, 2018.

Dissertação(mestrado)--Faculdade de Medicina da

Universidade de são Paulo.

Programa de Neurologia.

Descritores: 1.Acidente vascular cerebral

2. Função executiva 3.Terapia ocupacional 4.Cognição

5. Escalas 6.Estudos de validação

$\mathrm{USP} / \mathrm{FM} / \mathrm{DBD}-096 / 18$

Responsável: Kátia Maria Bruno Ferreira - CRB-8/6008 


\section{Dedicatória:}

Dedico esta tese ao meu marido Rodrigo e o nosso filho, Ricardo! Amo vocês! 


\section{AGRADECIMENTOS}

Este foi um longo período nas quais participaram pessoas muito especiais e que me ajudaram muito.

Em primeiro lugar, gostaria de agradecer aos pacientes e acompanhantes que participaram da pesquisa. Deslocaram-se de suas casas, uns com muita dificuldade, mas participaram e me ensinaram muito. Obrigada de coração!

Profa. Sonia Maria Dozzi Brucki, muito obrigada por todo o apoio desde o início! Nos momentos de maior e estresse e desespero você aparecia e conseguia me tranquilizar. Muito obrigada por assumir com tudo neste final do mestrado.

Profa. Carmen, talvez a senhora não saiba o quanto aquela nossa reunião informal de estatística me ajudou, tranquilizou e clareou as minhas ideias. Muito obrigada, afinal, consegui aprender muito com você naquele dia.

Aos meus amigos da pesquisa, Inara, Sarah, Eduardo e Karina. Estivemos juntos em momentos de crises, desespero e alegria. Obrigada pelo apoio e ajuda.

As queridas funcionárias da neurologia, Reiko, Sueli, Val e Thais. Obrigada pelo apoio e encorajamento. Nos momentos difíceis, vocês sempre tinham alguma palavra de conforto.

Aos queridos tradutores: Bia, Daltony e Sarah. Vocês fizeram um excelente trabalho, tornando a versão brasileira ainda mais bonita.

A Profa. Anette pela valiosa ajuda no projeto e como um exemplo de vida e pessoa. 
Não menos importante, meus pais e irmão que me deram todo o suporte e encorajamento nesta jornada.

Maridão, que turbulência foi este período. Você segurou as pontas e ainda trouxemos ao mundo o nosso terremotinho. 


\section{NORMATIZAÇÃO ADOTADA}

Esta dissertação está de acordo com as seguintes normas em vigor no momento desta publicação:

Referências: adaptado do International Committee of Medical Journal Editors (Vancouver).

Universidade de São Paulo. Faculdade de Medicina. Divisão de Biblioteca e Documentação. Guia de apresentações de teses, dissertações e monografias. Elaborado por Annelinese Carneiro da Cunha, Maria Julia A. L. Freddi, Maria F. Crestana, Marinalva de Souza Aragão, Suely Campos Cardoso, Valéria Vilhena. 3ํo edição. São Paulo. Divisão de Biblioteca e Documentação; 2011.

Abreviaturas dos títulos dos periódicos de acordo com a List of Journal Indexes in Index Medicus. 


\section{SUMÁRIO}

\section{LISTA DE ABREVIATURAS}

\section{LISTA DE FIGURAS}

\section{LISTA DE TABELAS}

\section{RESUMO}

\section{ABSTRACT}

1. INTRODUÇÃO

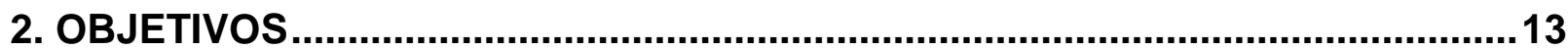

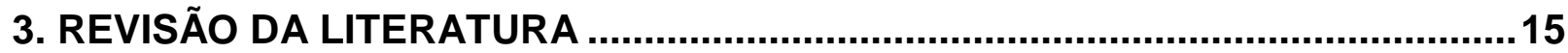

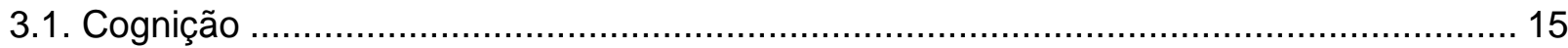

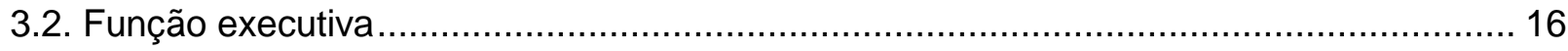

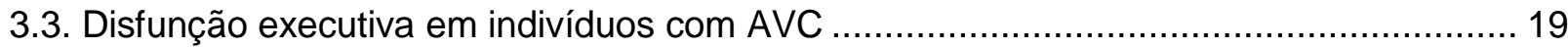

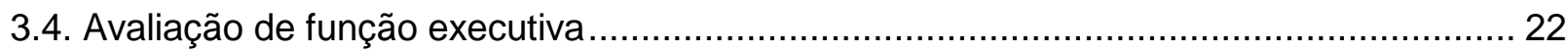

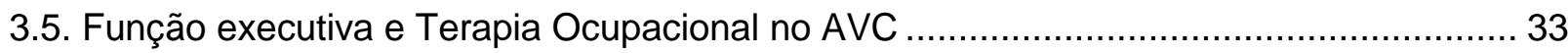

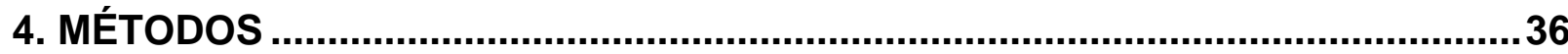

4.1. Caracterização do local, do período do estudo e dos grupos ......................................... 36

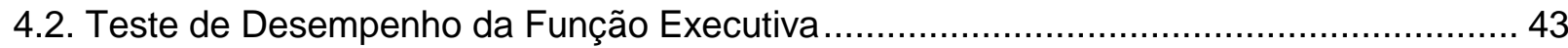

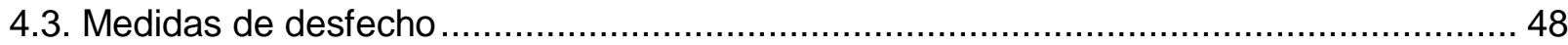

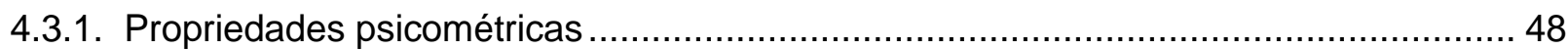

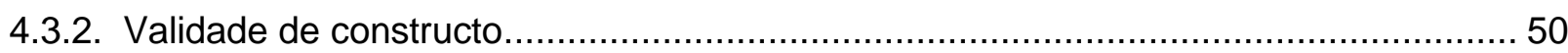

4.3.3. Relação entre a pontuação no Teste de Desempenho da Função Executiva no Sujeitos com AVC e variáveis demográficas, localização da lesão encefálica, sintomas de ansiedade e depressão.

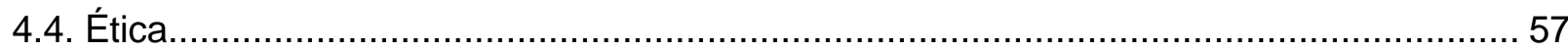

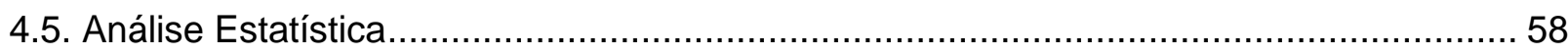

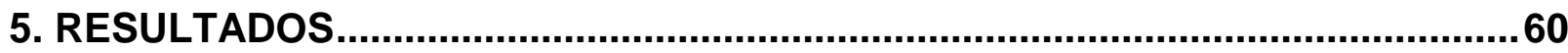

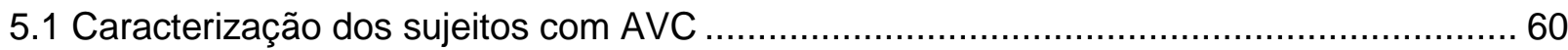

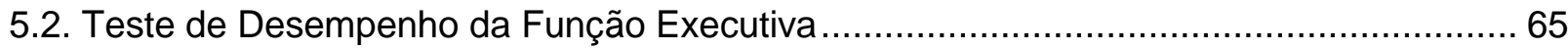

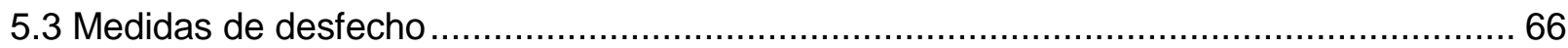

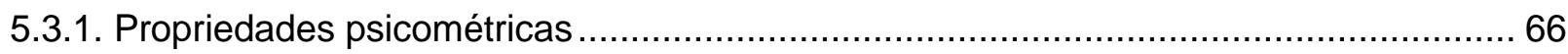

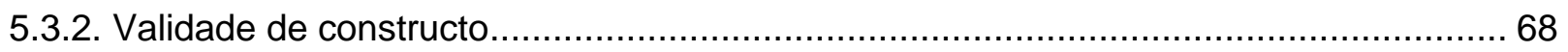


5.3.3. Relação da pontuação no Teste de Desempenho da Função Executiva dos Sujeitos com AVC e as variáveis demográficas, localização da lesão encefálica, sintomas de ansiedade e depressão....... 72

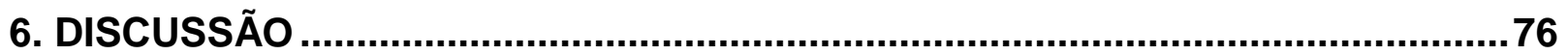

6.1. Composição da amostra e processo de avaliação dos sujeitos...................................... 77

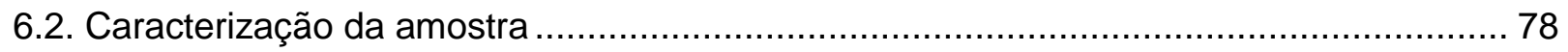

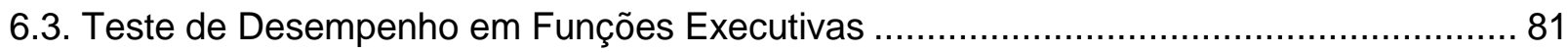

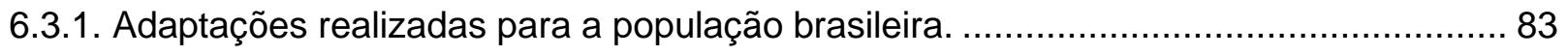

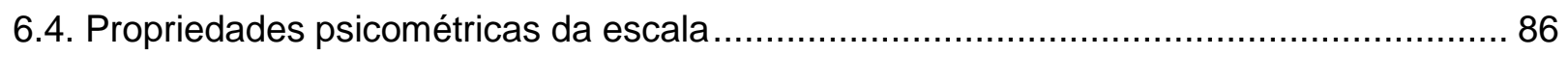

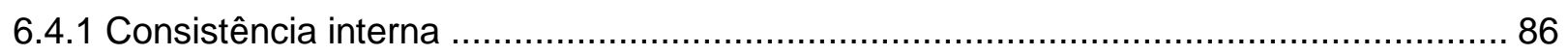

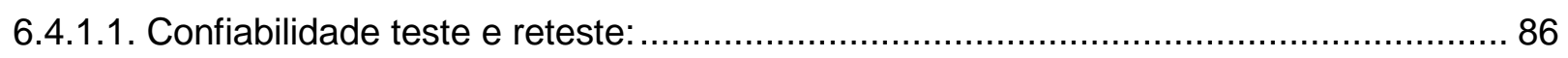

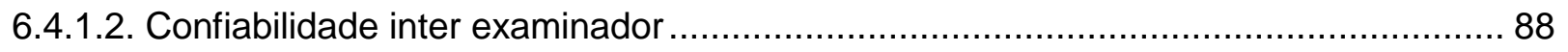

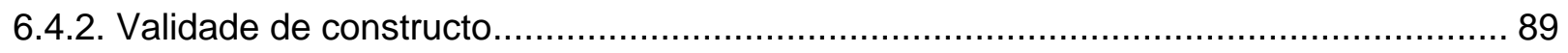

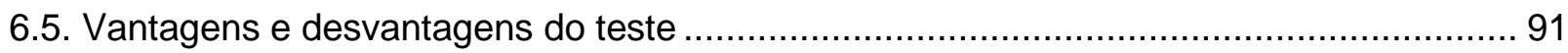

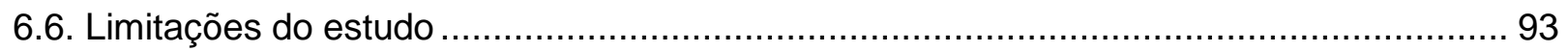

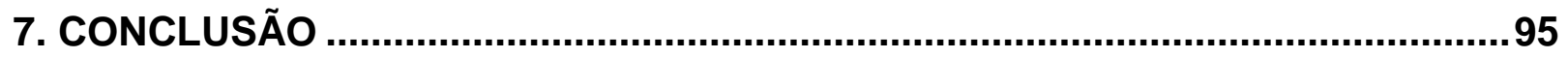

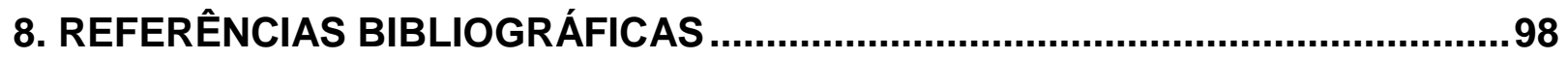

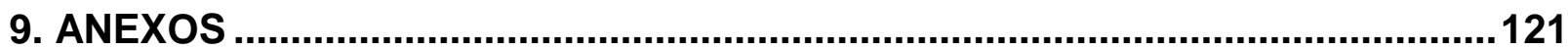

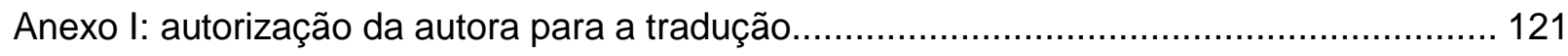

.

122

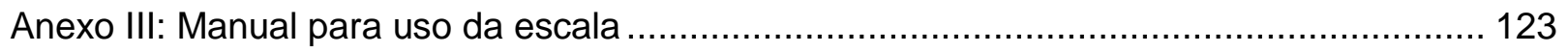

Anexo IV: Artigo publicado - Diversity of approaches in assessment of executive functions in stroke: limited evidence? (DOI: http://dx.doi.org/10.1016/j.ensci.2015.08.002) ....... 


\section{LISTA DE ABREVIATURAS}

AVC Acidente Vascular Cerebral

TDFE Teste de Desempenho da Função Executiva

AVD Atividades de Vida Diária

AIVD Atividades Instrumentais de Vida Diária

OMS Organização Mundial de Saúde

MEEM Mini Exame do Estado Mental 


\section{LISTA DE FIGURAS}

Figura 1. Fatores que recebem influência da Função Executiva 16

Figura 2. Fluxograma de inclusão dos sujeitos com AVC 37

$\begin{array}{ll}\text { Figura 3. Correlação entre a idade e anos de escolaridade } & 73\end{array}$ 


\section{LISTA DE TABELAS}

Tabela 1. Instrumentos de avaliação da função executiva em pacientes com até 1 mês após o AVC

Tabela 2. Instrumentos de avaliação da função executiva em pacientes com entre 1-6 meses após o AVC

Tabela 3. Instrumentos de avaliação da função executiva em pacientes acima de 6 meses após AVC

Tabela 4. Instrumentos de avaliação da função executiva em pacientes com AVC sem definição do tempo de lesão

Tabela 5. Características dos sujeitos com AVC

Tabela 6. Desempenho nos instrumentos de avaliação de função executiva

Tabela 7. Desempenho dos sujeitos com AVC em testes de avalição cognitiva (medianas e intervalos)

Tabela 8. Pontuação nas escalas de comprometimento de estruturas do corpo e de participação

Tabela 9. Pontuação em escala de participação (Escala de Impacto do AVC)

Tabela 10. Pontuação nas escalas de ansiedade e depressão

Tabela 11.Desempenho dos sujeitos com AVC no Teste de Desempenho

66 da Função Executiva

Tabela 12. Consistência interna do Teste de Desempenho da Função Executiva

Tabela 13. Confiabilidade Teste e reteste, Teste de Desempenho da Função Executiva

Tabela 14. Confiabilidade Inter examinador

Tabela 15.Correlação entre o Teste de Desempenho de Função executiva 69 e outros testes de função executiva 
Tabela 16. Correlação entre os instrumentos de rasteiro cognitivo e o

Teste de Desempenho da Função Executiva

Tabela 17. Correlação entre o Teste de Desempenho da Função

Executiva e as escalas de comprometimento de estruturas do corpo e de atividade

Tabela 18. Correlação entre o Teste de Desempenho da Função

72

Executiva e os domínios da Escala de Impacto do AVC

Tabela 19. Comparação entre o gênero e a pontuação de cada tarefa do

Teste de Desempenho da Função Executiva

Tabela 20. Comparação entre os anos de escolaridade a pontuação de

74 cada tarefa do Teste de Desempenho da Função Executiva

Tabela 21. Desempenho em cada tarefa separado por grupo de acordo com o local da lesão. As pontuações são mostradas como medianas e intervalos

Tabela 22. Correlação entre sintomas de ansiedade e depressão e o 


\section{RESUMO}

Conti J. Teste de desempenho da função executiva: adaptação transcultural, avaliação das propriedades psicométricas e validade de constructo em indivíduos com acidente vascular cerebral [dissertação]. São Paulo: Faculdade de Medicina, Universidade de São Paulo; 2018.

INTRODUÇÃO: As alterações cognitivas ocorrem em 30 a 55\% dos indivíduos com acidente vascular cerebral (AVC) e contribuem significativamente para a dependência funcional. Dentre as alterações cognitivas, a disfunção executiva ocorre em $18,5 \%$ a $39 \%$ dos casos. Quando o sujeito apresenta uma melhora funcional, consequentemente apresentará um ganho na qualidade de vida. Para o planejamento da reabilitação, é necessária uma avaliação adequada da disfunção executiva. Não há instrumentos de avaliação de disfunção executiva em língua portuguesa que tenham sido validados para serem aplicados a indivíduos com AVC por terapeutas ocupacionais no Brasil. O Teste de Desempenho da Função Executiva (TDFE) foi desenvolvido nos Estados Unidos por terapeutas ocupacionais, com o objetivo de avaliar a necessidade de auxílio para desempenhar quatro tarefas básicas do cotidiano: preparar uma refeição rápida, fazer uma ligação telefônica, tomar a medicação prescrita e pagar duas contas de consumo. Os objetivos deste trabalho são: (1) realizar a adaptação transcultural e avaliar as propriedades psicométricas (consistência interna, confiabilidade teste e reteste e inter examinador) da versão brasileira do Teste de Desempenho da Função Executiva em indivíduos com AVC; (2) avaliar a validade de constructo do Teste de Desempenho da Função Executiva; (3) avaliar a relação entre a pontuação no Teste de Desempenho da Função Executiva em indivíduos com AVC e variáveis demográficas, localização da lesão, sintomas de ansiedade e depressão. MÉTODOS: O estudo foi realizado no Laboratório de Neuroestimulação da Divisão de Clínica Neurológica do Hospital das Clínicas da Faculdade de Medicina da Unniversidade de São Paulo. Foram avaliados 86 indivíduos com AVC entre 02/05/2013 e 06/05/2016. A consistência interna foi avaliada pelo alfa de Cronbach. As confiabilidades inter e teste e reteste foram avaliadas pelo Coeficiente de Correlação Intraclasse (CCl). Para avaliação da validade de constructo foi calculado coeficiente de correlação de Spearman entre a pontuação no Teste de Desempenho da Função Executiva e desempenhos em outros instrumentos de avaliação de função executiva, assim como de escalas de comprometimento das estruturas do corpo, atividade e participação. RESULTADOS: O alfa de Cronbach calculado para a escala foi de 0,819. $\mathrm{O} \mathrm{CCl}$ para avaliação da confiabilidade teste e reteste foi de 0,435 (intervalo de confiança, 0, $096-0,684$ ). O CCl para avaliação da confiabilidade inter examinador foi 0,855 (intervalo de confiança, $0,516-0,855$ ). A pontuação no Teste de Desempenho da Função Executiva apresentou correlações estatisticamente significativas com as seguintes escalas: Fluência Verbal, rho=-0,452 ( $p=0,001)$; Teste do Relógio, rho=-0,324 ( $p=0,002)$; Teste de Extensão de Dígitos Diretos, rho=-0,219 ( $p=0,042)$; Teste de Extensão de Dígitos Inversos, rho=-0,324 ( $p=0,002)$, Teste do Mapa do Zoológico, rho=-0,388 $(p=0,001)$; teste Modificado dos Seis Elementos, $r=-0,463(p=0,001)$; Mini Exame do Estado Mental, rho=-0,352 ( $p=0,001)$; Memória Incidental (Bateria Breve de Rastreio Cognitivo), rho=0,252 ( $p=0,019$ );Memória Imediata 1 (Bateria Breve de Rastreio Cognitivo), rho=-0,308 ( $p=0,004$ ); Memória tardia (Bateria Breve de Rastreio Cognitivo), $r=-0,239$ ( $p=0,027)$; Questionário de Atividades Funcionais de Pfeffer, rho=0,420 ( $p=0,001)$; e escala de Lawton \& Brody rho=-0,313 $(p=0,003)$.CONCLUSÃO: o TDFE pode ser considerado como uma escala confiável e adequada avaliar a função executiva em pacientes com AVC.

Descritores: acidente vascular cerebral; função executiva; terapia ocupacional; cognição; escalas; estudos de validação 


\section{ABSTRACT}

Conti J. Executive function performance test: transcultural adaptation, assessment of psychometric properties and constructo validity in individuals with stroke [dissertation] São Paulo: "Faculdade de Medicina, Universidade de São Paulo"; 2018.

INTRODUCTION: Cognitive impairments occur in 30-55\% of patients with stroke and contribute significantly to functional dependence. Executive dysfunction occurs in $18.5 \%$ to $39 \%$ of patients who present cognitive impairments. Occupational therapy aims to facilitate independence and autonomy, hence improving quality of life. Adequate assessment of executive dysfunction is required in order to plan rehabilitation. There is a lack of validated tools that occupational therapists can use to assess executive dysfunction in individuals with stroke in Brazil. The Executive Function Performance Test was developed in the United States by occupational therapists, in order to assess the need for assistance to perform four basic daily tasks: prepare a quick meal, make a phone call, take the prescribed medication and pay two utility bills. The objectives of this work are to: (1) perform the cross-cultural adaptation and evaluate the psychometric properties (internal consistency, intra and inter rater reliabilities) of the Brazilian version of the Executive Function Performance Test in patients with stroke; (2) evaluate the construct validity of the Executive Function Performance Test; (3) evaluate the relation between scores in the Executive Function Performance Test in patients with stroke and demographic variables, location of the lesion, symptoms of anxiety and depression. METHODS: The study was conducted at the Neurostimulation Laboratory of the Clinical Neurology Division at Hospital das Clinicas, Sao Paulo University. We evaluated 86 patients with stroke between 02/05/2013 and 06/05/2016. Internal Consistency was assessed by Cronbach's alpha. The inter- and intra rater reliabilities were assessed by Intraclass Correlation Coefficients (ICC). Construct validity was evaluated by correlations between scores in the Executive Function Performance test and scores in other tools used for assessment of executive function, cognitive screening, scales of body structures impairments, participation and activity as well as instrumental activities of daily living. Spearman correlation coefficients were used to assess these correlations. RESULTS: The scale's Cronbach's alpha was 0.819 . The ICC for assessment of intra rater reliability was 0.435 (confidence interval, $0.096-0.684$ ). The ICC for assessment of intra examiner reliability was 0.855 (confidence interval, 0.516 to 0.855 ). There were statistically significant correlations between scores in the Executive Function Performance Test and the following scales: Verbal Fluency, rho $=-0.452(p=0.001)$; Clock Test, rho $=-0.324(p=0.002)$; Digit Span test (forward), rho $=-0.219$ $(p=0.042)$; Digit Span test (backwards) rho $=-0.324(p=0.002)$; Zoo map test, $r=-0.388(p=$ 0.001); Modified Six elements test, rho $=-0.463(p=0.001)$; Mini Mental State Examination, rho $=-0.352(p=0.001)$; Incidental memory (Brief Cognitive Battery), rho = -0.252 ( $p=0.019)$; Immediate memory 1 (Brief Cognitive Battery), rho $=-0.308(p=0.004)$; Delayed memory (Brief Cognitive Battery), rho $=-0.239(p=0.027)$; Functional Activities Questionnaire (Pfeffer), rho = $0.420(p=0.001)$; and Instrumental Activities of Daily Living Scale rho $=-0.313(p=$ 0.003).CONCLUSION: EFPT-BR is a valid and reliable tool for Occupational Therapists to evaluate the executive dysfunction in daily routine tasks in patients with stroke in Brazil.

Descriptors: stroke; executive function; occupational therapy; cognition; scales; validation studies 
1. INTRODUÇÃO 


\section{INTRODUÇÃO}

De acordo com a Organização Mundial de Saúde (OMS) o Acidente Vascular Cerebral (AVC) é definido como: "disfunção neurológica aguda de origem vascular com sintomas e sinais correspondentes ao comprometimento de áreas focais do cérebro" (WHO, 2014). O AVC isquêmico ocorre quando há diminuição ou interrupção do fluxo sanguíneo levando a infarto de áreas focais encefálicas, enquanto que no AVC hemorrágico ocorre uma hemorragia dentro do parênquima encefálico (hemorragia intraparenquimatosa) ou no espaço subaracnóideo (hemorragia meníngea) (Organização Pan-Americana de Saúde - Manual STEPS de Acidentes Vascular Cerebrais da WHO, 2005).

A incidência de AVC diminuiu nos países de renda mais alta, mas aumentou nos países de renda média ou baixa entre 1990 e 2010. Além disso, o número de indivíduos que sobreviveram a um AVC aumentou em torno de $84 \%$ em países de renda média ou baixa entre 1990 e 2010 (Feigin et al., 2014). No Brasil, há dois estudos populacionais sobre a incidência de AVC. Em Joinville, Santa Catarina foi observada uma incidência de 105,4/100.000 habitantes por ano entre 2005 e 2006 (Cabral et al., 2009). Em Matão, interior de São Paulo, entre 2003 e 2004 a incidência anual foi de 108/100.000 habitantes por ano (Minelli et al., 2007).

Quanto a incidência de AVC a partir do tipo de lesão, um estudo realizado na cidade de Fortaleza entre junho de 2009 e outubro de 2010, os autores observaram que a maioria dos sujeitos atendidos nos hospitais por AVC apresentaram uma lesão isquêmica (72,9\%), com um tempo médio de socorro após os primeiros sintomas de $12,9(3,8$ - 32,5) horas e apresentaram hipertensão como o principal sintoma. Ainda neste estudo, predominaram mulheres $(51,8 \%)$ e com idade média de $67,7( \pm 14,4)$ anos (Carvalho et al., 2011). 
Em um estudo mais recente, na cidade de Joinville, os autores, observaram um aumento na frequência de AVC entre os sujeitos com idade menor 45 anos (62\%) e aumento de $29 \%$ em sujeitos até 55 anos; sendo que o AVC isquêmico apresentou um aumento de $66 \%$ entre os casos (Cabral et al., 2017). Neste estudo, foi ressaltada a importância da conscientização e prevenção dos fatores de risco relacionados ao AVC, nesta faixa etária. Apesar do aumento de número de casos de AVC, a taxa de mortalidade após o evento diminuiu significativamente, cerca de $50 \%$ dos casos em todo o Brasil, sendo o Norte e Nordeste com a maior redução do número de pessoas que sofreram um AVC (Passos et al., 2016).

Outro fator importante a ser considerado em pessoas que sofreram um AVC é o acompanhamento hospitalar na fase aguda. Outro estudo comparou o atendimento de sujeitos que sofreram um AVC e permaneceram internados em enfermarias neurológicas/gerais com sujeitos acompanhados em uma unidade de AVC, foi observado um número menor de óbitos de sujeitos acompanhados na unidade de AVC, tanto imediatamente após o evento assim como 30 dias decorridos da lesão (Rocha et al., 2013). Mostrando assim a importância de um acompanhamento especializado para uma melhor recuperação após o AVC.

Com este aumento na incidência de AVC em adultos jovens (em fase produtiva), se torna importante discutir não apenas a prevenção, mas também a incapacidade gerada com o AVC. Uma medida da sobrecarga causada por diferentes doenças é a perda de anos de vida devido à incapacidade (DALYs - disability-adjusted life-years - Larson, 2013). No ano de 2010, o AVC representou a segunda causa de mortes no mundo e a terceira causa de perda de DALYs (Feigin et al, 2014).

Em outro estudo, os autores fizeram uma estimativa dos anos de vida do sujeito com sequelas após determinadas doenças (328) no mundo (Vos et al., 2017). Dentre 
as 30 doenças que mais deixam sequelas o AVC isquêmico está na $17^{\circ}$ posição no ano de 2016 (Vos et al., 2017). Quando discutido o número de anos perdidos por doenças diversas no mundo, as doenças cerebrovasculares (incluindo o AVC) e do coração foram consideradas líder em casos em 123 países no ano de 2016 para ambos os sexos (Naghavi et al., 2017). No Brasil, dentre as 10 doenças em que mais se perde anos de vida, o AVC está em 4ํlugar (Naghavi et al., 2017).

No Brasil os dados epidemiológicos mostram que 568.000/2.231.000 pessoas apresentam incapacidade grave após um AVC. Sendo que a prevalência foi maior em homens, com mais idade, menos escolaridade e morador da zona urbana (Bensenor et al., 2015). Em outro estudo sobre a sobrevida após o AVC que comparou hospitais em João Pessoa, Natal e São Paulo, os autores mostraram que 83\% (804/962) dos sujeitos apresentaram AVC isquêmicos e 16,4 \% (158/962) apresentaram AVC hemorrágico, sendo que a taxa de mortalidade foi maior entre os sujeitos com AVC hemorrágicos (Fernandes et al., 2012).Quando avaliada a taxa de mortalidade de sujeitos com AVC e suas causas no Brasil, um estudo apontou que as infecções causadas após o AVC são consideradas a principal causa de morte $(37 \%)$, principalmente nas mulheres (43,9\%) (Machado et al., 2012).

- Alterações cognitivas e funcionais após AVC

As sequelas neurológicas após um AVC contribuem para a dependência funcional. No estudo de Matão, foi estimado que $57 \%$ dos indivíduos que sofreram um primeiro AVC apresentavam dependência funcional, um ano após o evento (Minelli et al, 2007). Diversos aspectos interferem nesta dependência funcional do sujeito, entre eles a função cognitiva que pode sofrer alterações após AVC.

O comprometimento cognitivo sequelar ocorre em 30 a 55\% dos casos (Nys et al., 2007; Leśniak et al., 2008; Barker-Collo et al., 2010; Poulin et al., 2012) e contribui 
significativamente para a dependência (Poulin et al., 2012). Dentre as sequelas cognitivas, o déficit na função executiva pode ocorrer entre 18,5\%a $39 \%$ dos indivíduos com AVC, sendo apontada como o tipo de comprometimento mais frequente por alguns estudos (Nys et al., 2007; Leśniak et al., 2008; Poulin et al., 2012).

- Alteração cognitiva: em demência e neuropsicologia:

O comprometimento cognitivo vascular envolve todas as alterações cognitivas decorrentes do AVC ou de qualquer outra doença/lesão neurovascular e que podem levar a demência (Brucki et al.,2012). Neste estudo os autores avaliaram e acompanharam por um ano, 172 sujeitos após o AVC e observaram uma prevalência de $16,8 \%$ dos casos que apresentaram comprometimento cognitivo vascular ao término do estudo (Brucki et al.,2012). Outra pesquisa mostrou que além de ser um comprometimento frequente e gerar uma piora na funcionalidade de sujeitos mais idosos, dependendo do tamanho e da localização da lesão/ doença pode gerar um declínio cognitivo com consequências mais graves (Alves et al., 2008). Ainda neste estudo, foi observada a relação entre a alteração cognitiva (principalmente a função executiva) e a doença vascular isquêmica subcortical (Alves et al., 2008). Somado a isso, a perda do controle executivo frontal pode ser considerada um fator diferenciado para o diagnóstico da doença vascular isquêmica subcortical (Alves et al., 2008).

As alterações cognitivas e de função executiva na lesão/doença vascular podem levar ao processo demencial (Sudo et al.,2017). Embora os resultados tenham sido controversos, mostraram que os sujeitos com este tipo de lesão apresentaram um desempenho pior nos testes de função executiva (Teste das Trilhas e Teste de Stroop) (Sudo et al.,2017). Os autores ainda ressaltam a importância de um diagnóstico precoce da doença vascular isquêmica subcortical para amenizar as 
possíveis consequências em longo prazo, como a demência vascular (Sudo et al.,2017). Diversos estudos discutem sobre a doença vascular isquêmica subcortical e a diferença com outros tipos de demência. Além de ser considerada uma patologia de alta incidência, a doença vascular isquêmica subcortical tem como principal sintoma o déficit de função executiva (Matiolli e Caramelli, 2012). Neste estudo foram incluídos sujeitos com a doença vascular isquêmica subcortical, sujeitos com Doença de Alzheimer e sujeitos controles, mostrou que os sujeitos com a doença vascular isquêmica subcortical apresentaram pior desempenho no teste de fluência verbal, enquanto que os sujeitos com Doença de Alzheimer desempenharam pior na tarefa de evocação de memória (Matiolli e Caramelli, 2012).

- Função Executiva

A função executiva é considerada um domínio cognitivo central que controla diversas habilidades que geralmente estão relacionadas a tarefas mais complexas, novas ou que gerem conflitos para o sujeito (Godefroy e Stuss, 2007). As funções executivas envolvem planejamento, solução de problemas, capacidade em lidar com novas situações, tomar decisões e desempenhar tarefas complexas (Elliot, 2003). Estas funções fazem parte do processo cognitivo de adquirir, manter e aplicar o conhecimento (Burgess e Simons, 2009). Os déficits de função executiva englobam mudanças no comportamento e interferem no funcionamento de outros domínios cognitivos (Godefroy e Stuss, 2007).

Quando avaliada a funcionalidade dos sujeitos com AVC e sujeitos saudáveis, foi observado um pior desempenho dos sujeitos com AVC (Andrade et al., 2012). Além disso, os autores também observaram que o déficit de função executiva estava associado ao declínio da funcionalidade e sintomas depressivos em sujeitos com lesão subcortical isquêmica (Andrade et al., 2012). Os autores enfatizam a 
necessidade de investigar estes sintomas e déficits, pois podem indicar um comprometimento cognitivo vascular (Andrade et al., 2012).

Há correlações entre presença/gravidade de disfunção executiva e grau de comprometimento neurológico (Baum et al., 2008; Wolf et al., 2010) dependência funcional (Barker-Collo, 2010; Van de Port, et al., 2007; Cumming et al., 2013) e qualidade de vida (Van de Port, et al., 2007; Cumming et al., 2013). O déficit de função executiva pode ocorrer não apenas por uma lesão neurológica, mas também devido transtornos de humor (Vataja et al., 2005; Narushima et al., 2007; Tang et al., 2009; Melkas et al., 2010; Sibolt et al., 2013; Sobreiro et al., 2014). Sendo que este déficit influenciará as funções motoras, cognitivas e comportamentais (Liu-Ambrose et al., 2007; Rand et al., 2010; Kluding et al., 2011; Hayes et al., 2012; Liu-Ambrose e Eng, 2015).

Considerando a importância da cognição no processo de reabilitação de indivíduos com AVC e o papel central das funções executivas no desempenho cognitivo, é essencial que estas funções sejam mensuráveis por terapeutas ocupacionais.

Diversos estudos internacionais documentaram um pior desempenho de indivíduos com AVC que indivíduos saudáveis, em testes de função executiva aplicados a amostras não brasileiras (Leskela et al., 1999; Kramer et al., 2002; Mok et al., 2004; Vataja et al., 2005; Zinn et al., 2007; Baum et al.,2008; Wolf et al.2008, Josman et al., 2014; Motta et al., 2014).

- Processo de adaptação de um teste

Para a adaptação adequada a uma nova cultura, um instrumento deve não apenas ser traduzido para a nova língua, mas também adaptado às condições culturais da população a ser avaliada (Guillemin et al., 1993). A validade de um 
instrumento pode ser definida como a capacidade de medir o que ele se propõe a medir (Menezes e Nascimento, 2000). Além disso, a validação abrange a avaliação das propriedades psicométricas do instrumento, como confiabilidade (teste e inter examinador), validade (conteúdo, critério e constructo) e consistência interna.

Para que um instrumento seja adequado deve apresentar objetivo e o meio de alcança-lo, deste modo pode ser considerado com legítimo, pois mede o que se propõe a medir (Guillemin et al., 1993).

A validade do conteúdo se refere ao grau com que um instrumento evidencie um domínio especifico que ele deseja mensurar. Deve conter todos os itens do domínio que ele pretende medir. Fundamental que todo o domínio a ser avaliado seja descrito antes que o teste seja avaliado (Martins, 2006).

A validade de critério se refere ao grau com que o instrumento se correlaciona com um critério externo, o padrão ouro (Martins, 2006). Para este estudo não utilizamos a validade de critério, pois julgamos que não havia um padrão ouro (no momento da elaboração do projeto, dezembro de 2012) para que a escala fosse comparada.

Validade de constructo: é o grau com que o teste se relaciona consistentemente com outros instrumentos que apresentem a mesma teoria, os mesmos domínios a serem avaliados (Martins, 2006)

- Avaliação de funções executivas

Existem instrumentos de avaliação de função executiva em língua portuguesa como o Teste das Trilhas (Montiel e Seabra, 2012), o Teste de Stroop (Capovilla et al., 2005) e a Bateria de Avaliação Comportamental da Síndrome Disexecutiva 
(Armentano et al., 2009), entre outros. Porém, nenhum destes instrumentos pode ser aplicado por profissionais que não sejam psicólogos na prática clínica (Satepsi, Conselho Federal de Psicologia).

- Teste de Desempenho da Função Executiva

O Teste de Desempenho da Função Executiva (TDFE) foi desenvolvido pelo Programa de Terapia Ocupacional da Washington School University of Medicine em Saint Louis, nos Estados Unidos (Baum et al., 2008).

Este instrumento consiste na avaliação do desempenho em quatro tarefas do cotidiano: preparar uma refeição rápida, fazer uma ligação telefônica, tomar a medicação prescrita e pagar duas contas de consumo (Baum et al., 2008). As tarefas deste teste são habitualmente avaliadas por terapeutas ocupacionais. É possível observar o indivíduo executando tarefas simples do dia a dia, e avaliar o quanto ele é capaz de realizar uma tarefa com ou sem supervisão e/ou assistência para que seu desempenho seja o melhor possível e não prejudique sua segurança. A partir das observações é possível orientar o indivíduo e sua família sobre como lidar melhor com estas alterações.

O Teste de Desempenho da Função Executiva foi validado em inglês (Baum et al., 2008), sueco (Cederfeldt, 2011), hebraico (Katz et al., 2007) e coreano (Kim et al., 2017). É de domínio público, sendo possível acessá-la no site da Washington School University of Medicine:

(Http://www.ot.wustl.edu/ot/otweb.nsf/5af541d3cfd036a986257260005bc07d/ecc955 1f54901f1d8625791e0063d1a7!OpenDocument). 
A versão em língua inglesa deste instrumento apresenta excelente confiabilidade inter examinadores e consistência interna (Baum et al., 2008). Por esse motivo, e considerando que este instrumento pode ser aplicado por terapeutas ocupacionais, optamos por realizar sua tradução, adaptação transcultural e avaliar suas propriedades psicométricas.

O TDFE além de apresentar excelentes resultados para as propriedades psicométricas e ser validado em sujeitos com AVC, foi desenvolvido por Terapeutas Ocupacionais para Terapeutas Ocupacionais. Avalia as funções executivas a partir do desempenho em tarefas cotidianas, englobando as Atividades Instrumentais de Vida Diária (AIVDs) que são usualmente avaliadas durante o processo de reabilitação em Terapia Ocupacional.

É um teste padronizado, com manual de aplicação com as regras e normas descritas pelos autores que devem ser seguidas. É de domínio público, ou seja, é possível retirá-lo gratuitamente do site descrito anteriormente. Por estes motivos que está escala foi selecionada para este estudo.

De acordo com nossas hipóteses, a versão brasileira deste teste apresentaria características favoráveis de confiabilidade inter examinador, consistência interna e validade de constructo para sua aplicação no Brasil em protocolos de pesquisa ou na prática clínica, por terapeutas ocupacionais. Adicionalmente, o instrumento apresentaria boa confiabilidade teste e reteste (ainda não descrita na literatura) e poderia correlacionar-se com variáveis demográficas (idade, gênero e nível de escolaridade), sintomas leves de ansiedade e depressão. 
2. OBJETIVOS 


\section{OBJETIVOS}

\section{Primário}

Realizar a adaptação transcultural e avaliar as propriedades psicométricas da versão brasileira do Teste de Desempenho da Função Executiva em indivíduos com AVC. Avaliaremos: consistência interna, confiabilidade teste e reteste e inter examinador.

\section{Secundários}

- Avaliar a validade de constructo do Teste de Desempenho da Função Executiva a partir das escalas de função executiva, de comprometimento das estruturas do corpo, participação e atividade.

- Avaliar a relação entre a pontuação no Teste de Desempenho da Função Executiva em indivíduos com AVC e variáveis demográficas, localização da lesão e sintomas de ansiedade e depressão. 
3. REVISÃO DA LITERATURA 


\section{REVISÃO DA LITERATURA}

\subsection{Cognição}

Cognição é definida como a habilidade de adquirir, manter e aplicar o conhecimento (Williamson, 2006). Permite que o indivíduo ajuste suas ações de acordo com o ambiente para que seja atingido um objetivo. A cognição engloba: memória, atenção, concentração, praxia, funções executivas, orientação espacial e temporal, comunicação e percepção (Grieve \& Gnanasekaran, 2008). Alguns exemplos práticos que podem ocorrer após uma lesão encefálica como o AVC: (1) a dificuldade em realizar uma tarefa, quando as funções motoras estão intactas, pode ser causada por dificuldade de reconhecer o objeto (ou compreender como ele funciona); (2) dificuldade de realizar uma tarefa em sequência; (3) déficit de atenção; (4) ou dificuldades para organizar a rotina (Grieve \&Gnanasekaran, 2008). Estes déficits podem causar alterações na maneira de pensar, sentir e/ou agir, interferindo na capacidade de reter informações e recordar conhecimentos adquiridos anteriormente. Os déficits cognitivos em longo prazo podem ser um obstáculo para a evolução funcional do indivíduo, contribuindo até mesmo para uma possível institucionalização ou a necessidade de cuidados de saúde de alta complexidade (Patel et al., 2002).

A disfunção cognitiva contribui substancialmente para os déficits e perda da qualidade de vida (Cumming et al., 2013). Frequentemente torna-se uma barreira para o retorno ao trabalho. A disfunção executiva é um déficit cognitivo que representa um papel importante na funcionalidade do indivíduo, pois influencia as outras funções cognitivas e motoras (Figura 1). 
Figura 1. Aspectos são influenciados pela função executiva

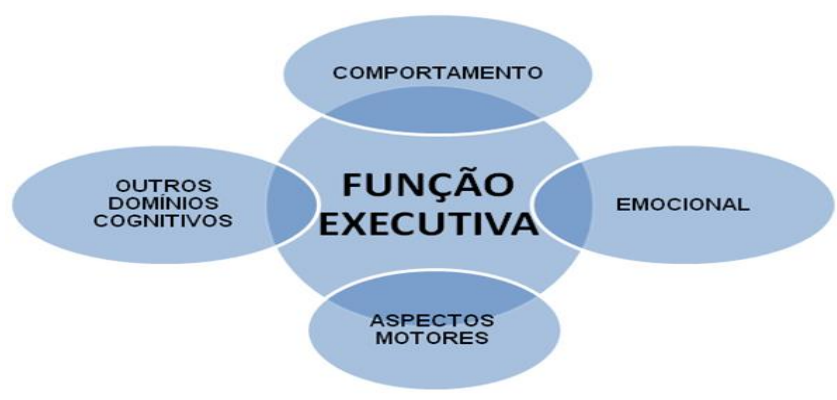

\subsection{Função executiva}

A função executiva engloba: mudanças de ações e capacidade de retorno para a ação anterior, perseveração (em uma ação ou comportamento), flexibilidade mental, pensamento abstrato, capacidade para iniciar uma ação ou comunicação, capacidade de se monitorar e manipular dados para resolver um problema (Zinn et al., 2007). Considerada fundamental para as demais funções cognitivas, está relacionada à atenção seletiva, ou seja, à capacidade de inibir distratores para manter a atenção no que de fato é importante naquele momento. Quando uma ação (por mais complexa que seja) se torna conhecida pelo indivíduo, a função executiva torna-se menos crítica (Elliott, 2003). A função executiva foi separada e organizada nos seguintes domínios: (1) alternar: a capacidade de iniciar diversas atividades ao mesmo tempo e retornar a cada uma; (2) atualizar: monitorar as informações e organizá-las de acordo com os diferentes objetivos, e recuperá-las quando necessário; e (3) inibir: inibir estímulos e foco de uma tarefa ou problema (Miyake et al., 2000). Neste último estudo, os autores ainda discutem a relação entre estas funções, e como elas interferem umas nas outras e no processo de reabilitação (Miyake et al., 2000).

Disfunções executivas podem comprometer o status funcional de indivíduos com AVC devido à influência em outros aspectos do sujeito como depressão 
(Sombreiro et al., 2014; Melkas et al., 2010; Narushima et al., 2007; Bour et al., 2011), incontinência emocional (reações afetivas exageradas em que o sujeito é incapaz de inibi-la) (Tang et al, 2009), dificuldades motoras, como de equilíbrio (Rand et al., 2010; Hayes et al., 2013; Kluding et al., 2011; Liu-Ambrose et al., 2015) e na capacidade em dirigir (Motta et al., 2014). Interferem na rotina diária, incluindo a capacidade de lidar com situações não familiares em novos ambientes e assim, levando a um declínio na qualidade de vida.

As funções executivas são influenciadas pelo processo de envelhecimento, bem como pela presença de depressão. (Simon e Ribeiro, 2011; Kirova et al., 2015; Alexoupoulos et al., 2005; Terroni et al., 2012; Ojagbemi et al., 2014). O sintoma de depressão é considerado como uma sequela frequente em sujeitos pós-avc, variando entre $25 \%$ a $70 \%$ dos indivíduos (Taylor-Piliae et al, 2013), sendo que estes sintomas (disfunção executiva e depressão) podem aparecer simultaneamente com uma frequência estimada de 13,3\% dos sujeitos (Vataja et al, 2005). A depressão também pode interferir no comportamento e no processo de recuperação; sendo associada ao aumento da recorrência de AVC e maior dificuldade para lidar com suas dificuldades e dependência para as atividades cotidianas mais complexas (Sibolt et al, 2013, Melkas et al, 2010, Vataja et al, 2005). Por estes motivos a depressão e a disfunção executiva devem ser consideradas quando avaliado o sujeito com AVC, são sintomas que quando em conjunto impactam de maneira drástica qualidade de vida do indivíduo.

O lobo frontal desempenha um papel fundamental no processamento das funções executivas. A região dorsolateral do lobo frontal, conectada ao hipocampo é relacionada às funções de fluência verbal, atenção alternada e mudança de foco, planejamento, inibição de estimulo distrator, memória de trabalho, resolução de 
problema e raciocínio abstrato. A região ventromedial está associada principalmente ao controle da motivação. E, por fim, a região orbitofrontal é associada ao comportamento social adequado (Alvarez e Emory, 2006; Godefroy e Stuss, 2007). lobo frontal apresenta diversas conexões com regiões corticais e subcorticais, inclusive com o tronco cerebral. Portanto, as funções executivas sofrem influência destas conexões e de outras estruturas do encéfalo (Alvarez e Emory, 2006).

Embora o lobo frontal seja considerado como a principal estrutura responsável pelas funções executivas, outras áreas, como anteriores e posteriores do cérebro, além das regiões corticais e subcorticais também influenciam as funções executivas (Godefroy e Stuss, 2007; Apfelbaum, 2014; Bettcher et al., 2016).

Para facilitar a compreensão das alterações de comportamento após uma lesão do lobo frontal, estas funções foram agrupadas, da seguinte maneira: hipoatividade (falta de iniciativa e motivação para realização das tarefas do dia a dia), hiperatividade (inquietação), perseveração (persistir sempre em uma mesma ação ou comportamento), comportamento de dependência do ambiente (quando o sujeito permanece dependente de seu ambiente, das pistas e dicas que lá estão e apresenta dificuldades para se adaptar em ambientes desconhecidos), descontrole das emoções e comportamento antissocial (labilidade emocional ou incapacidade de demonstrar emoções), anosognosia (dificuldade para reconhecer seus próprios déficits), confabulação e comportamento sexual inapropriado (Godefroy et al, 2004). Sujeitos que apresentam estes déficits geralmente mostram maior dependência nas tarefas cotidianas, principalmente aquelas que são realizadas na comunidade e/ ou são novas para ele (a). Portanto, é essencial que o terapeuta identifique estes sintomas durante o processo de reabilitação. 
Os três principais circuitos frontal-subcorticais que envolvem a função executiva são: (1) pré-frontal dorsolateral, (2) circuito do cíngulo anterior; e (3) circuito orbito frontal (Bonelli e Cummings, 2007). A região dorsolateral tem origem na porção anterior do lobo frontal e seus neurônios são projetados para o núcleo caudado, sendo esta região responsável pelas seguintes funções: antecipação, planejamento, seleção de um alvo/objetivo, monitoramento e feedback do desempenho de alguma tarefa (Bonelli e Cummings, 2007). Os neurônios do cíngulo anterior interferem nas seguintes estruturas: região ventromedial do núcleo caudado, região ventral do putamen, núcleo accubens e região do tubérculo olfatório. Lesões nesta região provocam mutismo e apatia, sendo que em lesões bilaterais o mutismo é mais intenso e persistente do que em lesões unilaterais. O terceiro circuito se origina na região do giro orbital e giro frontal medial inferior, sendo que seus neurônios se projetam para a região do núcleo caudado ventromedial e porção dorsal do globo pálido e região rastro medial da substancia negra. Lesões nesta região geram alteração de comportamento (desinibido) e labilidade emocional (Bonelli e Cummings, 2007).

Diversas teorias e definições sobre a função executiva são descritas na

literatura conforme descrito acima. É considerada uma função complexa, onde a principal estrutura responsável por sua ação é o lobo frontal. Esta função influenciará outros aspectos, como o motor, emocional e comportamento. Estes estudos descritos também mostraram uma gama de déficits que podem surgir a partir de diferentes lesões em diversas partes do encéfalo.

\subsection{Disfunção executiva em indivíduos com AVC}

A disfunção executiva é frequentemente encontrada em sujeitos que sofreram um AVC (18,5 a 39\% dos casos de AVC), contribuindo para uma maior dependência 
dos sujeitos (Nys et al, 2007). Entre os efeitos da disfunção executiva em indivíduos que sofreram um AVC, mais precisamente na fase aguda da lesão, estão: dificuldade para iniciar uma ação (andar, vestir, falar); perseverar em um comportamento inadequado (agressivo ou sexualmente desinibido); dificuldade de planejamento e resolução de problemas, gerando prejuízo na realização de tarefas de maneira mais segura; dificuldade de lembrar as orientações e exercícios realizados em sessões de reabilitação, devido a alterações na atenção, memória e planejamento (Zinn et al., 2007).

Podem ser observadas alterações nas funções executivas em infartos de (Godefroy e Stuss, 2007):

- Artéria cerebral média que irriga além do lobo frontal, regiões subcorticais (como o putamen, parte dorsolateral do núcleo caudado, parte dorsolateral da capsula interna e centro semioval).

- Artéria cerebral anterior que irriga regiões do córtex orbital, giro do cíngulo e área motora suplementar. Em infartos unilaterais, os déficits mais comuns são alterações leves de função executiva, afasia e heminegligência. Já em lesões bilaterais (ao atingir o corpo caloso) os déficits mais comuns são mutismo na fase aguda e uma grave síndrome do comportamento disexecutivo.

Outros locais de infartos que podem levar as alterações de função executiva são os territórios da artéria tuberotalâmica anterior (ramo da artéria comunicante posterior) e da artéria paramediana (proveniente da porção proximal da artéria cerebral posterior) (Godefroy e Stuss, 2007). 
Infartos lacunares também levam as alterações de função executiva, quanto maior o seu número de lacunas acometidas (principalmente na região dos gânglios da base, tálamo e giro frontal subcortical), mais evidentes os déficits (Godefroy e Stuss, 2007).

Lesões de substância branca (Fazekas et al., 2003) e doenças dos pequenos vasos (Vernooij et al., 2008) também contribuem para déficits de função executiva. Lesões de substância branca são comuns (prevalência de até $90 \%$ ) em pessoas acima de 60 anos saudáveis (Nichtweiss et al., 2012; Bolandzadeh, 2012), já as doenças dos pequenos vasos apresentam uma prevalência de 17,8\% em pessoas de 60-69 anos (saudáveis) e de 38,3\% idosos acima 80 anos (Vernooij et al., 2008). Com uma incidência relativamente alta, os déficits de função executiva devem ser cuidadosamente avaliados nestas lesões/doenças (Di Carlo et al., 2000; Rockwood et al., 2000; Partridge et al., 2014). As disfunções executivas ocorrem em 38\% de indivíduos com lesões dos pequenos vasos (Gregorie et al., 2012).

Não apenas a lesão isquêmica pode levar a disfunção executiva, mas também as hemorragias. A disfunção executiva é observada em 15 a 18\% dos indivíduos com hemorragia subaracnoide. Os sintomas são mais frequentes em indivíduos com ruptura de aneurismas da artéria comunicante anterior, sendo mais frequentes as alterações em lesão do lobo frontal, porção anterior do corpo caloso e áreas subcorticais subjacentes. Hemorragias intraparenquimatosas frontais, estriatais, talâmicas, e tromboses venosas cerebrais comprometendo o seio sagital superior podem também causar disfunção executiva (Godefroy e Stuss, 2007). 
É importante que estes dados de locais de lesão sejam descritos para que possamos compreender melhor a estrutura afetada e o déficit apresentado (Conti et al., 2015).

\subsection{Avaliação de função executiva}

Avaliações de cognição, humor e comportamento são recomendadas para indivíduos que sofreram um AVC (Lees et al., 2012). Indivíduos com AVC podem apresentar dificuldades graves nas funções executivas, porém, durante a avaliação clínica, estas alterações podem passar despercebidas se não forem investigadas especificamente. Infelizmente, a maioria das escalas disponíveis não mede as habilidades funcionais no mundo real, mas sim em uma situação protegida, como a sala de atendimento do terapeuta (Burgess \& Simons 2009).

O Mini Exame do Estado Mental (MEEM) é um teste de rastreio de disfunção cognitiva bastante utilizada na prática clínica. Estudos com pacientes pós-AVC frequentemente relatam pontuação no MEEM, porém, é falho na avaliação das funções executivas em fases agudas de AVC pode superestimar o déficit cognitivo (Pedlebury e Rothwell, 2009).

Quando comparado a sensibilidade entre o MEEM ao Montreal Cognitive Assessment (MoCA), foi observado que em pacientes pós AVC o MoCA se mostrou mais sensível ao declínio cognitivo. As funções visoespaciais e de memória foram melhor avaliadas pelo MEEM, enquanto que, a linguagem e funções executivas pelo MoCA (Cumming et al., 2013).

Considera-se difícil avaliar a disfunção cognitiva através de testes convencionais e recomenda-se que a avaliação seja feita por uma combinação de testes que avaliem 
não apenas a cognição de modo geral, mas também mais especificamente a função executiva (Edmans et al., 2001).

No artigo de Conti et al. (2015) foram revistos os testes de função executiva mais utilizados para indivíduos com AVC (Anexo IV), que foram: Teste das Trilhas (em 17 artigos), Teste de Stroop (em 15 artigos), Teste de Extensão dos Dígitos (em 15 artigos), Wisconsin Card Sorting Test (em 11 artigos), Teste de fluência verbal (em 11 artigos) e Avaliação Comportamental da Síndrome de Disexecutiva (BADS) (em quatro artigos). A maioria dos estudos usou mais de uma ferramenta para avaliar as funções executivas, as combinações mais observadas foram:

- Teste das Trilhas, Teste de Extensão dos Dígitos e Fluência Verbal (Roussel et al., 2012; Sibolt et al., 2013 e Sobreiro et al., 2014)

- Teste de Extensão dos Dígitos, Teste das Trilhas e teste de Stroop (Melkas et al., 2010; Rand et al., 2010 e Hayes et al., 2013);

- Teste de Extensão dos Dígitos e Teste das Trilhas (Baum et al., 2008 e Tamez et al., 2011).

Como o artigo foi publicado em 2015 realizamos novas buscas e mais artigos foram acrescentadas as tabelas 3 (cinco artigos) e (três artigos). 
Tabela 1. Instrumentos de avaliação para função executiva em pacientes com até 1 mês após o AVC

\begin{tabular}{|c|c|c|c|c|}
\hline Referência & $\begin{array}{l}\text { Instrumento de } \\
\text { avaliação }\end{array}$ & Objetivo & $\begin{array}{l}\text { Característica da } \\
\text { amostra }\end{array}$ & $\begin{array}{l}\text { Proprieda } \\
\text { de } \\
\text { Psicomét } \\
\text { rica }\end{array}$ \\
\hline $\begin{array}{l}\text { Sobreiro et } \\
\text { al., } \\
2014 \\
\text { Brasil }\end{array}$ & $\begin{array}{l}\text { Teste de Extensão } \\
\text { dos Dígitos, Teste de } \\
\text { Fluência Verbal e } \\
\text { Teste das Trilhas }\end{array}$ & $\begin{array}{l}\text { Relação entre } \\
\text { depressão/ disfunção } \\
\text { executiva em pacientes } \\
\text { com AVC }\end{array}$ & $\begin{array}{l}\text { Primeiro AVC isquêmico } \\
(n=87) \text {. Grupo mais } \\
\text { idoso }(>60 a \text {; } n=62) \text { e } \\
\text { grupo mais jovem } \\
(\leq 60 a ; n=25) \\
\text { AVC que afete LCEPT } \\
(n=27) \text { ou não }(n=48)\end{array}$ & $\begin{array}{l}\text { Não } \\
\text { descritas }\end{array}$ \\
\hline $\begin{array}{l}\text { Roussel et } \\
\text { al., } \\
2012 \\
\text { França }\end{array}$ & $\begin{array}{l}\text { Teste de Extensão } \\
\text { dos Dígitos, Teste de } \\
\text { Fluência Verbal e } \\
\text { Teste das Trilhas, } \\
\text { Wisconsin Card } \\
\text { Sorting Test- } \\
\text { Modificado (M- } \\
\text { WCST), Teste da } \\
\text { Torre de Londres e } \\
\text { teste de Stroop }\end{array}$ & $\begin{array}{l}\text { Relação entre memória } \\
\text { de trabalho e FE }\end{array}$ & $\begin{array}{l}\text { AVC Frontal } \\
(n=17, \text { idade média, } \\
47 a) ; \text { AVC "posterior" } \\
(n=12, \text { idade média, } \\
43,3 a) \\
C G(n=29, \text { ldade } \\
\text { média, } 46,3 a)\end{array}$ & $\begin{array}{l}\text { Não } \\
\text { descritas }\end{array}$ \\
\hline $\begin{array}{l}\text { Tamez et } \\
\text { al., } 2011 \\
\text { Estados } \\
\text { Unidos }\end{array}$ & $\begin{array}{l}\text { Teste de Extensão } \\
\text { dos Dígitos e Teste } \\
\text { das Trilhas }\end{array}$ & $\begin{array}{l}\text { Desempenho dos } \\
\text { pacientes que } \\
\text { sofreram um AVC na } \\
\text { execução dos testes } \\
\text { TMT e DS. Determinar } \\
\text { se os pacientes com } \\
\text { lesão frontal têm pior } \\
\text { desempenho nos } \\
\text { testes do que } \\
\text { pacientes com lesões } \\
\text { em outras regiões. }\end{array}$ & $\begin{array}{l}\text { TMT: lesões não frontais ( } n \\
=122) \text { e lesões frontais } \\
(n=4) \text {. } \\
\text { TED: Lesões não frontais ( } n \\
=175) \text { e lesões frontais }(n= \\
52) .\end{array}$ & $\begin{array}{l}\text { Não } \\
\text { descrita } \\
S\end{array}$ \\
\hline $\begin{array}{l}\text { Cederfeldt } \\
\text { et al.,2011 } \\
\text { Suécia }\end{array}$ & $\begin{array}{l}\text { Teste de } \\
\text { Desempenho da } \\
\text { Função Executiva } \\
\text { e Assessment of } \\
\text { Motor and Process } \\
\text { Skills (AMPS) }\end{array}$ & Validade concorrente & $\operatorname{AVC}(n=23)$ & $\begin{array}{l}\text { Validade } \\
\text { concorren } \\
\text { te: } \\
\text { rho }=0,61\end{array}$ \\
\hline $\begin{array}{l}\text { Zurveza- } \\
\text { Chavarri } \\
\text { a and } \\
\text { Tsanadis } \\
2011 \\
\text { Estados } \\
\text { Unidos }\end{array}$ & $\begin{array}{l}\text { Executive Clock } \\
\text { Drawing Task } \\
\text { (CLOX) }\end{array}$ & $\begin{array}{l}\text { Confiabilidade para o } \\
\text { teste CLOX: CLOX } 1 \\
\text { (desenho livre do } \\
\text { relógio) e CLOX } 2 \\
\text { (cópia do relógio) }\end{array}$ & $\begin{array}{l}\text { AVC }(n=66, \text { idade } \\
\text { média, 58,8a) } \\
\text { Hemisfério direito (52\%), } \\
\text { hemisfério esquerdo } \\
(30 \%) \text {, bilateral }(8 \%) \text {, } \\
\text { Não definido }(11 \%)\end{array}$ & $\begin{array}{l}\text { Confiabili } \\
\text { dade } \\
\text { teste: } \\
\text { CLOX } 1, \\
r=0,62 \\
\text { CLOX } 2 \\
r=0,68\end{array}$ \\
\hline $\begin{array}{l}\text { Wolf et al., } \\
2011 \\
\text { Estados } \\
\text { Unidos }\end{array}$ & $\begin{array}{l}\text { Sorting Test, Color- } \\
\text { Word Interference, } \\
\text { Teste das Trilhas e } \\
\text { Teste de } \\
\text { Desempenho da } \\
\text { Função Executiva }\end{array}$ & $\begin{array}{l}\text { Determinar a } \\
\text { frequência da } \\
\text { disfunção executiva } \\
\text { logo após o AVC }\end{array}$ & $\begin{array}{l}\mathrm{n}=53, \text { idade média, } \\
56,2 \mathrm{a} \\
1 \text { semana após o AVC }\end{array}$ & $\begin{array}{l}\text { Não } \\
\text { descritas }\end{array}$ \\
\hline
\end{tabular}




\begin{tabular}{|c|c|c|c|c|}
\hline $\begin{array}{l}\text { Referenci } \\
\text { a }\end{array}$ & $\begin{array}{l}\text { Instrumento de } \\
\text { avaliação }\end{array}$ & Objetivo & $\begin{array}{l}\text { Característica da } \\
\text { amostra }\end{array}$ & $\begin{array}{l}\text { Proprieda } \\
\text { de } \\
\text { Psicomét } \\
\text { rica }\end{array}$ \\
\hline $\begin{array}{l}\text { Jodzio and } \\
\text { Biechowsk } \\
\text { a } 2010 \\
\text { Polonia }\end{array}$ & $\begin{array}{l}\text { Teste de Fluência } \\
\text { Verbal e Teste das } \\
\text { Trilhas } \\
\text { Go- No Go Task } \\
\text { Wisconsin Card } \\
\text { Sorting Test (WCST) }\end{array}$ & $\begin{array}{l}\text { Investigar os efeitos } \\
\text { das lesões: hemisfério } \\
\text { (direito/esquerdo) e } \\
\text { posição } \\
\text { (anterior/posterior) no } \\
\text { desempenho do teste } \\
\text { WCST }\end{array}$ & $\begin{array}{l}\text { AVC unilateral e } \\
\text { isquêmico } \\
(n=44 \text {, idade média, } \\
56 a)\end{array}$ & $\begin{array}{l}\text { Não } \\
\text { descritas }\end{array}$ \\
\hline $\begin{array}{l}\text { Bour et al., } \\
2010 \\
\text { Holanda }\end{array}$ & $\begin{array}{l}\text { Teste de Stroop e } \\
\text { Concept Shifting } \\
\text { Test }\end{array}$ & $\begin{array}{l}\text { Relação entre } \\
\text { sintomas depressivos } \\
\text { e disfunção executiva }\end{array}$ & $\begin{array}{l}\text { Primeiro AVC e unilateral } \\
(n=116 \text {, idade média, } \\
65,8 a)\end{array}$ & $\begin{array}{l}\text { Não } \\
\text { descritas }\end{array}$ \\
\hline $\begin{array}{l}\text { Wolf et al., } \\
2010 \\
\text { Estados } \\
\text { Unidos }\end{array}$ & $\begin{array}{l}\text { Teste de } \\
\text { Desempenho da } \\
\text { Função Executiva } \\
\text { (TDFE) }\end{array}$ & $\begin{array}{l}\text { Avaliar se os } \\
\text { componentes do teste } \\
\text { TDFE são sensíveis } \\
\text { aos déficits de FE }\end{array}$ & $\begin{array}{l}\text { AVC (primeiro) } \\
(\mathrm{n}=20, \text { idade média, } \\
58,8 \mathrm{a})\end{array}$ & $\begin{array}{l}\text { Confiabili } \\
\text { dade Inter } \\
\text { examinad } \\
\text { or: ICC= } \\
0,91 \\
\text { Consistên } \\
\text { cia } \\
\text { interna: } \\
\alpha=0,94\end{array}$ \\
\hline $\begin{array}{l}\text { Tang et al., } \\
2009 \\
\text { China }\end{array}$ & $\begin{array}{l}\text { Frontal Assessment } \\
\text { Battery - Chinês, } \\
\text { Teste de Stroop, } \\
\text { Wisconsin Card } \\
\text { Sorting Test- } \\
\text { Modificado (M- } \\
\text { WCST), } \\
\text { Teste de Fluência } \\
\text { Verbal e } \\
\text { Go- No Go Task }\end{array}$ & $\begin{array}{l}\text { Relação entre função } \\
\text { executiva e } \\
\text { incontinência } \\
\text { emocional }\end{array}$ & $\begin{array}{l}\text { AVC }(n=39, \text { idade } \\
\text { média, 63,8a) } \\
\text { GC }(n=39, \text { idade média, } \\
64,4 a)\end{array}$ & $\begin{array}{l}\text { Não } \\
\text { descritas }\end{array}$ \\
\hline $\begin{array}{l}\text { Zinn et al, } \\
2007 \\
\text { Estados } \\
\text { Unidos }\end{array}$ & $\begin{array}{l}\text { Wisconsin Card } \\
\text { Sorting Test } \\
\text { (WCST), Teste de } \\
\text { Extensão dos Dígitos } \\
\text { and } \\
\text { DKEFS }\end{array}$ & $\begin{array}{l}\text { Frequência de DE. } \\
\text { Relação entre DE, } \\
\text { gravidade do AVC e } \\
\text { riscos pré mórbidos. }\end{array}$ & $\begin{array}{l}\text { AVC }(n=47, \text { Idade } \\
\text { média, } 65,8 a) \\
\text { AIT }(n=9, \text { idade média, } \\
64,1 \mathrm{a}) \\
\text { CG }(n=10 \text {, idade média, } \\
58,5 a)\end{array}$ & $\begin{array}{l}\text { Não } \\
\text { descritas }\end{array}$ \\
\hline
\end{tabular}

$\mathrm{CG}=$ Grupo controle. $\mathrm{FE}=$ Função executiva. $\mathrm{DE}=$ Disfunção executiva. $\mathrm{a}=$ anos. $n=$ número de sujeitos. LCEPT = Sistema límbico-cortical-estriato-palido- tálamo. AIT= ataque isquêmico transitório. rho= coeficiente de correlação de Spearman. $r=$ coeficiente de correlação de Pearson. $\alpha=$ alfa de Crombach. 
Tabela 2. Instrumentos de avaliação para função executiva em pacientes entre 1-6 meses após o AVC

\begin{tabular}{|c|c|c|c|c|}
\hline Referência & $\begin{array}{l}\text { Instrumento de } \\
\text { avaliação }\end{array}$ & Objetivo & $\begin{array}{l}\text { Característica } \\
\text { da amostra }\end{array}$ & $\begin{array}{l}\text { Propriedade } \\
\text { Psicométrica }\end{array}$ \\
\hline $\begin{array}{l}\text { Sibolt et al., } \\
2013 \\
\text { Finlândia }\end{array}$ & $\begin{array}{l}\text { Wisconsin Card } \\
\text { Sorting Test (WCST), } \\
\text { Teste de Extensão dos } \\
\text { Dígitos, Teste de } \\
\text { Fluência Verbal e } \\
\text { Teste das Trilhas, e } \\
\text { Teste de Stroop }\end{array}$ & $\begin{array}{l}\text { Associação da DE e } \\
\text { depressão } \\
\text { aumentem as } \\
\text { chances de um AVC } \\
\text { recorrente. }\end{array}$ & $\begin{array}{l}\text { Primeiro AVC } \\
\text { isquêmico }(\mathrm{n}= \\
223, \text { Idade } \\
\text { média, } 71 \mathrm{a}) \\
\text { Apenas 205 } \\
\text { realizaram o } \\
\text { teste de FE }\end{array}$ & $\begin{array}{l}\text { Não } \\
\text { descritas }\end{array}$ \\
\hline $\begin{array}{l}\text { Park et al., } \\
2011 \\
\text { Coréia do } \\
\text { Sul }\end{array}$ & $\begin{array}{l}\text { Teste de Extensão dos } \\
\text { Dígitos, Teste de } \\
\text { Fluência Verbal e } \\
\text { Teste de Stroop }\end{array}$ & $\begin{array}{l}\text { Investigar os } \\
\text { padrões dos déficits } \\
\text { neuropsicológicos } \\
\text { incluindo a FE }\end{array}$ & $\begin{array}{l}\text { AVC em artéria } \\
\text { cerebral } \\
\text { posterior }(\mathrm{n}= \\
12 \text {, idade } \\
\text { média, 68,5a) }\end{array}$ & $\begin{array}{l}\text { Não } \\
\text { descritas }\end{array}$ \\
\hline $\begin{array}{l}\text { Melkas et } \\
\text { al., } 2010 \\
\text { Finlandia }\end{array}$ & $\begin{array}{l}\text { Wisconsin Card } \\
\text { Sorting Test (WCST), } \\
\text { Teste de Extensão dos } \\
\text { Dígitos, Teste de e } \\
\text { Teste das Trilhas e } \\
\text { teste de Stroop }\end{array}$ & $\begin{array}{l}\text { Investigar a } \\
\text { influência da } \\
\text { depressão e DE } \\
\text { após o AVC após } 3 \\
\text { meses de lesão }\end{array}$ & $\begin{array}{l}\text { AVC ( } \mathrm{n}=257 \\
\text { Idade média, } \\
71,9 a)\end{array}$ & $\begin{array}{l}\text { Não } \\
\text { descritas }\end{array}$ \\
\hline $\begin{array}{l}\text { Vataja et al., } \\
2003 \\
\text { Finlandia }\end{array}$ & $\begin{array}{l}\text { Wisconsin Card } \\
\text { Sorting Test (WCST), } \\
\text { Teste de Extensão dos } \\
\text { Dígitos, Teste de } \\
\text { Fluência Verbal, Teste } \\
\text { das Trilhas e Teste de } \\
\text { Stroop }\end{array}$ & $\begin{array}{l}\text { Avaliar a hipótese de } \\
\text { que pacientes com } \\
\text { DE teriam mais } \\
\text { infartos que afetam o } \\
\text { circuito fronto- } \\
\text { subcortical e mais } \\
\text { alterações de } \\
\text { substância branca }\end{array}$ & $\begin{array}{l}\text { AVC }(\mathrm{n}=214 \\
\text { ldade média, } \\
55-85 \mathrm{a})\end{array}$ & $\begin{array}{l}\text { Não } \\
\text { descritas }\end{array}$ \\
\hline $\begin{array}{l}\text { Vataja et al., } \\
2005 \\
\text { Finlândia }\end{array}$ & $\begin{array}{l}\text { Wisconsin Card } \\
\text { Sorting Test (WCST), } \\
\text { Teste de Extensão dos } \\
\text { Dígitos, Teste de } \\
\text { Fluência Verbal, Teste } \\
\text { das Trilhas e Teste de } \\
\text { Stroop }\end{array}$ & $\begin{array}{l}\text { Síndrome depressão } \\
\text { - disexsecutiva } \\
\text { (SDD) pode estar } \\
\text { relacionada a } \\
\text { disfunções no } \\
\text { circuito frontal- } \\
\text { subcortical. }\end{array}$ & $\begin{array}{l}\text { AVC isquêmico } \\
(\mathrm{n}=158, \text { Idade } \\
\text { média, 55-85 a) } \\
\text { GC } n=28, \\
\text { (idade média, } \\
67 a)\end{array}$ & $\begin{array}{l}\text { Não } \\
\text { descritas }\end{array}$ \\
\hline $\begin{array}{l}\text { Pohjasvaara } \\
\text { et al. } 2002 \\
\text { Finlandia }\end{array}$ & $\begin{array}{l}\text { Wisconsin Card } \\
\text { Sorting Test (WCST) e } \\
\text { Teste de Stroop }\end{array}$ & $\begin{array}{l}\text { Avaliar a FE em } \\
\text { sujeitos com AVC }\end{array}$ & $\begin{array}{l}\text { AVC isquêmico } \\
(\mathrm{n}=256, \text { idade } \\
\text { média, } 71,1 \mathrm{a})\end{array}$ & $\begin{array}{l}\text { Não } \\
\text { descritas }\end{array}$ \\
\hline $\begin{array}{l}\text { Leeds et al., } \\
2001 \\
\text { Inglaterra }\end{array}$ & $\begin{array}{l}\text { Cambridge Cognitive } \\
\text { Examination - Revised } \\
\text { (CAMCOG-R), testes } \\
\text { de Weighl e Raven }\end{array}$ & $\begin{array}{l}\text { Avaliar a validade } \\
\text { concorrente: } \\
\text { subtestes de FE do } \\
\text { CAMCOG-R em } \\
\text { comparação com os } \\
\text { testes Weighl e } \\
\text { Raven }\end{array}$ & $\begin{array}{l}\text { AVC }(n=83 \\
\text { idade média, } \\
75 a)\end{array}$ & $\begin{array}{l}\text { Weighl: } r= \\
0.46 \text {; } \\
\text { Raven: } r= \\
0.59\end{array}$ \\
\hline
\end{tabular}




\begin{tabular}{|c|c|c|c|c|}
\hline Referencia & $\begin{array}{l}\text { Instrumento de } \\
\text { avaliação }\end{array}$ & Objetivo & $\begin{array}{l}\text { Característica da } \\
\text { amostra }\end{array}$ & $\begin{array}{l}\text { Propriedad } \\
\text { e } \\
\text { Psicométri } \\
\text { ca }\end{array}$ \\
\hline
\end{tabular}

\begin{tabular}{|c|c|c|c|c|}
\hline $\begin{array}{l}\text { Leskela et } \\
\text { al., } 1999 \\
\text { Finlandia }\end{array}$ & $\begin{array}{l}\text { Teste de Fluência } \\
\text { Verbal, Teste das } \\
\text { Trilhas, Teste de } \\
\text { Stroop e Wisconsin } \\
\text { Card Sorting Test } \\
\text { (WCST) }\end{array}$ & $\begin{array}{l}\text { AVC frontal causa } \\
\text { DE ou déficits no } \\
\text { processo mental }\end{array}$ & $\begin{array}{l}\text { AVC isquêmico: } \\
\text { frontal } \\
(\mathrm{n}=62 \text {, idade } \\
\text { média, } 70,9 \mathrm{a}) \text {; } \\
\text { não frontal }(\mathrm{n}= \\
188, \text { idade } \\
\text { média, } 70,3 \mathrm{a}) \text {; } \\
\mathrm{CG}(\mathrm{n}=39 \text {, } \\
\text { idade média, } \\
66,5 \mathrm{a})\end{array}$ & $\begin{array}{l}\text { Não } \\
\text { descritas }\end{array}$ \\
\hline
\end{tabular}

$\mathrm{CG}=$ Grupo controle. $\mathrm{FE}=$ Função executiva. $\mathrm{DE}=$ Disfunção executiva $. \mathrm{a}=$ anos. $\mathrm{n}=$ número de sujeitos. $A V D=$ Atividades de Vida Diária. $r=$ coeficiente de correlação de Pearson.

Tabela 3. Instrumentos de avaliação para função executiva em pacientes acima de 6 meses após AVC

\begin{tabular}{|c|c|c|c|c|}
\hline $\begin{array}{l}\text { Referênci } \\
\text { a }\end{array}$ & $\begin{array}{l}\text { Instrumento de } \\
\text { avaliação }\end{array}$ & Objetivo & $\begin{array}{l}\text { Característica da } \\
\text { amostra }\end{array}$ & $\begin{array}{l}\text { Propriedade } \\
\text { Psicométrica }\end{array}$ \\
\hline $\begin{array}{l}\text { Chui et al., } \\
2017\end{array}$ & $\begin{array}{l}\text { Wisconsin Card } \\
\text { Sorting Test (WCST), }\end{array}$ & \multirow{3}{*}{$\begin{array}{l}\text { Validar Wisconsin Card } \\
\text { Sorting Test (WCST) em } \\
\text { sujeitos com AVC }\end{array}$} & $\begin{array}{l}\text { AVC }(n=98, \text { idade } \\
\text { média: } 56,6 \text { a) }\end{array}$ & \multirow{2}{*}{$\begin{array}{l}\text { Validade } \\
\text { ecológica: } \\
\text { pobre - } \\
\text { moderada }\end{array}$} \\
\hline \multirow[t]{2}{*}{ Taiwan } & \multirow[t]{2}{*}{7 tarefas do teste } & & $\begin{array}{l}27 \text { meses após o } \\
\text { AVC }\end{array}$ & \\
\hline & & & $\begin{array}{l}\text { AVC: isquêmico e } \\
\text { hemorrágico }\end{array}$ & $\begin{array}{l}\text { Validade } \\
\text { discriminante e } \\
\text { convergente: } \\
\text { aceitável }\end{array}$ \\
\hline $\begin{array}{l}\text { Poulin et } \\
\text { al., } 2017\end{array}$ & \multirow{3}{*}{$\begin{array}{l}\text { Wisconsin Card } \\
\text { Sorting Test (WCST), } \\
\text { Delis-Kaplan Executive } \\
\text { Function System } \\
\text { (DKEFS), Color-Word } \\
\text { interference subtest, } \\
\text { Teste das Trilhas }\end{array}$} & \multirow{2}{*}{$\begin{array}{l}\text { Estudo piloto para avaliar } \\
\text { a eficácia de } 2 \text { métodos de } \\
\text { intervenção em sujeitos } \\
\text { com disfunção executiva } \\
\text { após o AVC. }\end{array}$} & $\begin{array}{l}\text { AVC (12 meses após } \\
\text { a lesão) }\end{array}$ & \multirow[t]{3}{*}{ Não descritas } \\
\hline \multirow[t]{2}{*}{ Canada } & & & $\begin{array}{l}\text { Grupo CO-OP ( } n=5 \text {, } \\
\text { idade média } 49 \text { a) }\end{array}$ & \\
\hline & & $\begin{array}{l}\text { (1)Cognitive Orientation to } \\
\text { daily } \\
\text { Occupational Performance } \\
\text { (CO-OP) approach; (2) } \\
\text { Computer-based EF } \\
\text { training }\end{array}$ & $\begin{array}{l}\text { Grupo do } \\
\text { computador }(n=4, \\
57,75 \text { a) }\end{array}$ & \\
\hline
\end{tabular}




\begin{tabular}{|c|c|c|c|c|}
\hline $\begin{array}{l}\text { Referenci } \\
\text { a }\end{array}$ & $\begin{array}{l}\text { Instrumento de } \\
\text { avaliação }\end{array}$ & Objetivo & $\begin{array}{l}\text { Característica da } \\
\text { amostra }\end{array}$ & $\begin{array}{l}\text { Propriedade } \\
\text { Psicométric } \\
\text { a }\end{array}$ \\
\hline $\begin{array}{l}\text { Turunen et } \\
\text { al., } 2016 \\
\text { Finlândia }\end{array}$ & $\begin{array}{l}\text { Teste das Trilhas, } \\
\text { Teste de Stroop, } \\
\text { Wechsler Intelligence } \\
\text { Scale (WAIS), } \\
\text { Wisconsin Card } \\
\text { Sorting Test (WCST), } \\
\text { Teste de Extensão de } \\
\text { Dígitos E Teste de } \\
\text { Fluência Verbal }\end{array}$ & $\begin{array}{l}\text { Comparar diversos } \\
\text { instrumentos de memória } \\
\text { em sujeitos com e sem } \\
\text { alteração de função } \\
\text { executiva (FE) }\end{array}$ & $\begin{array}{l}\text { AVC } \\
\text { Grupo com } \\
\text { Disfunção executiva } \\
\text { ( } n=66 \text {, idade média } \\
59,1 \text { a) } \\
\text { Grupo FE intacta } \\
(n=113 \text {, idade média } \\
51,3\end{array}$ & Não descritas \\
\hline $\begin{array}{l}\text { Hamilton } \\
\text { et al., } \\
2017 \\
\text { Inglaterra }\end{array}$ & $\begin{array}{l}\text { Teste de Fluência } \\
\text { Verbal e Brixton Test }\end{array}$ & $\begin{array}{l}\text { (1) Diferenças entre } \\
\text { pessoas com AVC } \\
\text { no hemisfério direito } \\
\text { e esquerdo quanto a } \\
\text { Theory of Mind } \\
\text { (ToM) } \\
\text { (2) Desempenho dos } \\
\text { sujeitos com AVC no } \\
\text { ToM tem influência } \\
\text { das alterações de } \\
\text { função executiva }\end{array}$ & $\begin{array}{l}\text { AVC } \\
\text { Lesão de hemisfério } \\
\text { direito }(n=15 \text {, idade } \\
\text { média } 67,8 \text { a). } \\
\text { Lesão de hemisfério } \\
\text { esquerdo } \\
(n=15 \text {, idade média } \\
67,73 a) \\
\text { GC }(n=40, \text { idade } \\
\text { média } 66,63 a)\end{array}$ & Não descritas \\
\hline $\begin{array}{l}\text { Roussel et } \\
\text { al., } 2016 \\
\text { França }\end{array}$ & $\begin{array}{l}\text { Behavioral } \\
\text { Dysexecutive Syndrome } \\
\text { Inventory, Teste das } \\
\text { Trilhas, Teste de } \\
\text { Stroop, Teste de } \\
\text { Fluência Verbal, Brixton } \\
\text { Test, Subteste dos } 6 \\
\text { elementos do BADS, } \\
\text { Modified Card Sorting } \\
\text { Test e Teste de } \\
\text { Extensão de Dígitos }\end{array}$ & $\begin{array}{l}\text { (1) Avaliar o tipo de } \\
\text { disfunção executiva } \\
\text { de acordo com o tipo } \\
\text { de AVC } \\
\text { (2) Examinar a } \\
\text { sensibilidade do } \\
\text { Harmonization } \\
\text { standards protocol } \\
\text { (HSP). }\end{array}$ & $\begin{array}{l}\text { AVC, aneurisma e } \\
\text { trombose venosa } \\
\text { cerebral ( } n=237, \\
\text { idade média } 48,7 \text { a) } \\
\text { Hemisfério direito, } \\
\text { esquerdo e ambos } \\
\text { hemisférios } \\
\text { Frontal, posterior, } \\
\text { lesões mais } \\
\text { profundas, fossa } \\
\text { posterior }\end{array}$ & Não descritas \\
\hline $\begin{array}{l}\text { Liu- } \\
\text { Ambrose } \\
\text { and Eng, } \\
2015 \\
\text { Canada }\end{array}$ & $\begin{array}{l}\text { Teste de Extensão dos } \\
\text { Dígitos e Teste de } \\
\text { Stroop }\end{array}$ & $\begin{array}{l}\text { Compreender o } \\
\text { processo de controle } \\
\text { executivo e o } \\
\text { desempenho no } \\
\text { equilíbrio. }\end{array}$ & $\begin{array}{l}\text { AVC leve } \\
n=63(65 a)\end{array}$ & Não descritas \\
\hline $\begin{array}{l}\text { Kegel et } \\
\text { al, } \\
2014 \\
\text { Estados } \\
\text { Unidos }\end{array}$ & $\begin{array}{l}\text { Delis-Kaplan } \\
\text { Executive Function } \\
\text { System (DKEFS), } \\
\text { Color-Word } \\
\text { interference subtest, } \\
\text { Teste das Trilhas e } \\
\text { Letter-Number } \\
\text { Sequencing }\end{array}$ & $\begin{array}{l}\text { Avaliar a relação entre } \\
\text { FE e estratégias para } \\
\text { lidar com as situações } \\
\text { novas e desconhecidas }\end{array}$ & $\begin{array}{l}\text { AVC }(n=15 \text {, idade } \\
\text { média, 60a) } \\
27 \% \text { AVC direito } \\
73 \% \text { AVC esquerdo }\end{array}$ & Não descritas \\
\hline
\end{tabular}




$\begin{array}{lllll}\text { Referenci } & \begin{array}{l}\text { Instrumento de } \\ \text { avaliação }\end{array} & \text { Objetivo } & \begin{array}{l}\text { Característica da } \\ \text { amostra }\end{array} & \begin{array}{l}\text { Propriedade } \\ \text { Psicométric }\end{array}\end{array}$
avaliação amostra

Josman et Virtual Action Planning al., 2014 - Supermarket (VAP-S), Israel

Behavioral Assessment of Dysexecutive

Syndrome (BADS),

Observed Tasks of

Daily Living-

Revised(OTDL-R)

\section{Validade concorrente e} de construto

Hemisfério direito
$(n=12)$
hemisfério esquerdo
$(n=11)$
AVC Bilateral
$(n=1)($ Idade
média, 58,9a)
GC
$(n=24$, idade
média, 60,1a)

AVC ( $n=24$, idade média: 52,1a) e CG $(n=31$, idade média: 50,6a)
VAP-S (número de compras) e:

BADS, $r=0.42$;

OTDL-R, $r=$ 0.64 VAP-S (ações corretas) e: BADS, $r=0.61$; OTDL-R, 0.68 OTDL-R e

BADS: $r=0.72$

Não descritas

Escala de memória de trabalho é sensível para avaliar pacientes com AVC.

Investigar se a decodificação da informação interfere em longo prazo na memória de trabalho

$\begin{array}{ll}\text { Hayes et } & \text { Teste das Trilhas, Teste } \\ \text { al., 2012 } & \text { de Stroop, Mapa do } \\ \text { Irlanda } & \text { Zoológico (subteste do } \\ & \begin{array}{l}\text { Behavioral Assessment } \\ \text { of Dysexecutive } \\ \text { Syndrome), Frontal }\end{array} \\ & \text { Assessment Battery e } \\ & \text { Teste de Extensão dos } \\ & \text { Dígitos Inversos }\end{array}$

Kluding et Teste de Extensão dos

2010

Como a FE afeta o

desempenho para

deambular nos testes de

marcha (deambular por

10 metros)

$$
\begin{aligned}
& \text { AVC }(\mathrm{n}=20, \text { idade } \\
& \text { média, } 69,1 \mathrm{a}) \\
& \text { Capacidade para } \\
& \text { deambular com ou } \\
& \text { sem dispositivo } \\
& \text { auxiliar }
\end{aligned}
$$

\begin{tabular}{|c|c|c|}
\hline $\begin{array}{l}\text { Relação entre a melhora } \\
\text { nas atividades aeróbicas } \\
\text { e mudanças na cognição } \\
\text { e FE }\end{array}$ & $\begin{array}{l}\text { AVC }(n=9, \text { idade } \\
\text { média, 63,7a) }\end{array}$ & Não descritas \\
\hline $\begin{array}{l}\text { Exercícios e prática } \\
\text { motora (incluindo } \\
\text { alongamento, } \\
\text { alongamento, e } \\
\text { exercícios específicos) e } \\
\text { recreação podem } \\
\text { melhorar a FE e } \\
\text { memória }\end{array}$ & $\begin{array}{l}\text { AVC ( } n=11 \text {, idade } \\
\text { média, 67a) } \\
\text { Capaz de deambular } \\
\text { por } 3 \text { metros sem } \\
\text { dispositivo de } \\
\text { marcha }\end{array}$ & Não descritas \\
\hline
\end{tabular}
Não descritas al., 2011 Dígitos Inversos e

Estados Flanker Test

Unidos

Rand, Flanker Test

Relação entre a melhora nas atividades aeróbicas e FE Teste das Trilhas, Teste de Stroop e

Canada Teste de Extensão dos Dígitos Inversos 


\begin{tabular}{|c|c|c|c|c|}
\hline $\begin{array}{l}\text { Referenci } \\
\text { a }\end{array}$ & $\begin{array}{l}\text { Instrumento de } \\
\text { avaliação }\end{array}$ & Objetivo & $\begin{array}{l}\text { Característica da } \\
\text { amostra }\end{array}$ & $\begin{array}{l}\text { Propriedade } \\
\text { Psicométric } \\
\text { a }\end{array}$ \\
\hline
\end{tabular}

\begin{tabular}{|c|c|c|c|c|}
\hline $\begin{array}{l}\text { Baum et } \\
\text { al., } \\
2008 \\
\text { Estados } \\
\text { Unidos }\end{array}$ & $\begin{array}{l}\text { Teste de Desempenho } \\
\text { da Função Executiva } \\
\text { (TDFE), Teste de } \\
\text { Fluência Verbal, Teste } \\
\text { das Trilhas, Teste de } \\
\text { Extensão dos Dígitos, } \\
\text { Medida de } \\
\text { Independência } \\
\text { Funcional (MIF), entre } \\
\text { outros }\end{array}$ & $\begin{array}{l}\text { Examinar a } \\
\text { confiabilidade e validade } \\
\text { do TDFE }\end{array}$ & $\begin{array}{l}\text { AVC }(n=73) ; \text { Leve } \\
\text { (NIHSS = } \\
n=59, \text { idade média, } \\
64,5 a) ; \text { Moderado } \\
\text { (NIHSS = } 10,6, n= \\
14, \text { idade média, } \\
64,1 y) ; \text { CG }(n=22, \\
\text { idade média, } 59,4 a)\end{array}$ & $\begin{array}{l}\text { Confiabilidade } \\
\text { inter } \\
\text { examinador: } \\
\text { ICC = 0,91; } \\
\text { Consistência } \\
\text { interna: } \alpha= \\
\text { 0,94; Validade } \\
\text { concorrente: } \\
\text { Teste de } \\
\text { Fluência Verbal } \\
\text { ( } r=-0,47) \\
\text { Teste das } \\
\text { Trilhas B } \\
\text { ( } r=0,39), \text { Teste } \\
\text { de Extensão } \\
\text { dos Dígitos } \\
\text { Inverso } \\
(r=-0,49) ; \\
\text { MIF } \\
(r=-0,40)\end{array}$ \\
\hline $\begin{array}{l}\text { Ownswort } \\
\text { h and } \\
\text { Shum } \\
2008 \\
\text { Australia }\end{array}$ & $\begin{array}{l}\text { Behavioral Assessment } \\
\text { of Dysexecutive } \\
\text { Syndrome (BADS)e } \\
\text { Tinkertoy Test }\end{array}$ & $\begin{array}{l}\text { Desempenho nas } \\
\text { medidas de função } \\
\text { executiva em sujeitos } \\
\text { com AVC que estão } \\
\text { empregados ou não }\end{array}$ & $\begin{array}{l}\text { AVC }(n=27, \text { idade } \\
\text { média, 47,3a) }\end{array}$ & Não descritas \\
\hline $\begin{array}{l}\text { Liu- } \\
\text { Ambrose } \\
\text { et al., } \\
2007 \\
\text { Canadá }\end{array}$ & $\begin{array}{l}\text { Teste de Stroop e } \\
\text { Teste de Extensão dos } \\
\text { Dígitos }\end{array}$ & $\begin{array}{l}\text { Processo de controle } \\
\text { executivo e o } \\
\text { desempenho do } \\
\text { equilíbrio e mobilidade }\end{array}$ & $\begin{array}{l}\text { AVC }(n=63 \text {, idade } \\
\text { média, } 65 a) \text { Capaz } \\
\text { de deambular por } 10 \\
\text { metros de maneira } \\
\text { independente }\end{array}$ & Não descritas \\
\hline $\begin{array}{l}\text { Narushim } \\
\text { a et al., } \\
2007 \\
\text { Inglaterra }\end{array}$ & $\begin{array}{l}\text { Wisconsin Card Sorting } \\
\text { Test (WCST), e } \\
\text { Controlled Oral Word } \\
\text { Association (COWA) }\end{array}$ & $\begin{array}{l}\text { Examinar os efeitos dos } \\
\text { antidepressivos } \\
\text { (nortriptilina e fluoxetina) } \\
\text { nos déficits de FE após o } \\
\text { AVC }\end{array}$ & $\begin{array}{l}\text { AVC }(n=30 \text {, idade } \\
\text { média, } 65,5 a \text { no } \\
\text { grupo nortriptilina ou } \\
\text { fluoxetina; } n=17, \\
\text { idade média, } 71,7 a \\
\text { grupo placebo) }\end{array}$ & Não descritas \\
\hline
\end{tabular}

$\mathrm{CG}=$ Grupocontrole. $\mathrm{FE}=$ Funçãoexecutiva $. \mathrm{DE}=$ Disfunçãoexecutiva $. \mathrm{a}=$ =anos. $\mathrm{n}=$ número । sujeitos. $r=$ coeficiente de correlação de Pearson. $\alpha=$ alfa de Crombach. 
Tabela 4. Instrumentos de avaliação da função executiva em pacientes com AVC sem definição do tempo de lesão

\begin{tabular}{|c|c|c|c|c|}
\hline Referência & Instrumento de avaliação & Objetivo & $\begin{array}{l}\text { Característica da } \\
\text { amostra }\end{array}$ & $\begin{array}{l}\text { Proprieda } \\
\text { de } \\
\text { Psicométri } \\
\text { ca }\end{array}$ \\
\hline \multirow{6}{*}{$\begin{array}{l}\text { Kim et al., } \\
2017\end{array}$} & \multirow{6}{*}{$\begin{array}{l}\text { EFPT, Teste de Extensão } \\
\text { dos Dígitos, Korean Color- } \\
\text { Word Stroop Test (K- } \\
\text { CWST), Teste das Trilhas e } \\
\text { Assessment of Motor and } \\
\text { Process Skills (AMPS) }\end{array}$} & \multirow{6}{*}{$\begin{array}{l}\text { Desenvolver a versão } \\
\text { adaptada para } \\
\text { coreanos do EFPT }\end{array}$} & \multirow{6}{*}{$\begin{array}{l}\text { AVC }(n=34, \\
\text { idade média } 54,4)\end{array}$} & $\mathrm{ICC}=0,87$ \\
\hline & & & & $\begin{array}{l}\text { Pontuação } \\
\text { total } \\
\alpha=0,77\end{array}$ \\
\hline & & & & $\begin{array}{l}\text { Refeição } \\
\alpha=0,61\end{array}$ \\
\hline & & & & $\begin{array}{l}\text { Telefonem } \\
\text { a } \alpha=0,56\end{array}$ \\
\hline & & & & $\begin{array}{l}\text { Medicação } \\
\alpha=0,53\end{array}$ \\
\hline & & & & $\begin{array}{l}\text { Contas } \\
\alpha=0,63\end{array}$ \\
\hline \multirow{2}{*}{$\begin{array}{l}\text { Jankowsk } \\
\text { a et al., } \\
2017\end{array}$} & \multirow{5}{*}{$\begin{array}{l}\text { Wisconsin Card Sorting Test } \\
\text { (WCST), Teste das Trilhas, } \\
\text { Teste de Fluência verbal }\end{array}$} & \multirow{5}{*}{$\begin{array}{l}\text { Avaliar o efeito da } \\
\text { localização do AVC na } \\
\text { fisioterapia e na } \\
\text { melhora da FE }\end{array}$} & $\operatorname{AVC}(n=90)$ & \multirow{5}{*}{$\begin{array}{l}\text { Não } \\
\text { descritas }\end{array}$} \\
\hline & & & Localização: & \\
\hline \multirow[t]{3}{*}{ Polônia } & & & $\begin{array}{l}\text { trontal, subcortical } \\
\text { e trás. }\end{array}$ & \\
\hline & & & $\mathrm{GC}(\mathrm{n}=45)$ & \\
\hline & & & $\begin{array}{l}1-12 \text { meses } \\
\text { após o AVC }\end{array}$ & \\
\hline $\begin{array}{l}\text { Saa et al., } \\
2017\end{array}$ & \multirow{2}{*}{$\begin{array}{l}\text { Complex Task Performance } \\
\text { Assessment (CPTA), Delis- } \\
\text { Kaplan Executive Function } \\
\text { System (DKEFS), } \\
\text { Wisconsin Card Sorting Test } \\
\text { - Modificado (M-WCST), } \\
\text { Teste das Trilhas, Wechsler } \\
\text { Test of Adult Reading }\end{array}$} & \multirow{2}{*}{$\begin{array}{l}\text { Desenvolver uma } \\
\text { alternativa para o } \\
\text { Complex Task } \\
\text { Performance } \\
\text { Assessment (CPTA). }\end{array}$} & \multirow[t]{2}{*}{$\begin{array}{l}\text { AVC }(n=26, \text { idade } \\
\text { média } 48,92 .)\end{array}$} & \multirow[b]{2}{*}{$\begin{array}{l}\text { Pontuação } \\
\text { das } 2 \\
\text { versões } \\
\text { foram } \\
\text { comparada } \\
\text { s com } \\
\text { Spearman } \\
\text { e } \\
\text { mostraram } \\
\text { correlação } \\
\text { estatistica } \\
\text { mente } \\
\text { significativa } \\
r=0,44 \text {, } \\
p=0,03 \text {. }\end{array}$} \\
\hline $\begin{array}{l}\text { Estados } \\
\text { Unidos }\end{array}$ & & & & \\
\hline $\begin{array}{l}\text { Motta et al, } \\
2014 \\
\text { Austrália }\end{array}$ & $\begin{array}{l}\text { Behavioral Assessment of } \\
\text { Dysexecutive Syndrome } \\
\text { (BADS) e Teste das Trilhas }\end{array}$ & $\begin{array}{l}\text { Investigar a relação } \\
\text { entre função executiva } \\
\text { e desempenho na } \\
\text { direção }\end{array}$ & $\begin{array}{l}\text { AVC }(\mathrm{n}=19, \\
\text { idade média, } \\
70,1 \mathrm{a}) ; \mathrm{CG}(\mathrm{n}= \\
\text { 22, idade média, } \\
64 \mathrm{a})\end{array}$ & $\begin{array}{l}\text { Não } \\
\text { descritas }\end{array}$ \\
\hline
\end{tabular}




\begin{tabular}{|c|c|c|c|c|}
\hline Referencia & Instrumento de avaliação & Objetivo & $\begin{array}{l}\text { Característica da } \\
\text { amostra }\end{array}$ & $\begin{array}{l}\text { Propried } \\
\text { ade } \\
\text { Psicomét } \\
\text { rica }\end{array}$ \\
\hline
\end{tabular}

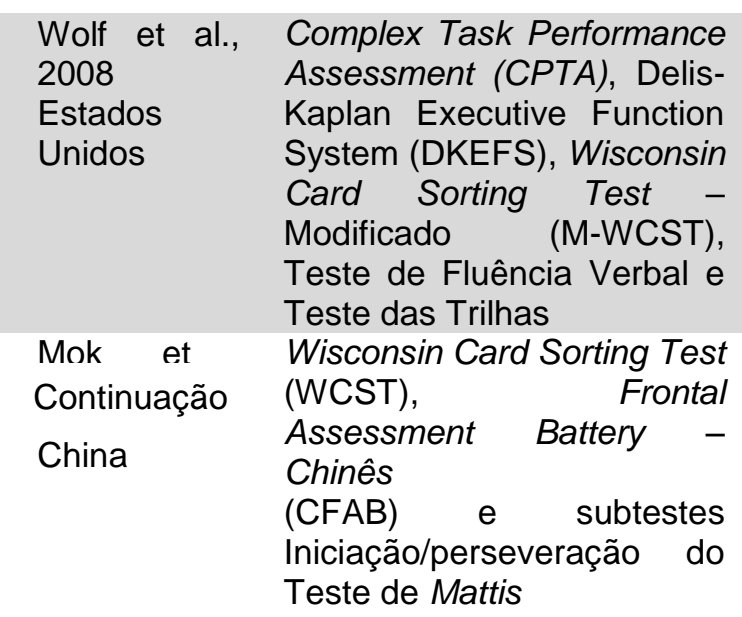

\begin{abstract}
Van der
Werf et al., 2003

Holanda

(WCST), Teste de Fluência Verbal, Teste de Stroop, Teste de Extensão dos Dígitos, Tower London Test
\end{abstract}

Kramer et

al., 2002

Estados

Unidos

\author{
Avaliar a síndrome $\operatorname{AVC}(\mathrm{n}=6$, idade \\ disexecutiva com CPTA média, 55,7a) \\ $C G(n=4$, idade \\ média, 55,7a)
}

Não descritas

Avaliar a validade e Pequenos infartos confiabilidade da CFAB sub corticais $(n=$ 31, idade média, $73,5 a) C G(n=41$, idade média, 69,6a)

\section{CFAB:}

Consistênci a interna: $\alpha=0,77$ Confiabilid ade inter examinado $r$ : rho $=0,85$ Confiabilid ade teste: rho $=0,89$ Validade concorrent e: $r=0,63$

Avaliar se o tálamo interfere nas seguintes funções: memória, FE e AVC $(n=22$, idade entre: 22 e 83a) Infartos talâmicos

Não descritas atenção
Avaliar se a DE pode ser encontrada indivíduos com lesões lacunares subcorticais e sem demência.
Lesões lacunares sub corticais ( $\mathrm{n}=$ 39 , idade média, $73,7 a) C G(n=27$, idade média, $72,8 a)$
Não descritas

$\mathrm{CG}=\mathrm{Grupo}$ controle. $\mathrm{FE}=$ Função executiva. $\mathrm{DE}=$ Disfunção executiva $. \mathrm{a}=$ anos. $\mathrm{n}=$ número de sujeitos. rho $=$ coeficiente de correlação de Spearman. $r=$ coeficiente de correlação de Pearson. $\alpha=$ alfa de Cronbach 


\subsection{Função executiva e Terapia Ocupacional no AVC}

Em um estudo sobre as definições de função executiva sob a ótica da Terapia Ocupacional, este domínio foi visto como a função cognitiva mais complexa e fundamental durante o processo de aprendizagem atividades novas, não rotineiras, mais dinâmicas e complexas (divididas em etapas) (Cramm et al., 2013). Durante o processo de reabilitação dos sujeitos com alterações cognitivas (após uma lesão neurológica, como o $\mathrm{AVC}$ ), a independência para as atividades de vida diária, de ocupação e lazer é um dos objetivos da Terapia Ocupacional (Langhorne et al., 2011). Como o objetivo da terapia ocupacional é o ganho funcional e independência do sujeito, se torna imprescindível a preocupação maior com as estruturas corporais, cognitiva e/ou uso de equipamentos/ adaptações que facilitem a independência do sujeito durante o processo da reabilitação física (Richards et al., 2005).

Os déficits das funções executivas podem levar a dificuldade para realizar tarefas antes conhecidas e do cotidiano do sujeito como cuidar da casa e dirigir, afetando diretamente a independência e autonomia do sujeito; bem como o retorno ao trabalho (Cramm et al., 2013). Para a terapia ocupacional o processo de reabilitação está baseado no desempenho do sujeito em suas atividades cotidianas tornando fundamental a compreensão destes déficits e como eles interferem diretamente no sujeito e sua autonomia.

A partir da avaliação e compreensão dos déficits de função executiva o terapeuta ocupacional planejará o processo de reabilitação, que pode envolver maneiras de amenizar e/ou se adaptar a estas dificuldades. O processo de reabilitação tem como objetivo tratar estas alterações que causem 
limitações às atividades instrumentais e básicas de vida diária (Richards et al., 2005; Morrison, et al., 2015).

Deste modo o uso do TDFE se mostrou como um instrumento de avaliação não apenas as funções executivas, mas também o desempenho do sujeito durante a execução de tarefas cotidianas. Sua validação para a população brasileira é fundamental para que o terapeuta ocupacional possa avaliar de modo adequado seu paciente. 
4. MÉTODOS 


\section{MÉTODOS}

\subsection{Caracterização do local, do período do estudo e dos grupos}

O estudo foi realizado no Laboratório de Neuroestimulação da Divisão de Clínica Neurológica do Hospital das Clínicas da Faculdade de Medicina da Universidade de São Paulo. Foram avaliados 86 indivíduos com AVC entre 02/05/2013 e 06/05/2016. Cada avaliação durou em torno de duas horas por sujeito, sendo estendida para até três horas para aqueles com dificuldade maior no desempenho das escalas aplicadas. Embora o tempo de aplicação de todos os testes foi longo, os sujeitos puderam fazer pausas para ir ao banheiro, tomar água e se alimentarem sem prejudicar a aplicação das escalas, deste modo nenhum deles referiu cansaço nem fadiga. O Teste de Desempenho da Função Executiva foi o último a ser aplicado em todos os sujeitos.

- Casuística

- Pacientes com AVC

A Figura 2 mostra o fluxo de constituição da amostra. Os sujeitos com AVC foram recrutados na Enfermaria, Pronto-Socorro e Ambulatórios de Neurologia do Hospital das Clínicas.

De um total de 803 pacientes triados, foram excluídos 717 sujeitos conforme o fluxograma mostrado na Figura 2. 
Figura 2. Fluxograma de inclusão dos Sujeitos com AVC

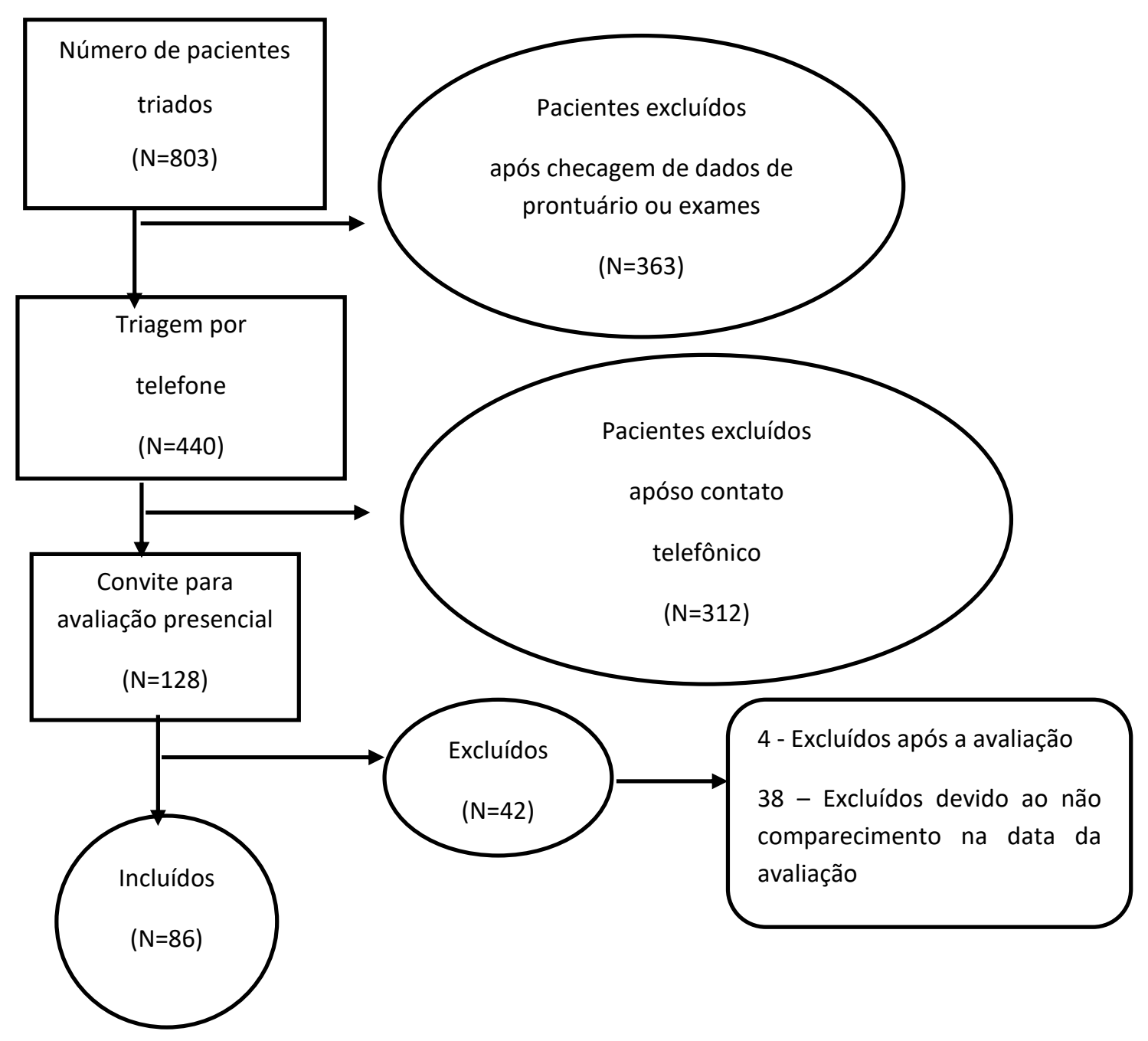

Os critérios de inclusão foram:

(1) Idade entre 18 e 80 anos;

(2) AVC isquêmico ou hemorrágico no mínimo seis meses antes e comprovado por ressonância magnética ou tomografia computadorizada. Estas imagens foram obtidas no sistema do HCmed do Hospital das Clínicas sendo na sua maioria imagens realizadas durante a fase aguda, porém, alguns sujeitos trouxeram as imagens e laudos de exames realizados em outros hospitais ou laboratórios; 
(3) Capacidade para colaborar com os testes, ou seja, compreender os testes e executá-los (mesmo que com auxilio) e comparecer às sessões de avaliação. Sujeitos que faltaram no dia da avaliação sem justificativa, nem contato para novo agendamento foram automaticamente excluídos da pesquisa.

Os critérios de exclusão foram:

(1) Depressão grave avaliada pelas seguintes escalas: Escala de Hamilton Depressão (acima de 8/31 pontos) (Moreno e Moreno, 1998; Gallucci et al., 2001) e Manual Diagnóstico e Estatístico de Transtornos Mentais - DSM-IV (5 ou mais dos seguintes sintomas estiveram presentes durante as últimas 2 semanas e representam uma mudança do padrão de funcionamento anterior; pelo menos um destes sintomas é (1) Humor deprimido ou (2) perda de interesse ou prazer) (American Psychiatric Association, 1994; Matos et al., 2005).

(2) Antecedente de condições psiquiátricas como esquizofrenia, transtorno afetivo bipolar e alcoolismo. Estes antecedentes foram questionados ao sujeito e/ou acompanhante. Os casos confirmados foram desligados da pesquisa;

(3) Alterações clínicas não controladas, tais como: doença renal crônica em processo de diálise e tumor em processo de quimioterapia. Estes antecedentes foram questionados ao sujeito e/ou acompanhante. Os casos confirmados foram desligados da pesquisa;

(4) Outras doenças neurológicas, como antecedentes de demência e doença de Parkinson. Estes antecedentes foram questionados ao sujeito e/ou acompanhante. Os casos confirmados foram desligados da pesquisa;

(5) Uso de antidepressivos tricíclicos, por apresentarem como efeito colateral sedação e lentidão nas respostas (Moreno et al., 1999); 
(6) Afasia que comprometesse a compreensão do estudo e o desempenho nas avaliações.

Oitenta e seis sujeitos foram incluídos. As seguintes características foram avaliadas: idade, gênero, etnia, nível de escolaridade (quantidade de anos em que cursou a escola e/ou curso técnico e/ou ensino superior), tempo desde o AVC, lado da lesão e fatores de risco para doença vascular (antecedentes de hipertensão arterial, diabetes mellitus, tabagismo e cardiopatia, insuficiência arterial periférica, arritmia cardíaca, entre outras patologias relatadas pelo sujeito), conforme referido pelo indivíduo. Foram também aplicadas as seguintes escalas:

$\checkmark$ Inventário de Edinburgh (Oldfield, 1971) que avalia a preferência manual. Nesta escala, são aplicadas 10 questões sobre preferências manuais para executar tarefas motoras habituais (Teixeira e Motriz, 2000). Os dois itens adicionais para preferência de membro inferior e olho, não foram avaliados nesta pesquisa (Oldfield, 1971). Cada item assinalado equivale a um ponto adicionado e computado, gerando assim um índice de preferência manual (Teixeira e Motriz, 2000). O desempenho é calculado de acordo com a fórmula abaixo:

(Soma da pontuação do lado direito - soma da pontuação do lado esquerdo $)] \times 100$ \{(Soma da pontuação do lado direito + soma da pontuação do lado esquerdo) $\}$

$\checkmark$ Escala Modificada de Rankin, que avalia a incapacidade funcional. $\mathrm{Na}$ versão original a pontuação varia de zero (sem sintoma) a cinco (incapacidade grave) (Rankin, 1957) e na versão modificada foi incluído o grau 6 (morte) (Brito et al, 2013). Esta escala foi validada em indivíduos brasileiros com AVC (Caneda et al, 2006, Cincura et al, 2008).

$\checkmark$ Escala de AVC do NIH (National Institutes of Health Stroke Scale), que avalia o comprometimento neurológico e é amplamente utilizada em indivíduos com AVC. A 
pontuação varia de 0 (menor comprometimento neurológico) a 42 (pior comprometimento) (Brott et al, 1989; Caneda et al, 2006). Esta escala foi validada em indivíduos brasileiros com AVC (Caneda et al, 2006, Cincura et al, 2008). Antes de utilizar a escala, a pesquisadora executante recebeu treinamento e certificação pelo The American Stroke

Association (https://learn.heart.org/Activity/2695217/Detail.aspx);

$\checkmark$ Índice de Barthel, que avalia a capacidade de realizar atividades de vida diária (AVD). A pontuação varia de zero (maior dependência para as atividades de vida diária) a 100 (menor dependência) (Mahoney et al., 1965; Paixão e Rechenheim, 2005). Esta escala foi validada em indivíduos brasileiros com AVC (Caneda et al., 2006 Cincura et al., 2008).

$\checkmark$ Escala de impacto do AVC, 3.0 (Carod-Artal et al., 2008). Trata-se de um questionário que avalia a qualidade de vida do sujeito após o AVC, do ponto de vista dele. A escala é dividida em nove domínios: problema físico referente ao AVC (4 perguntas); memória e pensamento (7 perguntas); alterações de humor (9 perguntas); habilidades de comunicação (7 perguntas); atividades do dia a dia (10 perguntas); mobilidade em casa (9 perguntas); uso da mão afetada (5 perguntas); participação nas atividades na comunidade (8 perguntas); e recuperação após o AVC (quantificar de $0 \%$ - sem recuperação a $100 \%$ - recuperação completa). A pontuação de cada domínio da escala varia entre 0 (pior participação/qualidade de vida após o AVC) a 100 (melhor desempenho possível) (Carod-Artal et al, 2008, Vellone et al, 2015, Mohammad et al, 2015). Quanto maior a pontuação total, melhor a qualidade de vida do sujeito. Nesta escala os domínios são somados separadamente conforme a formula abaixo que foi traduzida do manual de administração da escala. Sendo que apenas no domínio 3 os itens "f", "h" e "i", apresentam uma pontuação diferente: a 
pontuação 1 se torna 5, 2 se torna 4, 3 se mantém, 4 se torna 2 e 5 se torna 1 (Stuart e Ware, 1992). Esta escala foi validada em indivíduos brasileiros com AVC (CarodArtal et al, 2008).

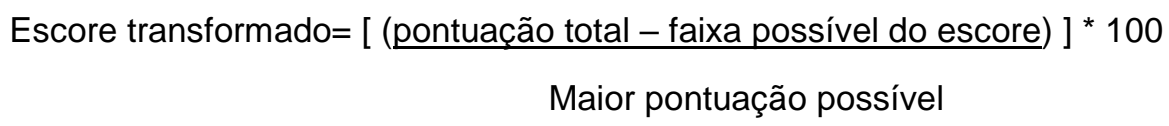

$\checkmark \quad$ Mini Exame do Estado Mental, um teste de rastreio para avaliar brevemente as seguintes funções cognitivas: orientação temporal, orientação espacial, memória, habilidade matemática simples, linguagem e praxia. Identifica funções que devem ser melhor investigadas. A pontuação varia de 0 (pior comprometimento cognitivo) a 30 (melhor desempenho) (Folstein et al, 1975; Brucki et al, 2003). A pontuação para sujeitos não alfabetizados é de 19/30 e para alfabetizados, de 23/30 (Brucki et al, 2003). Em língua inglesa foi validada para sujeitos com AVC (Cumming et al, 2013). No Brasil, foi validada em adultos (58,9 anos $\pm 17,7$ ) (Brucki et al, 2003) e em idosos saudáveis ( $\geq 65$ anos) (Lourenço e Veras, 2006; Santos et al, 2010).

Bateria Breve de Rastreio Cognitivo (Nitrini et al, 1994) que avalia a capacidade de identificar e nomear objetos, memória (incidental, imediata e tardia), aprendizado, fluência verbal, função executiva e habilidades viso espaciais. As tarefas de percepção, nomeação, memória (incidental, imediata 1 e 2, tardia e reconhecimento) variam de 0 (pior capacidade de memória) a 10 (melhor capacidade de memória). Um quadro com 10 figuras (sapato, pente, casa, avião, balde, tartaruga, livro, sapato, colher e chave) é apresentado para o sujeito, que deve nomear as figuras (tarefas de percepção e nomeação). Em seguida, o quadro com as figuras é retirado e o sujeito deve dizer quais figuras ele (a) recorda (memória incidental). O avaliador anota as figuras lembradas pelo sujeito (Vitiello et al, 2007). Em seguida o sujeito tem 30 segundos para memorizar estas figuras e repeti-las para o avaliador, que anota 
novamente o número de acertos (memória imediata1). Esta etapa se repete (memória imediata 2). Em seguida são aplicados as escalas de Fluência Verbal Animal e o teste de Relógio (tarefas de função executiva). O avaliador solicita que o sujeito relembre as 10 figuras após aproximadamente cinco minutos e anota os acertos (memória tardia). Por fim, apresenta outro quadro com vinte figuras e solicita que o sujeito identifique quais figuras ele (a) viu antes, pontuando o número de acertos. Valores considerados normais para memória são de recordar sete figuras por tarefa (Vitiello et al, 2007). Os subitens de função executiva estão descritos mais adiante (no item "desfechos, validade") juntamente com as demais avaliações de função executiva. A escala foi validada para indivíduos brasileiros com algum distúrbio neurológico (cefaleia, alterações do sistema nervoso periférico, epilepsia, distúrbios do movimento, doenças vasculares, distúrbios do sono, ataxia e outros) (Vitiello et al., 2007).

Avaliação de humor: Foram utilizadas a Escala Hospitalar de Ansiedade e Depressão - HAD (Zigmond e Snaith, 1983) e a Escala de Avaliação de Depressão de Hamilton (HAM-D). Na HAD há 14 itens, dos quais sete são voltados para a avaliação da ansiedade e sete para a depressão. A pontuação de cada item varia de zero a três pontos, sendo que zero corresponde a ausência de sintomas de depressão ou ansiedade. A pontuação considerada aceitável é menor dos oito pontos para cada um dos dois sintomas (Zigmond e Snaith, 1983). Esta escala foi validada na Holanda para sujeitos com AVC (Aben et al., 2002). No Brasil está escala foi validada em sujeitos com transtorno de humor sem AVC (Botega et al., 1995). Estas escalas são de aplicação fácil e rápida, além de apresentarem a nota de corte para depressão.

Na HAM-d, com 31 itens, a pontuação varia de 0 (não apresenta depressão) a 31 (Hamilton, 1960). Pontuações abaixo de 10 são considerados muito leves para a 
inclusão de pacientes em estudos com medicamentos. De acordo com um estudo (Furukava et al, 2007) sujeitos com a pontuação 7 a 8 não apresentam depressão, portanto para este estudo optamos pela nota de corte abaixo de 8 pontos. Esta escala foi validada na Holanda para sujeitos com AVC (Aben et al 2002). No Brasil suas características psicométricas foram descritas em sujeitos com depressão sem AVC (Moreno e Moreno, 1998).

\subsection{Teste de Desempenho da Função Executiva}

Este teste foi desenvolvido para utilização na prática clínica por terapeutas ocupacionais. O teste avalia o grau de auxílio requerido para o desempenho das seguintes tarefas: preparar uma refeição rápida, fazer uma ligação telefônica, tomar a medicação prescrita e pagar duas contas de consumo. Os seguintes domínios da função executiva são avaliados: iniciação, organização, sequenciamento, julgamento e segurança, finalização. Em cada tarefa, cada um destes cinco domínios é avaliado durante a execução. A pontuação varia de 0-25 para cada tarefa. Quanto maior a pontuação, pior é o desempenho do sujeito (Baum et al, 2008). Para que o instrumento seja aplicado de maneira adequada, além de seguir uma norma rígida, existe um questionário pré-teste que auxilia o avaliador a conhecer a familiaridade do participante com as tarefas.

Esta escala foi validada em sujeitos com AVC e esquizofrenia. Apresentou excelentes resultados na versão em inglês: confiabilidade inter examinador $(\mathrm{CCl}=$ $0,91)$ e consistência interna $(\alpha=0,94)$. Foi comparado com outros testes de avaliação de funções executivas (Teste de Fluência Verbal Animal, Teste das Trilhas- A e B e Teste de Extensão dos Dígitos), correlacionando-se de modo significativo a estas medidas (Baum et al., 2008). 
A versão sueca foi comparada com ferramentas de avaliação das atividades de vida diária e funções executivas (avaliação das habilidades motoras e processuais) e sua validade concorrente foi boa $(r h o=0,61)$ (Cederfeldt et al, 2011).

Na versão coreana que foi publicada recentemente (Kim et al., 2017), os autores descreveram algumas alterações nas atividades, como: preparo de mingau de arroz ao invés de mingau de aveia; transferência bancaria para pagamento das contas ao invés de pagamento em cheque via correio. Para esta validação, os autores avaliaram a validade de critério a partir dos seguintes testes: Teste de Stroop (Cores: $r=-0,43$; Palavras-cores: $r=-0,41$ ), Teste das Trilhas (Trilhas A: $r=-0,65$; Trilhas $B: r=-0,68$ ), Teste de Extensão de Dígitos (Direto: $r=-0,34$; Inverso: $r=-0,25$ ) e Assessment of Motor and Process Skills (AMPS Início/resposta: $r=-0,45$; AMPS conclusão $r=-0,53$ ). Foi descrito também a consistência interna ( $\alpha=0,77$ para a pontuação total) e confiabilidade inter-examinador (ICC =0,87 também para o total).

\section{Adaptação transcultural}

O processo de Adaptação transcultural e validação desta escala foram feitos a partir dos padrões estabelecidos por Guillemin e colegas (Guillemin et al., 1993, Guillemin et al.,1995 e Beaton et al., 2000).

Após o consentimento da autora para realizar a validação da escala, foi realizado o seguinte processo de tradução:

Etapa 1: Duas terapeutas ocupacionais fluentes em inglês (Juliana Conti e Sarah Monteiro dos Anjos) e dois tradutores profissionais e leigos no assunto (que trabalharam juntos: Daltony Nobrega e Beatriz Peine) realizaram a tradução para a língua portuguesa do instrumento, de maneira independente, gerando assim três versões do teste. 
Etapa 2: Estas versões foram comparadas quanto à equivalência cultural e linguística, sendo necessárias algumas alterações nas tarefas realizadas (as alterações estão descritas a seguir). Nesta etapa as palavras e termos foram adaptados para melhor compreensão do instrumento, os materiais descritos foram selecionados e adequados de acordo com o manual.

Etapa 3: A versão final foi traduzida para língua inglesa (tradutora profissional: Priscila Moura Arakaki). A retro tradução foi realizada por uma tradutora independente e totalmente cega ao instrumento original e leiga no assunto.

Etapa 4: A versão final foi revisada e comparada com a versão original pelas duas terapeutas ocupacionais fluentes em inglês (Juliana Conti e Sarah Monteiro dos Anjos). Onde os ajustes foram realizados antes que o teste fosse aplicado no primeiro sujeito da pesquisa. Nesta etapa novas correções e adequações da linguagem foram realizadas para que a escala se tornasse mais adequada a nossa cultura.

O processo foi realizado para o manual de instrução, folhas de pontuação e manual de pistas/dicas.

\section{Aplicação do teste}

O teste avalia o grau de auxílio requerido para o desempenho das seguintes tarefas: preparar uma refeição rápida, fazer uma ligação telefônica, tomar a medicação prescrita e pagar duas contas de consumo (Baum et al., 2008). Os seguintes domínios da função executiva são avaliados: iniciação, organização, sequenciamento, julgamento e segurança, finalização.

O manual do Teste de Desempenho da Função Executiva foi traduzido para o português (Anexo I). 
O desempenho é avaliado de acordo com cinco níveis de pistas e assistência que o terapeuta necessita oferecer para a execução de cada tarefa:

$\checkmark \quad 0$ pontos: sem auxílio

$\checkmark 1$ ponto: orientação verbal indireta

$\checkmark 2$ pontos: orientação com gesto

$\checkmark 3$ pontos: assistência verbal direta

$\checkmark 4$ pontos: assistência física

$\checkmark 5$ pontos: não pode fazer.

Durante a execução da tarefa, o avaliador observa e mensura cada um dos cinco domínios da função executiva. A pontuação varia de 0-25 para cada tarefa. Quanto maior a pontuação, pior é o desempenho do sujeito (Baum et al., 2008).

Caso o participante apresente alguma dificuldade motora que impeça a realização de alguma fase da tarefa, dificuldade para leitura ou desconhecimento prévio de como realizar parte da tarefa, o examinador deverá completar a etapa pelo participante, sendo que está dificuldade não será pontuada.

$\mathrm{Na}$ versão brasileira foram necessárias algumas alterações para adequar o teste à cultura local:

- O preparo de uma refeição simples (mingau de aveia) foi substituído pelo preparo de café, pelo fato de o café ser um alimento mais usual na cultura brasileira do que o mingau de aveia.

- O telefonema para um supermercado foi substituído por um telefonema para uma farmácia. Não é habito de o brasileiro fazer as compras por telefone e solicitar a entrega em casa, porém ligar para a farmácia e solicitar a medicação em casa se mostrou mais usual. 
- Na tarefa da medicação, na versão americana o nome do sujeito está escrito na etiqueta do medicamento, porém, no Brasil esta não é uma prática habitual; portanto, o sujeito foi orientado a comparar o receituário médico com o nome do medicamento. Cores diferentes foram adicionadas aos fracos de medicamentos para que sujeitos analfabetos fossem capazes de identificar a medicação adequada. Sendo que os sujeitos foram capazes de ler apenas seus nomes no receituário médico.

- Na versão em inglês o sujeito deve preencher um cheque e enviá-lo pelo correio para uma empresa juntamente com uma conta a ser paga. Na versão brasileira o sujeito deve separar a quantia correta de dinheiro em um envelope contendo notas e moedas (dinheiro de brinquedo) para pagar uma conta, e entregá-la ao terapeuta. Como os sujeitos analfabetos foram capazes de identificar seus nomes e valores das contas de consumo, não foi necessário realizar nenhuma alteração nesta tarefa quanto a leitura e escrita.

As avaliações foram realizadas em uma sala silenciosa e iluminadas dentro do Laboratório de Neuroestimulação da Divisão Clínica Neurológica. Todos os itens necessários para executar as quatro tarefas e os itens distratores (canecas, colheres, correspondências, moedeiro, caixa de medicação com nome incorreto, papel de rascunho) ficaram acondicionados em uma caixa plástica, conforme as orientações do manual de instruções. Para a tarefa de preparo do café foi optado pelo uso do micro-ondas para aquecer a água, pois no hospital não é permitido o uso de fogão (nem a gás nem elétrico). 


\subsection{Medidas de desfecho}

\subsubsection{Propriedades psicométricas}

As seguintes propriedades psicométricas da versão brasileira do Teste de Desempenho da Função Executiva foram avaliadas nos sujeitos com AVC: consistência interna, confiabilidade teste e reteste.

\section{Consistência interna}

A consistência interna é medida pelo grau de coerência ou uniformidade entre as respostas de diferentes sujeitos para um mesmo instrumento. Em uma escala que possui diversos itens, idealmente todos eles deveriam medir com a mesma consistência uma mesma variável. Os subitens da escala devem ser comparados com a pontuação final para avaliar a correlação entre eles e se medem aquilo que se propõem a medir de maneira coerente.

A consistência interna foi medida a partir do a de Cronbach (Maroco e Garcia -Marques, 2006), e classificada em: excelente $(\geq 0,9)$, boa $(0,7 \leq \alpha<0,9)$, aceitável $(0,6 \leq \alpha<0,7)$, ruim $(0,5 \leq \alpha<0,6)$ e inaceitável $(\alpha<0,5)$. Valores acima de 0,7 são aceitáveis e acima de 0,9 é considerado como duplicado, redundante, devendo eliminar este item. Portanto os valores preferencialmente devem ser entre 0,8 a 0,9 (Maroco e Garcia -Marques, 2006).

Quando avaliado o coeficiente de alfa de Cronbach, é calculado um valor para a escala em sua totalidade e outro valor para cada item da escala. Sendo assim, se este item for retirado da escala o valor de a será alterado (para melhora da escala ou piora). Deste modo é possível compreender o quanto cada item da escala é representativo do total (Maroco e Garcia -Marques, 2006). 


\section{Confiabilidade teste e reteste}

A confiabilidade mede se o instrumento pode ou não ser replicado (Koo and Li, 2016). Ocorre a partir da comparação dos resultados em situações semelhantes e sucessivas. A medida de confiabilidade quer mostrar o quanto a avaliação de um mesmo sujeito ou objeto produz um resultado igual (Martins, 2006). Se divide em confiabilidade teste e reteste que corresponde à semelhança entre resultados obtidos com um teste, quando aplicado em dois momentos diferentes em um mesmo participante; e confiabilidade inter examinador avalia se o resultado no desempenho no teste é semelhante quando aplicado por dois avaliadores distintos (Martins, 2006).

Oitenta e seis sujeitos com AVC foram submetidos a uma avaliação pela Terapeuta Ocupacional 1 (Juliana Conti) de acordo com as instruções do manual de aplicação do teste. Parte dos sujeitos (30/86) foi submetida a uma segunda avaliação feita pela mesma terapeuta, 30-45 dias após, para avaliação da confiabilidade teste e reteste.

Para a avaliação da confiabilidade inter examinador, o desempenho de 40 sujeitos foi filmado durante a primeira avaliação e a Terapeuta Ocupacional 2 (Sarah Monteiro dos Anjos), pontuou seu desempenho sem conhecer a pontuação conferida pela Terapeuta Ocupacional 1. Ambas as terapeutas ocupacionais discutiram e escreveram a versão do manual, antes de iniciar a coleta de dados.

As confiabilidades teste e reteste e inter examinador foram classificadas de acordo com o Coeficiente de Correlação Intraclasse (CCI) em: excelente $(\geq 0,9)$, bom $(0,75-0,90)$, moderado $(0,50-0,75)$, fraco $(\leq 0,5)$ (Koo and Li, 2016). 


\subsubsection{Validade de constructo}

A validade de constructo é a capacidade com que um instrumento se correlaciona com outros instrumentos que apresentem objetivos semelhantes (Martins, 2006). Para isso, inicialmente é necessário desenvolver hipóteses relacionadas à escala em questão, como ela deve ser, o que conterá e como administrá-la, além de discutir os erros e necessidade de aprimoramento do instrumento (McDowell, 2006; Martins, 2006). Deste modo é possível avaliar se cada item da escala é representativo ou não dentro da escala como um todo (McDowell, 2006).

Para a avaliação da validade de constructo, correlacionamos o Teste de desempenho da Função Executiva com outras escalas e também com o desempenho entre indivíduos com AVC.

\section{Correlações entre o Teste de Desempenho da Função Executiva e outros} instrumentos

Instrumentos de avaliação de função executiva

A seguir estão descritas as escalas de função executiva que foram selecionadas para a avaliação de constructo do Teste de Desempenho da Função Executiva. Foram selecionadas cinco escalas diferentes, pois estas avaliam os diferentes domínios da função executiva: memória de trabalho, flexibilidade mental, planejamento, organização e resolução de problemas. Embora sejam escalas de uso exclusivo da psicologia, todas as escalas foram aplicadas após um treinamento e discussão com uma profissional da área. Como estas escalas foram aplicadas apenas como fim de pesquisa e não para diagnóstico clínico não houve restrição. Estas escalas de função executiva foram selecionadas por serem instrumentos comumente 
encontrados na literatura e de aplicação relativamente simples e rápida. Além da função executiva estas escalas avaliam também outros domínios da cognição como atenção e memória.

De acordo com nossa hipótese, esperávamos encontrar correlações estatisticamente significativas entre o Teste de Desempenho da Função Executiva e os seguintes instrumentos:

$\checkmark$ Teste de Extensão dos Dígitos (direto e inverso) (Wechsler, 1939; Cunha, 1993): Parte integrante da bateria Wechsler Adult Intelligence Scale (WAIS) que avalia a memória operacional e função executiva. Neste teste o avaliador repete uma sequência de números (inicialmente com dois números) e o sujeito deve repetila (ordem direta), sendo que a quantidade de números em sequência aumenta, até que chegue a sete números para o sujeito repetir. $O$ avaliador considera como pontuação final a sequência de números que o sujeito foi capaz de repetir. Em seguida outra sequência de números é falada pelo avaliador (do mesmo modo), porém o sujeito deve repetir em ordem inversa. A pontuação é considerada da mesma maneira. A pontuação da escala varia 0 (pior desempenho, incapaz de repetir qualquer sequência numérica) a 7 (melhor desempenho, capaz de repetir até uma sequência de 7 números, nas ordens direta e inversa). São considerados normais sequências de números repetidas corretamente de extensão maior ou igual a 5 para ordem direta e maior ou igual a 3 para ordem inversa (Lezak, 1995).

$\checkmark$ Teste de Stroop na versão para sujeitos analfabetos (Kulaif e Valle, 2008). Composta de quatro cartões: cartão 1 é composto pelas figuras de 24 retângulos coloridos; cartão 2 contém 12 retângulos coloridos intercalados com 12 números (4, 5, 8 e 9); cartão 3 contém 24 números (4, 5, 8 e 9) desenhados de cores 
diferentes (azul, verde, preto e rosa); cartão 4 composto por 24 números (4, 5, 8 e 9 na cor preta).

O sujeito deve repetir os itens que estão nos cartões (cores e/ou números), seguindo uma sequência (da esquerda para a direita, de cima para baixo), rapidamente. Se errar, não retoma a sequência e o avaliador cronometra o tempo, que será considerado como a pontuação do teste. No cartão 3 o sujeito deve repetir apenas as cores pintadas que formam os números (não devem repetir os números) no cartão (Kulaif e Valle, 2008). A pontuação (ou escore de interferência) é definida com a subtração do tempo (em segundos) do cartão 3 (números coloridos) menos o cartão 1 (retângulos coloridos). Sendo que quanto menor o tempo em que o indivíduo executa a tarefa, melhor é o seu desempenho e menor são as alterações de função executiva. Em um estudo realizado com sujeitos saudáveis separados em dois grupos de acordo com os anos de escolaridade, o grupo com até quatro anos apresentou um escore de interferência médio de 19,1 segundos e o grupo acima de quatro anos, de 14,9 segundos (Kulaif e Valle, 2008).

$\checkmark$ Subteste do Mapa do Zoológico e Modificado dos Seis Elementos da Bateria de Avaliação Comportamental da Síndrome Disexecutiva (Wilson et al., 1996; Armentano et al., 2011). O subteste do Mapa do Zoológico é dividido em duas partes. Na primeira parte (tarefa 1) o sujeito deve visitar seis locais do zoológico (prédeterminados, que estão desenhados no mapa de zoológico) seguindo regras impostas, porém na ordem em que ele (a) julgar correta; na segunda parte (tarefa 2) o sujeito deve executar a tarefa exatamente na ordem pré-estabelecida. Em ambas as situações, o mapa do zoológico e as regras estão posicionados na frente do sujeito e ele pode consultá-los a qualquer momento. O avaliador deve anotar a sequência e locais visitados pelo sujeito, assim como se ele infringiu alguma regra. 
A pontuação total se dá a partir da soma do número de acertos da tarefa 1 e da tarefa 2, sendo que este valor corresponderá a um valor final que varia de 0 (pior desempenho, comprometimento de função executiva) a 4 (melhor desempenho, sem prejuízo nas funções executivas) (Wilson et al., 1996, Armentano et al., 2011). Os artigos de validação (versão original) não apresentaram os valores normais, apenas os dados psicométricos (Wilson et al., 2003; Norris e Tate, 2000). Em um estudo que comparou sujeitos de um grupo controle com indivíduos com doença de Alzheimer e sujeitos com comprometimento cognitivo leve, a pontuação apresentada pelos sujeitos do grupo controle foi em média $2,43( \pm 1,11)$ e mediana foi 2 (Armentano et al., 2011).

$\checkmark$ Subteste Modificado dos Seis Elementos é composta por seis blocos de tarefas (2 para copiar as figuras geométricas, 2 para nomear as figuras e 2 para realizar contas simples de matemática). O sujeito tem 10 minutos para executá-las. O avaliador explica para o sujeito que não terá tempo suficiente para executar todas as tarefas de todos os blocos, mas que ele (a) deve executar pelo menos um pouco de cada bloco de tarefa e seguir as regras impostas. Os blocos de tarefas, cronômetro, papel, caneta e as regras/instruções são posicionadas em frente ao sujeito. $\mathrm{O}$ avaliador deve pontuar o número de tarefas completas pelo sujeito e o número de vezes que infringiu as regras. A pontuação total é dada pelo número de tarefas executadas de cada bloco menos o número de vezes que as regras não foram cumpridas, sendo que este número corresponderá a um valor final que varia de 0 (pior desempenho, comprometimento de função executiva) a 4 (melhor desempenho, sem prejuízo nas funções executivas) (Armentano et al., 2011). Em um estudo que comparou sujeitos de um grupo controle com indivíduos com doença de Alzheimer e sujeitos com comprometimento cognitivo leve, a pontuação 
apresentada pelos sujeitos do grupo controle foi em média $3,72( \pm 0,58$, desviopadrão) e mediana foi 4 (Armentano et al., 2011).

$\checkmark \quad$ Fluência Verbal Semântica, subteste da Bateria Breve de rastreio Cognitivo (Vitiello et al., 2007). O avaliador solicita para o sujeito que diga o maior número de animais (todo o tipo de animal: mamífero, inseto, aves, répteis) em um minuto. Para esta tarefa a pontuação é definida como aceitável: acima de 9 nomes de animais para analfabetos; acima de 12 nomes de animais para 1 a 7 anos de escolaridade e acima de 13 nomes de animais para indivíduos com escolaridade igual ou superior a 8 anos (Caramelli et al., 2003). Este teste foi validado em brasileiros com doença de Alzheimer (Caramelli et al., 2003).

$\checkmark \quad$ Teste do Desenho do Relógio subteste da Bateria Breve de rastreio Cognitivo (Sunderland et al., 1989; Nitrini et al., 1994; Nitrini et al., 2004). O avaliador solicita para o sujeito que desenhe um relógio: desenhe um círculo, com os números de 1 a 12 e os ponteiros marcando 02 h45min. Para a tarefa do relógio a pontuação varia de 1 (pior desempenho, não tentou/não conseguiu fazer o relógio) a 10 (melhor desempenho) São considerados anormais os valores abaixo de 9 (Sunderland et al., 1989). Esta escala foi validada para sujeitos idosos saudáveis da população brasileira (Atalaia-Silva e Lourenço 2008).

Instrumentos de rastreio cognitivo global

De acordo com nossa hipótese, esperávamos encontrar uma correlação fraca entre o Teste de Desempenho da Função Executiva e o Mini Exame do Estado mental (Folstein et al., 1975; Brucki et al., 2004), descrito no item 4.1 de caracterização do local e grupo.

Esperávamos encontrar correlações com os itens de percepção, nomeação e memória (incidental, imediata 1 e 2, tardia e reconhecimento) da Bateria Breve de 
Rastreio Cognitivo (Nitrini et al., 2004) (descrita no item 4.1 de caracterização do local e grupo). A função executiva é relevante para a organização das instruções e para a memória (Worthinggton, 2005 e Markowitisch, 2005).

Escalas de comprometimento das estruturas do corpo, participação e atividade De acordo com a Classificação Internacional de Funcionalidade (CIF) a funcionalidade e incapacidade englobam dois componentes (Farias e Buchalla, 2005):

$\checkmark$ Parte 1. Funcionalidade e Incapacidade. É dividido em funções e estruturas e funções corporais, atividades e participação.

$\checkmark$ Parte 2. Fatores contextuais. É dividido em fatores ambientais e pessoais.

De acordo com nossa hipótese, esperávamos encontrar correlações estatisticamente significativas entre o Teste de Desempenho da Função Executiva e as seguintes escalas, agrupadas de acordo com a Classificação Internacional de Funcionalidade (Farias e Buchalla, 2005; Salter et al., 2005):

$\checkmark$ Comprometimento das estruturas e funções corporais: avaliado pela Escala de AVC do NIH (National Institutes of Health Stroke Scale- NIHSS).

$\checkmark$ Atividade: avaliada pela Escala Modificada de Rankin, pelo Índice de Barthel, pelo questionário de Atividades Funcionais (Pfeffer et al., 1982; Paixão e Rechenheim, 2005) e pela Escala de Lawton e Brody (Lawton e Brody, 1969; Paixão e Rechenheim, 2005). Os dois últimos apresentam questões sobre atividades do cotidiano, tais como: tomar medicação, ir ao supermercado, preparar uma refeição, ir a locais distantes, cuidar da casa, entre outras. O objetivo questionário de Atividades Funcionais e da Escala de Lawton e Brody é avaliar se o indivíduo (do ponto de vista dele/a) é capaz ou não de realizar estas tarefas, seja com auxílio ou não. A pontuação total em ambos os testes ocorre pela soma de cada item respondido. Cada item no questionário de Atividades Funcionais varia de zero a três (pontuação total de zero a 
30) e na escala de Lawton \& Brody varia de um a três (pontuação total de nove a 27) (Paixão e Rechenheim, 2005).

No questionário de Atividades Funcionais, quanto mais próximo a pontuação for de zero, mais independente é o sujeito, enquanto na escala de Lawton \& Brody, quanto mais próximo de 27 for a pontuação total, mais independente é o indivíduo (Paixão e Rechenheim, 2005). Estas escalas foram descritas em alguns estudos em idosos saudáveis (Paixão e Rechenheim, 2005) e em idosos com demência (Canon e Novelli, 2012), mas não foram validadas em brasileiros.

$\checkmark \quad$ Participação: avaliada pela Escala de impacto do AVC, 3.0 (Carod-Artal et al., 2008).

\subsubsection{Relação entre a pontuação no Teste de Desempenho da Função Executiva no Sujeitos com AVC e variáveis demográficas, localização da lesão encefálica, sintomas de ansiedade e depressão.}

\section{Variáveis demográficas}

Foi avaliada a associação entre a pontuação no Teste de Desempenho da Função Executiva nos sujeitos com AVC e a idade, como variável contínua. Esperávamos que houvesse um melhor desempenho em sujeitos mais jovens devido a descrições anteriores do comprometimento da função executiva associado ao envelhecimento (Apfelbaum, 2010).

O desempenho no Teste de Desempenho da Função Executiva no Sujeitos com AVC foi comparado em homens e mulheres, e entre indivíduos com escolaridade entre zero e quatro anos, ou superior a quatro anos. 


\section{Localização da lesão}

Foram feitas as comparações entre indivíduos com lesões supratentoriais em hemisfério direito, hemisfério esquerdo, bilaterais ou lesões infratentoriais

\section{Sintomas de ansiedade e depressão}

Avaliamos sintomas leves de depressão e ansiedade com as Escala de Hamilton para Depressão (Hamilton, 1960; Moreno e Moreno, 1998) e a Escala Hospitalar de Ansiedade e Depressão - HAD (Zigmond e Snaith, 1983; Botega et al., 1995).

\section{4. Ética}

O projeto e o termo de consentimento livre esclarecido foram aprovados pela Comissão de Ética para Análise de Projeto em Pesquisa do Hospital das Clínicas FMUSP em 06/03/2013, sob o Número do Parecer 214265, Registro on-line 9936 e CAEE: 08438913000000068 (Anexo II)

Todos os sujeitos selecionados receberam informações sobre a pesquisa e assinaram o Termo de Consentimento Livre e Esclarecido. Familiares ou responsáveis foram autorizados a assinar o Termo de Consentimento Livre e Esclarecido caso o participante apresentasse déficit motor grave de membro superior ou analfabetismo. Após a assinatura do sujeito ou familiar/responsável a pesquisadora executante iniciou a aplicação dos questionários e escalas. 


\subsection{Análise Estatística}

Média, desvio-padrão ou mediana e intervalos foram utilizados para a análise estatística descritiva, de acordo com a distribuição dos dados. A normalidade da distribuição foi avaliada pelo teste de Kolmogorov-Smirnov.

A consistência interna foi avaliada a partir do alfa de Cronbach (Maroco e Garcia-Marques, 2006). As confiabilidades inter e teste e reteste foram avaliadas pelo Coeficiente de Correlação Intraclasse $(\mathrm{CCl})$ com os respectivos intervalos de confiança de 95\% (Sainani, 2017).

Para avaliação da validade de constructo foram calculados coeficiente de correlação de Spearman (Kirkwood e Sterne, 2006) entre a pontuação no Teste de Desempenho da Função Executiva e os desempenhos nos instrumentos de avaliação mencionados no item validade de constructo (item 4.3.2).

A correlação entre o Teste de Desempenho das Funções Executivas e a idade foi avaliada pelo coeficiente de correlação de Spearman. A comparação do desempenho entre indivíduos com escolaridade entre 0 e 4 anos, ou acima de 4 anos, foi feita com o teste de Mann-Whitney. O mesmo teste foi utilizado para a comparação de desempenho entre homens e mulheres. Os desempenhos em indivíduos com diferentes localizações de lesões (hemisfério direito, hemisfério esquerdo, lesões bilaterais ou lesões infratentoriais) foram comparadas com o teste de Kruskall-Wallis. A comparação entre o desempenho de indivíduos com lesões no hemisfério direito e esquerdo foi feita com o teste de Mann-Whitney.

A análise estatística foi realizada com a Statistical Package for the Social Sciences (SPSS 20.0). 
5. RESULTADOS 


\section{RESULTADOS}

\subsection{Caracterização dos sujeitos com AVC}

Houve um predomínio de homens, destros e de indivíduos com lesões no hemisfério cerebral esquerdo. O tempo médio após o AVC foi de 44,1 $\$ 36$ meses. A média de escolaridade foi inferior a oito anos. Os principais fatores de risco para doença cerebrovascular foram tabagismo, hipertensão arterial e alterações cardíacas. Estas características estão mais detalhadas na tabela 5.

Na Tabela 6 é possível observar a pontuação dos sujeitos com AVC nas escalas de função executiva e os valores normais descritos na literatura. Os sujeitos com AVC de modo geral apresentaram um bom desempenho nas escalas de função executiva de acordo com resultados relatados na literatura: muito bom no Teste de Stroop, e no Mapa do Zoológico. O desempenho foi bom nos testes de Fluência Verbal Semântica e no teste do Relógio. O resultado foi regular no Teste Modificado dos Seis Elementos quando comparado com sujeitos saudáveis.

A Tabela 7 mostra o desempenho destes sujeitos em escalas de rastreio cognitivo. Os sujeitos com AVC apresentaram, de forma geral, um desempenho muito bom no Mini Exame do Estado Mental, assim como nos testes de memória da Bateria Breve de Rastreio Cognitivo. 
Tabela 5. Características dos sujeitos com AVC

\begin{tabular}{|c|c|}
\hline Características & $\mathrm{N}=86$ \\
\hline Idade em anos (Média \pm dvp) & $62,7 \pm 10,9$ \\
\hline \multirow[t]{2}{*}{ Sexo $(\%)$} & Mulheres 40,6 \\
\hline & Homens 59,4 \\
\hline Grupo étnico (B/N/At) & $66 / 17 / 3$ \\
\hline Anos de estudo & $7,4 \pm 5,0$ \\
\hline \multirow[t]{4}{*}{ Tempo de lesão (número de sujeitos, percentagem) } & 6 - 9 Meses - $5(5,8 \%)$ \\
\hline & $9-12$ Meses - $2(2,3 \%)$ \\
\hline & Acima de 12 meses - 79 \\
\hline & $(91,9 \%)$ \\
\hline \multirow[t]{6}{*}{ Local da lesão } & Hemisfério Direito - 23 \\
\hline & Hemisfério Esquerdo - 37 \\
\hline & Hemisfério Direito + esquerdo \\
\hline & -3 \\
\hline & Ponte - 16 \\
\hline & Cerebelo - 7 \\
\hline Preferência Manual (C/D/A) & $3 / 82 / 1$ \\
\hline HAS (\%) & 64,5 \\
\hline Diabetes Mellitus (\%) & 18,1 \\
\hline Doenças cardíacas (\%) & 37,8 \\
\hline Tabagismo (\%) & 35,3 \\
\hline Oldfield (Mediana/ intervalo) & $100(-100-100)$ \\
\hline
\end{tabular}

dvp = desvio padrão; HAS= hipertensão arterial sistêmica; \% = que apresentam esta condição; $B$ = brancos; $\mathrm{N}=$ negros e pardos; $\mathrm{At}=$ asiáticos; $\mathrm{C}=$ canhoto; $\mathrm{D}=$ destro; $\mathrm{A}=$ ambidestro. 
Tabela 6. Desempenho nos instrumentos de avaliação de função executiva

\begin{tabular}{|c|c|c|}
\hline Escalas de função executiva & $\begin{array}{l}\text { Pontuação } \\
(n=86)\end{array}$ & $\begin{array}{l}\text { Valores } \\
\text { de sujeitos normais }\end{array}$ \\
\hline $\begin{array}{l}\text { Fluência verbal semântica } \\
0-1 \text { anos escolaridade, } n=11\end{array}$ & $9.1( \pm 3,7) ; 1(0-1)$ & $\begin{array}{l}\text { Média de } 11 \text { animais } \\
\text { (Brucki et al., 1997) }\end{array}$ \\
\hline $\begin{array}{l}\text { Fluência verbal semântica } \\
1-4 \text { anos escolaridade, } n=27\end{array}$ & $13,6( \pm 4,6) ; 4(1-4)$ & $\begin{array}{l}\text { Média de } 12 \text { animais } \\
\text { (Brucki et al., 1997) }\end{array}$ \\
\hline $\begin{array}{l}\text { Fluência verbal semântica } \\
4-8 \text { anos escolaridade, } n=13\end{array}$ & $13,4( \pm 4,2) ; 6(5-8)$ & $\begin{array}{l}\text { Média de } 13 \text { animais } \\
\text { (Brucki et al., 1997) }\end{array}$ \\
\hline $\begin{array}{l}\text { Fluência verbal semântica } \\
\text { Acima de } 8 \text { anos escolaridade, } n=35\end{array}$ & $15,2( \pm 5,2) ; 12(9-22)$ & $\begin{array}{l}\text { Média de } 15 \text { animais } \\
\text { (Brucki et al., 1997) }\end{array}$ \\
\hline Relógio* & $6,3( \pm 2,79) ; 7(2-10)$ & $\begin{array}{l}\text { <9 são considerados } \\
\text { anormais } \\
\text { (Sunderland et al., 1989) }\end{array}$ \\
\hline Teste de Extensão de Dígitos Diretos & $5,8( \pm 1,23) ; 6(2-7)$ & $\begin{array}{l}\geq 5 \\
\text { (Lezak, 1995) }\end{array}$ \\
\hline Teste de Extensão de Dígitos Inversos & $3,0( \pm 1,27) ; 3(0-6)$ & $\begin{array}{l}\geq 3 \\
\text { (Caramelli et al., 2003) }\end{array}$ \\
\hline $\begin{array}{l}\text { Stroop (interferência, tempo em segundos) } \\
0-4 \text { anos de escolaridade, } n=38\end{array}$ & $\begin{array}{l}7(-17-67) \\
12( \pm 16,0)\end{array}$ & 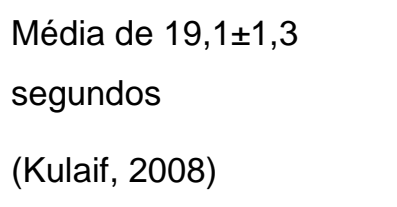 \\
\hline $\begin{array}{l}\text { Stroop (interferência, tempo em segundos) } \\
\text { Acima de } 4 \text { anos de escolaridade, } \\
n=48\end{array}$ & $\begin{array}{l}6(-6-39) \\
7( \pm 7,7)\end{array}$ & $\begin{array}{l}\text { Média de } 14,9 \pm 1,4 \\
\text { segundos } \\
\text { (Kulaif, 2008) }\end{array}$ \\
\hline $\begin{array}{l}\text { Pontuação sub testes do mapa do zoológico } 1 \\
\text { e } 2 \text { (BADS) }\end{array}$ & $2,2( \pm 0,73) ; 2(1-4)$ & $\begin{array}{l}\text { Mediana = } 2 \text { (grupo } \\
\text { controle) } \\
\text { (Armentano, 2011) }\end{array}$ \\
\hline Sub teste dos 6 elementos modificado (BADS) & $2,4( \pm 0,94) ; 2(0-4)$ & $\begin{array}{l}\text { Mediana = } 4 \text { (grupo } \\
\text { controle) } \\
\text { (Armentano, 2011) }\end{array}$ \\
\hline
\end{tabular}

BADS = Bateria de Avaliação Comportamental da Síndrome Disexecutiva; * testes integrantes da Bateria Breve de Rastreio Cognitivo 
Tabela 7: Desempenho dos sujeitos com AVC em testes de avaliação cognitiva (medianas e intervalos)

\begin{tabular}{|c|c|c|}
\hline Escalas de rastreio cognitivo & Pontuação ( $n=86$ ) & $\begin{array}{l}\text { Valores normais } \\
\text { (Vitiello et al., 2007) }\end{array}$ \\
\hline MEEM: Analfabetos $(n=11)$ & $19,4( \pm 1,55) ; 19(17-22)$ & $18 / 30$ \\
\hline $\begin{array}{l}\text { MEEM:1- } 4 \text { anos de } \\
\text { escolaridade }(n=27)\end{array}$ & $23,5( \pm 3,40) ; 25(20-30)$ & $21 / 30$ \\
\hline $\begin{array}{l}\text { MEEM:5-8 anos de escolaridade } \\
(n=13)\end{array}$ & $24,5( \pm 2,68) ; 24(21-29)$ & $24 / 30$ \\
\hline $\begin{array}{l}\text { MEEM: Acima de } 8 \text { anos de } \\
\text { escolaridade }(n=35)\end{array}$ & $26,5( \pm 2,78) ; 28(20-30)$ & $26 / 30$ \\
\hline Nomeação* & $9,7( \pm 0,89) ; 10(3-10)$ & $9 / 10$ \\
\hline Percepção visual* & $9,7( \pm 0,90) ; 10(3-10)$ & $9 / 10$ \\
\hline Memória incidental ${ }^{*}$ & $5,4( \pm 1,46) ; 5(2-10)$ & $7 / 10$ \\
\hline Memória imediata $1^{*}$ & $7,5( \pm 1,52) ; 8(3-10)$ & $7 / 10$ \\
\hline Memória imediata $2^{*}$ & $8,2( \pm 1,58) ; 8(3-10)$ & $7 / 10$ \\
\hline Memória tardia* & $7,4( \pm 1,96) ; 8(0-10)$ & $7 / 10$ \\
\hline Reconhecimento* & $9,5( \pm 1,05) ; 10(5-10)$ & $9 / 10$ \\
\hline
\end{tabular}

MEEM = Mini Exame do Estado Mental; *subtestes da Bateria Breve de Rastreio Cognitivo.

A Tabela 8 mostra a pontuação nas escalas de comprometimento das estruturas do corpo, participação e atividade. O comprometimento neurológico foi leve de acordo com o resultado da Escala de AVC do NIH.

Em relação às escalas de atividade (Tabela 8), a mediana da pontuação na escala Modificada de Rankin indicou um nível de incapacidade leve. A mediana da pontuação no Índice de Barthel sugeriu um alto nível de independência na realização de atividades básicas de vida diária. As pontuações no Questionário de Atividades Funcionais (Pfeffer et al., 1982) e na Escala de Lawton e Brody, também foram altas de modo geral. 
Tabela 8. Pontuação nas escalas de comprometimento de estruturas do corpo e de atividade

\begin{tabular}{|c|c|c|}
\hline $\begin{array}{l}\text { Escalas de comprometimento das estruturas } \\
\text { do corpo e atividade }\end{array}$ & $\begin{array}{l}\text { Pontuação } \\
\qquad(\mathrm{n}=86)\end{array}$ & Valores normais \\
\hline $\begin{array}{l}\text { Escala de AVC do NIH } \\
\text { (Mediana/ intervalo) }\end{array}$ & $\begin{array}{l}1,9( \pm 1,75) \\
1(0-6)\end{array}$ & $\begin{array}{l}\text { Mais próximo de } 0 \text {, } \\
\text { menor comprometimento } \\
\text { neurológico (Caneda et } \\
\text { al., 2006) }\end{array}$ \\
\hline $\begin{array}{l}\text { Escala Modificada de Rankin (Mediana/ } \\
\text { intervalo) }\end{array}$ & $\begin{array}{c}1,7( \pm 1,05) \\
2(0-4)\end{array}$ & $\begin{array}{l}\text { Mais próximo de } 0 \\
\text { menor incapacidade } \\
\text { (Caneda et al., 2006) }\end{array}$ \\
\hline $\begin{array}{l}\text { Índice de Barthel } \\
\text { (Mediana/ intervalo) }\end{array}$ & $\begin{array}{c}97,5( \pm 7,22) \\
100(40-100)\end{array}$ & $\begin{array}{l}\text { Mais próximo de } 100 \text {, } \\
\text { mais independente } \\
\text { (Caneda et al., 2006) }\end{array}$ \\
\hline $\begin{array}{l}\text { Questionário de Atividades Funcionais } \\
\text { (Pfeffer) }\end{array}$ & $\begin{array}{l}2,0( \pm 3,50) ; 26 \\
\quad(11-27)\end{array}$ & $\begin{array}{l}\text { Mais próximo de zero } \\
\text { mais independente } \\
\text { (Paixão e Rechenheim, } \\
\text { 2005) }\end{array}$ \\
\hline Escala de Lawton e Brody & $\begin{array}{c}24,5( \pm 4,03) ; 0 \\
(0-18)\end{array}$ & $\begin{array}{l}\text { Mais próximo de } 27 \text { mais } \\
\text { independente } \\
\text { (Paixão e Rechenheim, } \\
\text { 2005) }\end{array}$ \\
\hline
\end{tabular}

A Tabela 9 mostra o desempenho na Escala de impacto do AVC, 3.0 (CarodArtal et al., 2008, Mohammad et al., 2015), que mostra que em geral os sujeitos apresentaram uma qualidade de vida boa. Apenas o domínio 8 (participação nas atividades anteriores) que apresentou um resultado ruim.

A Tabela 10 apresenta as pontuações nas escalas de sintomas de ansiedade e depressão. As pontuações foram baixas, indicando leve depressão ou ausência conforme esperado pelos critérios de exclusão do estudo. 
Tabela 9. Pontuação em escala de participação (Escala de Impacto do AVC)

\begin{tabular}{ll}
\hline Escala de Impacto do AVC & $\begin{array}{l}\text { Pontuação por domínio } \\
(\mathbf{n = 8 6 )}\end{array}$ \\
\hline Domínio 1: Alterações físicas decorrentes do AVC & $78(13-100)$ \\
\hline Domínio 2: Memória e pensamento & $96(43-100)$ \\
Domínio 3: Sentimentos, humor e emoções & $81(19-100)$ \\
Domínio 4: Capacidade de comunicação & $100(61-100)$ \\
\hline Domínio 5: Atividades de vida diária & $90(18-100)$ \\
Domínio 6: Capacidade de se deslocar em casa & $86(17-100)$ \\
\hline Domínio 7: Capacidade de usar a mão afetada & $78(0-100)$ \\
Domínio 8: Participação nas atividades & $31(0-100)$ \\
Domínio 9: Escala de recuperação & $80 \%(0-100 \%)$ \\
\hline
\end{tabular}

Os valores estão em medianas/intervalos. O domínio 9 é a percentagem de recuperação após 0 AVC, como percebida pelo indivíduo.

Tabela 10. Pontuação nas escalas de ansiedade e depressão.

\begin{tabular}{llc}
\hline Escalas & $\begin{array}{l}\text { Pontuação } \\
(\mathbf{n}=\mathbf{8 6})\end{array}$ & Valores aceitáveis \\
\hline Escala Hospitalar de Ansiedade e Depressão - & $3,5( \pm 3,31) ;$ & $\leq 8$ sem ansiedade \\
Ansiedade & $3(0-14)$ & $\begin{array}{l}\text { (Zigmond e Snaith et } \\
\text { al., 1983) }\end{array}$ \\
Escala Hospitalar de Ansiedade e Depressão - & $3,6( \pm 3,97) ;$ & $\leq 8$ sem depressão \\
Depressão & $3(0-17)$ & $\begin{array}{l}\text { (Zigmond e Snaith et } \\
\text { al., 1983) }\end{array}$ \\
Escala de Avaliação de Depressão de Hamilton & $1,8( \pm 2,11) ;$ & $<7-8$ sintomas leves \\
& $1(0-8)$ & (Furukawa et al., 2007) \\
\hline
\end{tabular}

\subsection{Teste de Desempenho da Função Executiva}

A Tabela 11 mostra o desempenho dos sujeitos com AVC no Teste de Desempenho da Função Executiva. É possível observar que os sujeitos apresentaram uma pontuação baixa, indicando um ótimo desempenho nas tarefas. As melhores pontuações foram obtidas nas tarefas de culinária e telefonema. 
Tabela 11. Desempenho dos sujeitos com AVC no Teste de Desempenho da Função Executiva

\begin{tabular}{lcc}
\hline Teste de Desempenho da Função Executiva & Resultado $(\mathbf{n}=\mathbf{8 6})$ & $\begin{array}{c}\text { Pontuação em sujeitos } \\
\text { com AVC leve } \\
\text { (Baum et al., 2008) }\end{array}$ \\
\hline Culinária (Mediana/ intervalo) & $\begin{array}{c}1,0( \pm 1,8) ; \\
0(0-10)\end{array}$ & Média 2,98 $( \pm 4,90)$ \\
\hline Telefonema (Mediana/ intervalo) & $0,7( \pm 1,6) ; 0(0-9)$ & Média $1,83( \pm 2,27)$ \\
Medicação (Mediana/ intervalo) & $1,3( \pm 1,3) ; 1(0-7)$ & Média 0,92 $( \pm 1,34)$ \\
Contas (Mediana/ intervalo) & $1,7( \pm 2,9) ; 3(0-10)$ & Média 1,92 $( \pm 2,19)$ \\
\hline TDFE Total (Mediana/ intervalo) & & Média 7,87 $( \pm 8,42)$ \\
\hline TDFE: tempo total em minutos (Média $\pm d v p)$ & $\begin{array}{c}5,9( \pm 5,2) ; \\
5(0-32)\end{array}$ & \\
& $17(9,4-37,9)$ & \\
\hline
\end{tabular}

\subsection{Medidas de desfecho}

\subsubsection{Propriedades psicométricas}

\section{Consistência Interna}

A Tabela 12 mostra os resultados referentes ao desempenho dos sujeitos com AVC em cada tarefa da escala. A consistência interna foi considerada boa para as tarefas de culinária, uso do telefone e pagamento de contas, e aceitável para a de medicação.

A consistência interna da escala (pontuação total) pode ser considerada boa, com um alfa de Cronbach de 0,819. 
Tabela 12. Consistência interna do Teste de Desempenho da Função Executiva

\begin{tabular}{lcc}
\hline $\begin{array}{l}\text { Teste de Desempenho da } \\
\text { Função Executiva }\end{array}$ & Correlação do item com o total & $\begin{array}{c}\text { Alfa de Cronbach se } \\
\text { item excluído }\end{array}$ \\
\hline Culinária & 0,564 & 0,813 \\
Telefonema & 0,720 & 0,733 \\
Medicação & 0,607 & 0,793 \\
Contas & 0,704 & 0,740 \\
\hline
\end{tabular}

\section{Confiabilidade teste e reteste e inter examinador}

A Tabela 13 mostra os resultados da confiabilidade teste e reteste. São apresentadas as medianas e intervalos entre parênteses para o desempenho de cada tarefa, além dos coeficientes de correlação intraclasse e seus intervalos de confiança. Na Tabela 13 é possível observar a pontuação de cada sujeito em cada tarefa e a pontuação final nas avaliações 1 e 2, com a mesma examinadora.

Tabela 13. Confiabilidade Teste e reteste, Teste de Desempenho da Função Executiva

\begin{tabular}{lccccc}
\hline Teste de Desempenho da & $\mathbf{1}^{\mathbf{a}}$ avaliação & $\mathbf{2}^{\mathbf{a}}$ avaliação & \multirow{2}{*}{$\mathbf{C C l}$} & \multicolumn{2}{c}{ IC (95\%) } \\
\cline { 5 - 6 } Função Executiva & $\mathbf{( N = 3 0 )}$ & $\mathbf{( N = 3 0 )}$ & & Inferior & Superior \\
\hline Culinária & $0(0-2)$ & $0(0-2)$ & 0,000 & 0,000 & 0,362 \\
Telefonema & $0(0-3)$ & $0(0-2)$ & 0,190 & 0,000 & 0,515 \\
Medicação & $1(0-4)$ & $1(0-4)$ & 0,418 & 0,083 & 0,671 \\
Contas & $3(0-5)$ & $2(0-5)$ & 0,317 & 0,000 & 0,603 \\
\hline Pontuação total TDFE & $5(0-12)$ & $3(0-10)$ & 0,435 & 0,096 & 0,684 \\
\hline
\end{tabular}

Resultados em Mediana/ intervalo. CCl: Coeficiente de Correlação Intraclasse.

A Tabela 14 apresenta os resultados da confiabilidade inter examinador. A concordância quanto ao desempenho nas tarefas de culinária e telefonema foram 
consideradas excelentes; já na tarefa de contas, satisfatória e na tarefa de medicação, ruim.

Tabela 14. Confiabilidade Inter examinador

\begin{tabular}{lccccc}
\hline Teste de Desempenho da & $\mathbf{1 0}$ avaliador & 20 avaliador & \multirow{2}{*}{$\mathbf{C C l}$} & \multicolumn{2}{c}{$\mathbf{C C l}(95 \%)$} \\
\cline { 5 - 6 } Função Executiva & $(\mathrm{N}=40)$ & $(\mathrm{N}=40)$ & & Inferior & Superior \\
\hline Culinária & $1(0-10)$ & $0(0-10)$ & 0,750 & 0,577 & 0,859 \\
Telefonema & $0(0-8)$ & $0(0-9)$ & 0,758 & 0,574 & 0,867 \\
Medicação & $1(0-5)$ & $1,5(0-7)$ & 0,393 & 0,109 & 0,621 \\
Contas & $2,5(1-6)$ & $3(1-9)$ & 0,555 & 0,303 & 0,736 \\
\hline Pontuação total TDFE & $6(1-25)$ & $7(1-29)$ & 0,732 & 0,516 & 0,855 \\
\hline
\end{tabular}

Resultados em Mediana/ intervalo. CCl: Coeficiente de Correlação Intraclasse.

Embora este resultado de confiabilidade inter examinador tenha sido regular, se mostra diferente do descrito pela autora, que apresentou um resultado excelente: Culinária $\mathrm{CCl}=0,94$; Telefonema $\mathrm{CCl}=0,79$; Medicação $\mathrm{CCl}=0,87$ e Pagamento das contas $\mathrm{CCl}=0,89$ (Baum et al., 2008).

\subsubsection{Validade de constructo}

As Tabelas a seguir apresentam a correlação entre o Teste de Desempenho da Função Executiva e outros instrumentos de avaliação. 
Tabela 15. Correlação entre o Teste de Desempenho de Função executiva e outros testes de função executiva

\begin{tabular}{|c|c|c|c|c|c|c|}
\hline Correlação & & Culinária & Telefonema & Medicação & Contas & $\begin{array}{c}\text { Pontuação } \\
\text { total }\end{array}$ \\
\hline Fluência verbal & rho & $-0,243$ & $-0,358$ & $-0,333$ & $-0,365$ & $-0,452$ \\
\hline Semântica & $\mathrm{p}$ & 0,024 & 0,001 & 0,002 & 0,001 & $<0,001$ \\
\hline \multirow[t]{2}{*}{ Relógio } & rho & $-0,214$ & $-0,184$ & $-0,271$ & $-0,237$ & $-0,324$ \\
\hline & $p$ & 0,048 & 0,090 & 0,012 & 0,028 & 0,002 \\
\hline Teste de extensão & rho & $-0,117$ & $-0,181$ & $-0,101$ & $-0,319$ & $-0,219$ \\
\hline dos Dígitos Diretos & $\mathrm{p}$ & 0,282 & 0,096 & 0,356 & 0,003 & 0,042 \\
\hline Teste de Extensão & rho & $-0,109$ & $-0,355$ & $-0,181$ & $-0,384$ & $-0,324$ \\
\hline dos Dígitos inversos & $\mathrm{p}$ & 0,318 & 0,001 & 0,095 & $<0,001$ & 0,002 \\
\hline Stroop (escore de & rho & $-0,077$ & 0,035 & 0,207 & 0,163 & 0,116 \\
\hline interferência) & $p$ & 0,481 & 0,748 & 0,056 & 0,134 & 0,287 \\
\hline Escore do Zoo $1+$ & rho & $-0,333$ & $-0,419$ & $-0,228$ & $-0,314$ & $-0,388$ \\
\hline Zoo 2 do BADS & $p$ & 0,002 & $<0,001$ & 0,035 & 0,003 & $<0,001$ \\
\hline Escore do Teste & rho & $-0,178$ & $-0,388$ & $-0,347$ & $-0,463$ & $-0,463$ \\
\hline $\begin{array}{l}\text { Modificado dos } 6 \\
\text { elementos - BADS }\end{array}$ & $\mathrm{p}$ & 0,101 & $<0,001$ & 0,001 & $<0,001$ & $<0,001$ \\
\hline
\end{tabular}

Na Tabela 15 é possível observar que houve correlação estatisticamente significativa com todas as escalas de função executiva, com exceção do Teste de Stroop para analfabetos.

Na Tabela 16 é possível observar que houve correlação estatisticamente significativa entre o Mini Exame do Estado Mental e o Teste de Desempenho da Função Executiva, assim como entre o Subteste de Memória Imediata 1 (Bateria Breve de Rastreio Cognitivo) e todas as tarefas do Teste de Desempenho da Função Executiva, incluindo a pontuação final. Apenas a tarefa do telefonema apresentou correlação estatisticamente 
significativa com todos os itens Mini Exame do Estado Mental e Bateria Breve de Rastreio Cognitivo.

Na Tabela 17 é possível observar a correlação entre o Teste de Desempenho da Função Executiva e as escalas de comprometimento das estruturas do corpo, assim como as escalas de atividade. Não houve correlação da pontuação total da escala com as pontuações na Escala de AVC do NIH nem com a Escala Modificada de Rankin, porém houve correlação estatisticamente significativa com as pontuações no Índice de Barthel, no Questionário de Atividades Funcionais de Pfeffer e na Escala de Lawton e Brody.

Tabela 16.Correlação entre os instrumentos de rasteiro cognitivo e o Teste de Desempenho da Função Executiva

\begin{tabular}{|c|c|c|c|c|c|c|}
\hline \multicolumn{2}{|l|}{ Escalas de Cognição } & \multirow{2}{*}{$\begin{array}{r}\text { Culinária } \\
-0,247\end{array}$} & \multirow{2}{*}{$\begin{array}{r}\text { Telefonema } \\
-0,409\end{array}$} & \multirow{2}{*}{$\begin{array}{c}\text { Medicação } \\
-0,273\end{array}$} & \multirow{2}{*}{$\begin{array}{c}\text { Contas } \\
-0,283\end{array}$} & \multirow{2}{*}{$\begin{array}{c}\begin{array}{c}\text { Pontuação total } \\
\text { TDFE }\end{array} \\
-0,352\end{array}$} \\
\hline MFFM & rho & & & & & \\
\hline IVIEEIVI & $p$ & 0,022 & $<0,001$ & 0,011 & 0,008 & 0,001 \\
\hline \multirow{2}{*}{ Nomeação* } & rho & $-0,034$ & $-0,227$ & 0,036 & $-0,244$ & $-0,127$ \\
\hline & $p$ & 0,756 & 0,036 & 0,743 & 0,023 & 0,244 \\
\hline \multirow{2}{*}{ Percepção visual* } & rho & $-0,129$ & $-0,284$ & $-0,041$ & $-0,287$ & $-0,197$ \\
\hline & $p$ & 0,237 & 0,008 & 0,707 & 0,007 & 0,068 \\
\hline \multirow{2}{*}{ Memória incidental* } & rho & $-0,217$ & $-0,310$ & $-0,179$ & $-0,154$ & $-0,252$ \\
\hline & $\mathrm{p}$ & 0,045 & 0,004 & 0,099 & 0,157 & 0,019 \\
\hline \multirow{2}{*}{ Memória imediata $1^{*}$} & rho & $-0,245$ & $-0,382$ & $-0,232$ & $-0,216$ & $-0,308$ \\
\hline & $p$ & 0,023 & $<0,001$ & 0,031 & 0,045 & 0,004 \\
\hline \multirow{2}{*}{ Memória imediata $2^{*}$} & rho & $-0,178$ & $-0,369$ & $-0,096$ & $-0,075$ & $-0,204$ \\
\hline & $\mathrm{p}$ & 0,100 & $<0,001$ & 0,379 & 0,492 & 0,060 \\
\hline \multirow{2}{*}{ Memória tardia* } & rho & $-0,169$ & $-0,340$ & $-0,142$ & $-0,113$ & $-0,239$ \\
\hline & $p$ & 0,119 & 0,001 & 0,193 & 0,299 & 0,027 \\
\hline \multirow{2}{*}{ Reconhecimento* } & rho & $-0,042$ & $-0,249$ & $-0,112$ & $-0,180$ & $-0,170$ \\
\hline & $p$ & 0,701 & 0,021 & 0,306 & 0,097 & 0,118 \\
\hline
\end{tabular}

Coeficiente de correlação de Spearman. TDFE = Teste de Desempenho da Função Executiva; MEEM = Mini Exame do Estado Mental; *Bateria Breve de Rastreio Cognitivo 
Tabela 17.Correlação entre o Teste de Desempenho da Função Executiva e as escalas de comprometimento de estruturas do corpo e de atividade.

\begin{tabular}{|c|c|c|c|c|c|c|}
\hline \multicolumn{2}{|c|}{$\begin{array}{l}\text { Escalas de } \\
\text { caracterização }\end{array}$} & \multirow{2}{*}{$\begin{array}{c}\text { Culinária } \\
0,136\end{array}$} & \multirow{2}{*}{$\begin{array}{c}\text { Telefonema } \\
-0,086\end{array}$} & \multirow{2}{*}{$\begin{array}{c}\text { Medicação } \\
0,221\end{array}$} & \multirow{2}{*}{$\begin{array}{c}\text { Contas } \\
0,119\end{array}$} & \multirow{2}{*}{$\begin{array}{c}\begin{array}{c}\text { Pontuação total } \\
\text { TDFE }\end{array} \\
0,130\end{array}$} \\
\hline NuLCC & rho & & & & & \\
\hline צט IIII & $p$ & 0,212 & 0,431 & 0,041 & 0,276 & 0,231 \\
\hline \multirow{2}{*}{ Rankin } & rho & 0,108 & 0,061 & 0,149 & 0,181 & 0,178 \\
\hline & $\mathrm{p}$ & 0,323 & 0,575 & 0,172 & 0,096 & 0,102 \\
\hline \multirow{2}{*}{ Barthel } & rho & $-0,197$ & $-0,119$ & $-0,331$ & $-0,135$ & $-0,263$ \\
\hline & $\mathrm{p}$ & 0,068 & 0,275 & 0,002 & 0,216 & 0,014 \\
\hline Escala & rho & 0,380 & 0,219 & 0,303 & 0,295 & 0,420 \\
\hline $\begin{array}{l}\text { Funcional } \\
\text { de Pfeffer }\end{array}$ & $p$ & $<0,001$ & 0,042 & 0,005 & 0,006 & $<0,001$ \\
\hline Escala de & rho & $-0,269$ & $-0,148$ & $-0,322$ & $-0,186$ & $-0,313$ \\
\hline $\begin{array}{l}\text { Lawton \& } \\
\text { Brody }\end{array}$ & $\mathrm{p}$ & 0,012 & 0,175 & 0,002 & 0,086 & 0,003 \\
\hline
\end{tabular}

Na Tabela 18 é possível observar a correlação entre o total do Teste de Desempenho da Função Executiva e os domínios da Escala de Impacto do AVC (SIS- 3.0). Houve uma correlação estatisticamente significativa apenas com os domínios 4, 5 e 6 desta escala de qualidade de vida. 
Tabela 18. Correlação entre o Teste de Desempenho da Função Executiva e os domínios da Escala de Impacto do AVC

\begin{tabular}{lc}
\hline Escala de Impacto do AVC & Correlação com total TDFE (n=86) \\
\hline Domínio 1: Alterações físicas decorrentes do AVC & Rho=-0,187 (0,084) \\
\hline Domínio 2: Memória e pensamento & Rho=-0,201 (0,063) \\
\hline Domínio 3: Sentimentos, humor e emoções & Rho=-0,065 (0,555) \\
\hline Domínio 4: Capacidade de comunicação & Rho=-0,353 (0,001) \\
\hline Domínio 5: Atividades de vida diária & $R h o=-0,227(\mathbf{0 , 0 3 6})$ \\
\hline Domínio 6: Capacidade de se deslocar em casa & $R h o=-0,144(\mathbf{0 , 0 0 1})$ \\
\hline Domínio 7: Capacidade de usar a mão afetada & $R h o=-0,236(0,185)$ \\
\hline Domínio 8: Participação nas atividades & $R h o=-0,007(0,945)$ \\
\hline Domínio 9: Escala de recuperação & $R h o=-0,104(0,341)$ \\
\hline
\end{tabular}

\subsubsection{Relação da pontuação no Teste de Desempenho da Função Executiva dos Sujeitos com AVC e as variáveis demográficas, localização da lesão encefálica, sintomas de ansiedade e depressão}

Variáveis demográficas: idade, gênero e escolaridade

Paras as variáveis idade e escolaridade houve correlação estatisticamente significativa com a pontuação total da escala age (rho=0,290, p=0,007) e (rho= $-0,460, p=0,000)$. Indivíduos mais idosos apresentaram pior desempenho (Figura 3). Não houve correlação estatisticamente significativa rho $=0,150(0,169)$, quando comparado a idade e anos de estudo.

Figura 3. Correlação entre a idade e anos de escolaridade 


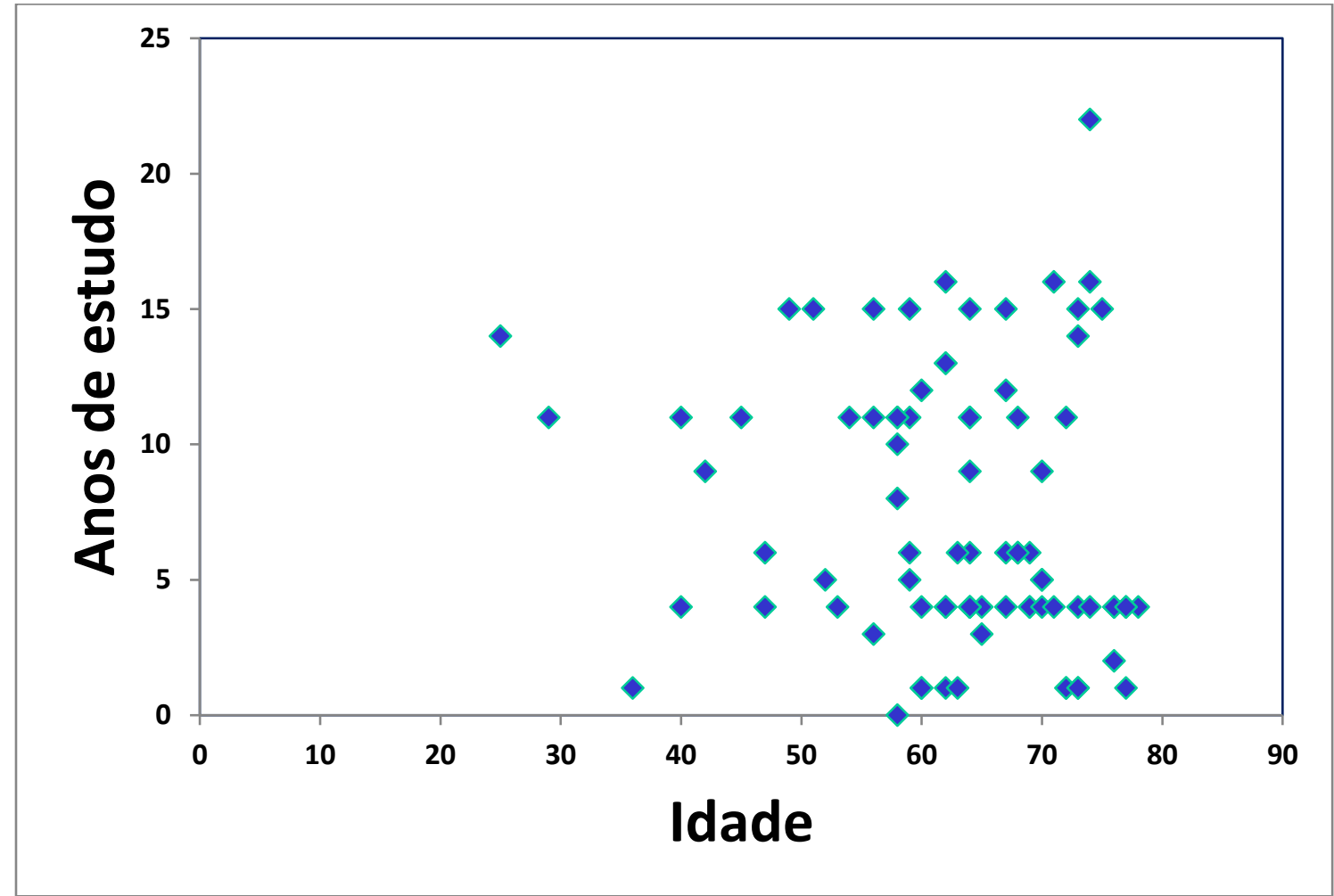

A Tabela 19 mostra a comparação do desempenho no Teste de Desempenho da Função Executiva em homens e mulheres. Não houve diferenças estatisticamente significativas entre o desempenho destes grupos em quaisquer tarefas.

Tabela 19. Comparação entre o gênero e a pontuação de cada tarefa do Teste de Desempenho da Função Executiva

\begin{tabular}{cccc}
\hline \multirow{2}{*}{ TDFE } & \multicolumn{2}{c}{ Gênero } & P \\
\cline { 2 - 3 } & Feminino & Masculino & \\
\hline \hline Culinária & $0(\mathbf{N}=\mathbf{3 7})$ & $\mathbf{( N = 4 9 )}$ & 0,063 \\
Telefonema & $0(0-4)$ & $0(0-9)$ & 0,870 \\
Medicação & $1(0-4)$ & $1(0-7)$ & 0,144 \\
Contas & $3(0-6)$ & $2(0-10)$ & 0,259 \\
\hline Pontuação total & & & 0,630 \\
TDFE & $5(1-14)$ & $5(0-32)$ & \\
\hline
\end{tabular}

Teste Mann-Whitney; medidas estão em mediana/intervalo; TDFE = Teste de Desempenho da Função Executiva 
A Tabela 20 mostra o desempenho dos sujeitos com AVC no Teste de Desempenho da Função Executiva de acordo com a escolaridade (0-4 anos de estudo e acima de 4 anos de estudo). Indivíduos com maior tempo de instrução apresentaram pontuações significativamente menores em todas as atividades e no total, exceção apenas da atividade de culinária.

Tabela 20. Comparação entre os anos de escolaridade a pontuação de cada tarefa do Teste de Desempenho da Função Executiva

\begin{tabular}{|c|c|c|c|}
\hline \multirow[b]{2}{*}{ TDFE } & \multicolumn{2}{|c|}{ Anos de Estudo } & \multirow[b]{2}{*}{$\mathbf{P}$} \\
\hline & $\begin{array}{l}\leq 4 \text { anos } \\
(N=38)\end{array}$ & $\begin{array}{l}>4 \text { anos } \\
(\mathrm{N}=48)\end{array}$ & \\
\hline Culinária & $0,5(0-10)$ & $0(0-6)$ & 0,443 \\
\hline Telefonema & $1(0-9)$ & $0(0-2)$ & $<0,001$ \\
\hline Medicação & $2(0-7)$ & $1(0-4)$ & 0,003 \\
\hline Contas & $4(1-10)$ & $2(0-6)$ & $<0,001$ \\
\hline $\begin{array}{l}\text { Pontuação total } \\
\text { TDFE }\end{array}$ & $7(0-32)$ & $3(0-14)$ & $<0,001$ \\
\hline
\end{tabular}

Teste Mann-Whitney; medidas estão em mediana/intervalo; TDFE = Teste de Desempenho da Função Executiva.

Quando observado os resultados no Teste de Desempenho da Função Executiva dos sujeitos de acordo com a localização da lesão não houve diferenças estatisticamente significativas $(p=0,363)$. Este resultado também ocorreu quando separados os pacientes em dois grupos: hemisfério direito e hemisfério esquerdo $(p=0,137)$. A Tabela 21 mostra as medianas das pontuações de acordo com a localização da lesão.

A Tabela 22 mostra a correlação entre as escalas de sintomas de ansiedade e depressão e o Teste de Desempenho da Função Executiva. Não houve correlações estatisticamente significativas. 
Tabela 21. Desempenho em cada tarefa separado por grupo de acordo com o local da lesão. As pontuações são mostradas como medianas e intervalos

\begin{tabular}{lcccccc}
\hline $\begin{array}{c}\text { Localização } \\
\text { da Lesão }\end{array}$ & $\mathbf{N}$ & Culinária & Telefonema & Medicação & Contas & $\begin{array}{r}\text { Pontuação } \\
\text { total TDFE }\end{array}$ \\
\hline H. Direito & 23 & $1(0-6)$ & $0(0-9)$ & $1(0-7)$ & $3(1-10)$ & $5(0-32)$ \\
Bilateral & 3 & $1(0-1)$ & $1(0-2)$ & $1(0-2)$ & $3(1-5)$ & $7(1-9)$ \\
H. Esquerdo & 37 & $0(0-10)$ & $0(0-8)$ & $1(0-5)$ & $2(0-6)$ & $3(1-25)$ \\
Infratentorial & 23 & $0(0-5)$ & $0(0-4)$ & $1(0-4)$ & $3(0-6)$ & $6(0-14)$ \\
\hline
\end{tabular}

H=hemisfério. Medidas estão em mediana/intervalo

Tabela 22.Correlação entre sintomas de ansiedade e depressão e o Teste de Desempenho da Função Executiva

\begin{tabular}{lcccccc}
\hline $\begin{array}{l}\text { Sintomas de } \\
\text { ansiedade } \\
\text { depressão }\end{array}$ & & Culinária & Telefonema & Medicação & Contas & $\begin{array}{c}\text { Pontuação Total } \\
\text { do TDFE }\end{array}$ \\
\hline HAD- & rho & 0,197 & 0,151 & 0,123 & 0,089 & 0,188 \\
ansiedade & $p$ & 0,077 & 0,175 & 0,273 & 0,426 & 0,091 \\
HAD- & rho & 0,003 & 0,055 & 0,075 & 0,056 & 0,081 \\
depressão & $p$ & 0,979 & 0,627 & 0,506 & 0,620 & 0,472 \\
Hamilton & rho & 0,071 & 0,089 & 0,176 & 0,056 & 0,145 \\
& $\mathrm{p}$ & 0,519 & 0,413 & 0,105 & 0,612 & 0,184 \\
\hline
\end{tabular}

Coeficiente de correlação de Spearman 
6. DISCUSSÃO

6. DISCUSSÃO 


\subsection{Composição da amostra e processo de avaliação dos sujeitos}

Conforme os resultados apresentados os sujeitos incluídos em sua maioria apresentavam uma condição clínica estável e boa funcionalidade, apresentando independência nas atividades de vida diária, com qualidade de vida razoável, conforme mostrou a Escala de Impacto do AVC. Esta amostra pode não representar realmente a realidade da população brasileira acometida por AVC, porém alguns fatores contribuíram para este contexto: dificuldade de transporte, distância percorrida até o hospital para participar da avaliação, disponibilidade do sujeito e acompanhante e dificuldade de locomoção. As avaliações foram agendadas, na maioria das vezes, em dias de consultas dos pacientes no hospital, para evitar o deslocamento excessivo até lá. Dificuldade de deslocamento é considerada uma barreira para inclusão de pacientes em estudos clínicos, principalmente no Brasil (Anjos et al., 2014). Não é a principal barreira, mas pode ser considerado como um impeditivo importante.

Outros estudos que também utilizaram sujeitos com AVC e o TDFE, apresentaram uma amostra semelhante, com sujeitos mais independentes (Cederfeldt et al., 2011; Rozental-Iluzet al., 2016; Kim et al., 2017 e Toglia et al., 2017) e com sequelas mais leves/ moderadas (Baum et al., 2008 e Toglia et al., 2017). Desta forma é possível compreender que a amostra deste estudo está de acordo com demais amostras na literatura.

Como esta é uma pesquisa composta por escalas cognitivas que exigem atenção e concentração dos sujeitos para a execução das tarefas, o ambiente tranquilo, foi essencial para que não houvesse fatores influenciando no desempenho, prejudicando assim no resultado final da pesquisa. Para a composição das escalas de avaliação, foram considerados os seguintes aspectos: escalas de aplicação simples; 
avaliadora executante o mais independente possível; com o mínimo gasto financeiro, pois este projeto não recebeu nenhum tipo de financiamento; e testes mais utilizados na literatura em pesquisas semelhantes.

Foi realizado treino prévio das avaliações para melhor compreensão dos testes e como utilizá-los. Optou-se pelo não cegamento das avaliações por três motivos: (1) nas outras versões, americana (Baum et al., 2008), sueca (Cederfeldt 2011) e coreana (Kim et al., 2017) os autores também não descreveram como sendo uma avaliação com cegamento; (2) para que houvesse maior independência da pesquisadora executante; (3) ausência de qualquer recurso financeiro para esta pesquisa, incluindo um avaliador cego.

\subsection{Caracterização da amostra}

Conforme descrito acima, os participantes deste projeto se mostraram mais independentes, porém é importante discutir o desempenho dos sujeitos do ponto de vista da função executiva e cognição. Quando comparados com o desempenho dos sujeitos saudáveis nas escalas de função executiva, os sujeitos com AVC incluídos nesta pesquisa apresentaram uma pontuação alta, nos testes: Fluência Verbal Semântica, com média de 15,2 ( $\pm 5,2)$ (considerada normal a menção de 15 animais para sujeitos com escolaridade acima de oito anos) (Brucki et al., 1997); Teste de Extensão de Dígitos Diretos com mediana de 6 (2-7) (considerado adequado repetir uma sequência $\geq 5$ números distintos) (Lezak, 1995); Teste de Extensão de Dígitos Diretos com mediana de 3 (0-6) (considerado adequado repetir uma sequência

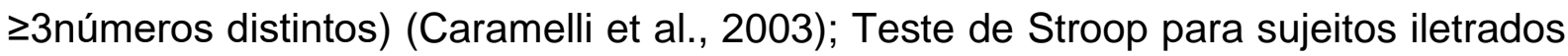
apresentou uma média para o score de interferência de $7( \pm 7,7)$ (sujeitos com mais de quatro anos de estudo), o que está acima do esperado, conforme a descrição da 
autora 14,9 $\pm 1,4$ (Kulaif, 2008); sub testes do mapa do zoológico 1 e 2 (BADS) mostrou mediana de 2 (1-4), que está semelhante ao estudo com grupo controle, onde a mediana foi de 2 (Armentano, 2011). Não apenas do ponto de vista de funcionalidade, mas também da função executiva, os sujeitos se mostraram com poucas sequelas, o que gerou um resultado próximo aos sujeitos normais.

A função cognitiva global, assim como a função executiva, não foi considerada como uma sequela importante para os participantes. Assim como em outros estudos, o desempenho nas tarefas cognitivas foi considerado bom: Mini Exame do Estado Mental com uma média de $26,5( \pm 2,78)$ para sujeitos com escolaridade acima de oito anos de estudos, se mostrando equivalente ao resultado de estudo com população semelhante (acima de 14 anos de estudos), média de 27,21 (2,04) (Kim et al., 2017).

Durante a aplicação dos testes houve uma influência maior do nível de escolaridade, principalmente para compreender o que foi solicitado e como executar cada um dos testes (impressão qualitativa). Nem todos os sujeitos se mostraram comprometidos e preocupados em executar as tarefas da melhora maneira possível, o que interferiu nos resultados. As avaliações em média levaram duas horas para serem completadas, sujeitos com menos anos de escolaridade levaram mais tempo para executa-la, devido à dificuldade de compreender o que estava sendo solicitado e o planejamento para executar uma atividade.

De modo geral os sujeitos incluídos se mostraram bem adaptados as suas sequelas e funcionalmente independentes, com uma condição clínica estável e com sequelas leves, como visto nas pontuações da Escala do NIH (1: 0-6, leve comprometimento neurológico) e índice de Barthel (100: 40 - 100, independente para as atividades de vida diária). Nos demais estudos de validação da escala, os autores descreveram amostras com perfis semelhantes: na versão americana (Baum et al., 
2008) os sujeitos apresentaram media na pontuação total na Escala de AVC do NIH de 2 para o grupo de AVC leve; e 10,64 para o grupo de AVC moderado) na versão sueca (Cederfeldt et al., 2011), os sujeitos apresentaram independência de acordo com o índice Barthel 100 (60-100); na versão coreana (Kim et al., 2017) os sujeitos também foram considerados independentes

Os sujeitos se mostraram independentes e com pouca incapacidade, resultado que também se refletiu quando aplicada a escala de qualidade de vida após o AVC (Escala de Impacto do AVC, 3.0), porém no item que discute sobre a participação nas atividades (incluindo atividades como lazer, viagem, trabalho e religião), os sujeitos apresentaram um desempenho ruim. Apesar de se considerar independentes, os sujeitos incluídos, em sua maioria, não se sentiam capazes de participar nas tarefas de lazer, ou frequentar a igreja ou até mesmo viajar. É importante mencionar o impacto na vida financeira dos sujeitos após o AVC, o que limitava sua participação em atividades de lazer e locomoção para locais mais distantes. Outro fator importante é que muitos dos sujeitos estavam aposentados ou recebendo benefício, o que fez com que sua pontuação em relação ao trabalho fosse baixa na escala.

Quando falamos de sujeitos com AVC, as sequelas motoras e cognitivas são essenciais, porém não podemos esquecer o lado emocional, fatores relacionados a saúde mental deste indivíduo. A depressão é considerada um problema de saúde mental bastante prevalente em sujeitos que sofreram um AVC, que exercerá uma influência negativa nos déficits de função executiva (Vataja et al., 2005, Melkas et al., 2010, Sibolt et al., 2013, Sobreiro et al., 2014). Por este motivo, os sujeitos com depressão grave foram excluídos deste projeto, o que também está de acordo com a literatura (em estudos semelhantes), em que sujeitos com este sintoma também foram excluídos (Rozental-luz et al., 2016 e Hahn et al., 2014). Já os estudos de validação 
em outras culturas não mencionaram a depressão. Alguns dos sujeitos apresentaram um sintoma de depressão considerado leve (Escala de Avaliação de Depressão de Hamilton mediana de 1: $0-8$, sendo considerado $<7-8$ sintomas leves, Furukawa et al., 2007), mas que não interferiu no resultado do teste.

Outro fator de saúde mental que pode aparecer em sujeitos com AVC é a ansiedade, embora não tenha sido um critério de exclusão, não foi um sintoma prevalente nesta amostra, conforme mostra o resultado do desempenho na Escala Hospitalar de Ansiedade e Depressão - Ansiedade, com uma mediana de 3 (0 - 14) ( $\leq 8$ sem ansiedade, Zigmond e Snaith et al., 1983).

\subsection{Teste de Desempenho em Funções Executivas}

O desempenho dos sujeitos da pesquisa, foi muito bom quando comparado com a versão original (Baum et al., 2008). As tarefas com melhor pontuação (mais próximas de 0 , indicando a independência) foram culinária (preparo do café) e telefonema (fazer uma ligação para a farmácia). Foram consideradas tarefas simples e comumente realizadas pelos sujeitos em sua rotina diária.

A versão americana (Baum et al., 2008) apresentou uma divisão entre os sujeitos: controle (sujeitos saudáveis), AVC leve e AVC moderado. Para cada um dos três grupos, uma das tarefas mostrou um desempenho melhor: grupo controle, tarefa do telefonema (média = 0,09); AVC leve, tarefa da medicação, (média =0,92); e AVC moderado, tarefa das contas a pagar (média $=4,43$ ). Na versão sueca (Cederfeldt et al., 2011) a tarefa que apresentou melhor pontuação (em sujeitos com AVC) foi a da medicação (mediana $=1$ ), seguida da tarefa de preparo do mingau (mediana $=3$ ). Para a versão coreana (Kim et al., 2017) a tarefa da medicação apresentou melhor desempenho pelos sujeitos com AVC (média= 3,56), seguida pela tarefa do 
telefonema (média $=4,00$ ). De modo geral as quatro versões, apresentaram um desempenho muito bom para o teste, muito próximo à categoria de independência. $A$ versão coreana e sueca apresentou como melhor tarefa, a medicação. Para a versão brasileira, esta não foi a melhor tarefa, um fator que possivelmente tenha contribuído foi o fato de envolver a leitura e a capacidade de flexibilidade mental (compreender que o medicamento da atividade é diferente do medicamento habitual).

Apenas a versão coreana descreveu alterações na escala (mingau de aveia foi substituído por mingau de arroz) para se adequar a sua população. $\mathrm{Na}$ versão brasileira, o mingau foi substituído pelo preparo do café. Além de ser considerada uma tarefa mais simples (com menos etapas) é muito habitual no cotidiano do brasileiro. $\mathrm{O}$ preparo do mingau envolve mais etapas, saber o momento correto de incluir a aveia, de desligar o fogo para ter o ponto mais adequado. Por outro lado, para preparar o café, cada um apresenta à sua maneira, mas que nem sempre uma etapa depende da outra: alguns colocam açúcar na água, outros misturam o pó na água e depois coam o café. Entretanto, ao final teremos o café, sem tantas complicações. Portanto, estas diferenças nas tarefas, podem gerar uma diferença no desempenho do sujeito, como mostram as quatro versões, ou seja, o mingau se mostrou mais complexo, portanto, com um desempenho pior.

A tarefa que apresentou pior desempenho na versão brasileira foi a de pagar as contas (mediana $=3$ ), também se mostrou a pior, nas versões sueca (mediana $=$ 7) (Cederfeldt et al., 2011) e coreana (média = 7,35) (Kim et al., 2017). Por outro lado, na versão americana (Baum et al., 2008), esta tarefa apresentou um bom desempenho, sendo a segunda colocada nos grupos controle (média $=0,23$ ) e de AVC moderado (média $=4,43$ ) e em terceiro lugar para o grupo de AVC leve (média $=1,92)$. Nesta tarefa, além das funções executivas envolvidas, também é necessário 
o uso das habilidades de leitura, escrita e flexibilidade mental (resolução de problema quando a situação é diferente do habitual).

Para executar a tarefa de pagar as contas é a mais complexa, pois se divide em etapas sequenciais (chegar o saldo bancário, definir se pagará uma ou duas contas) que devem ser obedecidas para que possa chegar ao resultado final adequado. Em sua grande maioria, os sujeitos referiram que não tinham o habito de checar o saldo bancário antes de pagar uma conta, quando recebiam o benefício se dirigiam à lotérica e pagavam todas as contas do mês de uma vez. Os sujeitos não tinham o habito de ler as datas de vencimento das contas a serem pagas (uma vencia no dia da avaliação e a outra, 15 dias depois), o que prejudicou o desempenho e resultado final da escala. Os sujeitos se mostraram mais atentos e preocupados com o valor de cada conta e com o tipo de conta (telefone e luz), do que com a data de vencimento. Outra justificativa, bastante utilizada pelos sujeitos, foi que a conta de luz (conta mais cara e com vencimento em 15 dias) é mais importante do que o telefone, ou seja, é preferível ficar sem telefone do que ficar sem luz.

\subsubsection{Adaptações realizadas para a população brasileira.}

Para que a escala se tornasse o mais próximo da cultura brasileira, foram necessárias algumas alterações. Estas alterações foram realizadas a partir da discussão com as Terapeutas Ocupacionais: (1) Sarah Monteiro dos Anjos, que realizou uma das traduções e participou da construção da versão final; e (2) Patrícia Buchain que está validando a escala em sujeitos com Demência. Outra versão que apresentou alteração na escala (para melhora adequação a população) foi a versão coreana (Kim et al., 2017), que substituiu o mingau de aveia por mingau de arroz, entrega de comida (supermercado) por comprar uma refeição (restaurante delivery), 
tomar medicação por tomar vitaminas e enviar um cheque para pagar as contas por transferir o valor da conta.

As alterações necessárias também foram discutidas com a autora, que esteve de acordo. O manual foi alterado para se adequar as novas tarefas, porém as regras de aplicação e a hierarquia das dicas/pista de mantiveram, conforme o acordo com a autora.

A opção pelo preparo de um café foi a mais difícil, pois foi necessário escolher uma atividade simples de culinária, mas que ao mesmo tempo tivesse etapas a serem cumpridas e que fosse mais comumente utilizada na rotina dos brasileiros. Conforme a versão americana (Baum et al., 2008), que tem uma receita de preparo de mingau de aveia (caso o sujeito não soubesse como preparar o mingau), uma receita de como preparar um café também fez parte da lista de materiais de aplicação do teste.

Para o brasileiro não é habitual a comprar pelo telefone de mantimentos, portanto optamos pela compra de medicamentos na farmácia. Geralmente em situações de emergência, podemos ligar para a farmácia mais próxima de nossa residência e solicitar algum medicamento. Para esta população, a ligação para a farmácia se mostrou mais comum, do que a para o supermercado.

A tarefa da medicação também necessitou de alteração, pois no Brasil, quando recebemos uma receita médica e compramos o medicamento, não está escrito o nome do paciente no frasco, conforme a versão americana. Os brasileiros devem comparar o nome da medicação (que está na embalagem) com a receita médica, além de seguir o modo de ingerir o medicamento que está descrito também no receituário. Como esta tarefa exige a habilidade de leitura e escrita, foi necessário mais uma alteração: colorir os frascos de cores diferentes, para que sujeitos analfabetos fossem 
capazes de reconhecer a medicação correta. Para esta tarefa, o sujeito deveria ser capaz de reconhecer a sua receita médica (na caixa de materiais existem duas receitas médicas, uma com o nome do sujeito da pesquisa e outra com o nome de outra pessoa fictícia) e selecionar o frasco de medicamento correspondente a receita medica. Para esta tarefa, os frascos de medicamentos e os receituários médicos foram fictícios. Todos os sujeitos incluídos e iletrados eram capazes de ler e reconhecer seu nome. Quando a instrução da tarefa foi fornecida, para os sujeitos iletrados, foi reforçada a necessidade de reconhecer sua medicação a partir da cor vermelha. Apesar de parecer uma "dica extra" e facilitar a execução da tarefa dos sujeitos iletrados, não foi exatamente assim que ocorreu, os sujeitos tiveram dificuldade por ser diferente do seu habitual. De modo geral os participantes referiam que reconheciam sua medicação habitual a partir do formato e cor, quando mudou (balinhas sem açúcar de cor verde - pastilhas Valda®), os sujeitos refeririam dificuldade para executar a tarefa. Mesmo com as alterações para adequação das tarefas, as dúvidas e complicações surgiram e possivelmente podem der discutidas e modificadas em estudos futuros.

Por fim, a tarefa de contas a pagar também exigiu alterações. Na versão americana (Baum et al., 2008), o sujeito deve enviar pelo correio um cheque pagando a conta. O que no Brasil não faz parte do cotidiano da população, mas sim o pagamento em agencia bancaria ou lotérica. Como o sujeito não iria ao banco para pagar uma conta fictícia, optamos por separar o dinheiro (fictício) e entrega-lo para a terapeuta. Conforme a versão americana (Baum et al., 2008), na versão brasileira, o sujeito também deve conferir o saldo bancário antes de definir qual conta deve pagar. Conferir o saldo bancário antes de pagar uma conta, também foi outra ação bastante questionada pelos participantes, porém esta é uma etapa importante da tarefa que 
interfere de modo substancial no resultado final. Conferir um saldo bancário para definir a conta a ser paga envolve as funções de resolução de problema e planejamento (função executiva).

Para esta tarefa de contas a pagar também são importantes as habilidades de leitura e escrita, onde foi necessário, utilizar o recurso das cores para o sujeito reconhecer as contas e a frases "data de vencimento" e "total a pagar". Os sujeitos incluídos eram capazes de reconhecer os números, datas e valores $(R \$)$. Apesar de apresentar este diferencial, os participantes iletrados, também não se beneficiaram, ou seja, apresentaram as mesmas dificuldades dos demais participantes, optando por pagar a conta mais cara e com vencimento 15 dias após a data da avaliação, deixando a conta que vencia no dia sem pagar.

\subsection{Propriedades psicométricas da escala}

A partir dos resultados é possível observar que o TDFE apresentou correlação estatisticamente significante com as escalas de função executiva e de atividade e participação, ou seja, esta escala pode ser considerada adequada e confiável para avaliar sujeitos com AVC. Estudos de mesma população apresentaram resultados semelhantes (Baum et al., 2008, Cederfeldtet al., 2011 e Kim et al., 2017).

\subsubsection{Consistência interna}

\subsubsection{Confiabilidade teste e reteste:}

Quando avaliado a confiabilidade teste e reteste a partir do Coeficiente de Correlação Intraclasse ou mesmo pelo Índice Kappa, os valores para as tarefas de culinária e telefonema mostraram-se baixos, porém a concordância entre as avaliações um e dois foi alta (20/30 para culinária e 21/30 para telefonema). Ocorreu 
uma alta prevalência de pontuação "0", o que demonstrou que os sujeitos estão independentes para estas tarefas. Como esta prevalência é muito alta os testes estatísticos se mostram desfavoráveis (Sainani, 2017). Do ponto de vista da estatística, quando há uma prevalência alta de uma mesma categoria, os valores apresentados pelo Coeficiente de Correlação Intraclasse ou mesmo pelo Indicie Kappa, o resultado será desfavorável, ou seja, sempre que houver uma amostra homogênea, o resultado será ruim (baixo) (Sainani, 2017).

Durante a aplicação do teste os sujeitos demonstraram um domínio maior destas duas tarefas (culinária e telefonema) realizando com maior independência. Durante a avaliação 2, diversos sujeitos optaram por realizar estas atividades de modo mais rápido e com atenção aos detalhes reduzida, o que prejudicou no resultado final.

As tarefas da medicação e pagar as contas apresentaram uma concordância fraca, porém um resultado regular. Estas tarefas envolvem outros domínios da função executiva, além de habilidades de leitura e interpretação de texto. Como 11/86 são iletrados, foram necessárias algumas alterações nestas tarefas para que não houvesse interferência deste fator no desempenho do sujeito. Estas tarefas foram consideradas mais complexas, as quais os sujeitos permaneciam por um período maior e cometiam mais erros.

O tempo entre as avaliações também pode ser um fator que contribuiu para este resultado, porém quando o tempo entre as avaliações é curto pode ocorrer o aprendizado ou se o tempo é muito longo a situação é outra, o momento do sujeito é outro. Foi estipulado inicialmente um tempo entre as avaliações de 30 dias, porém alguns sujeitos faltaram na data e foi necessário reagendamento, outros solicitaram que o agendamento da avaliação dois fosse no mesmo dia de outra consulta ou exame 
no Hospital das Clínicas para que não houvesse um deslocamento extra. Deste modo o tempo médio entre as avaliações foi de 41,9 ( \pm 19,2).

Os autores das versões americana (Baum et al., 2008), sueca (Cederfeldt 2011) e coreana (Kim et al., 2017) não publicaram os resultados de avaliação teste e reteste gerando uma dúvida sobre a realização ou não desta avaliação, portanto, este seria um resultado inédito para este teste.

\subsubsection{Confiabilidade inter examinador}

A confiabilidade inter examinador apresentou um resultado favorável (pontuação total, $\mathrm{CCl}=0,732$ ), porém, abaixo do apresentado nas versões americana (pontuação total, $\mathrm{CCl}=0,91$ ) e coreana (pontuação total, $\mathrm{CCl}=0,87$ ), consideradas como excelentes resultados (Baum, 2008; Kim et al, 2017). Para esta avaliação, o sujeito foi filmado e durante a execução das tarefas e Terapeuta Ocupacional 2 (SMA) avaliou sem saber a pontuação obtida pela Terapeuta Ocupacional 1 (JC). Deste modo, ambas avaliaram e analisaram a mesma situação de um mesmo sujeito. Nesta situação, não há o aprendizado, nem fatores que possam interferir no resultado final, porém são avaliadores, analisando uma mesma situação.

Houve uma opção por filmagem da avaliação, para que a terapeuta ocupacional 2 (SMA) pudesse analisar e pontuar os sujeitos conforme sua disponibilidade. Na literatura, a filmagem de uma avaliação para que o segundo avaliador analise foi citada em alguns estudos, embora o objetivo seja o mesmo, avaliar a confiabilidade, os instrumentos destes estudos foram outros (Jensen et al, 2016 e Yang et al, 2016). Os autores da versão americana não descreveram como foi realizada a avaliação inter examinador, apenas descreveu os resultados. 


\subsubsection{Validade de constructo}

A partir dos resultados é possível afirmar que esta é uma escala confiável e possível de ser reproduzida. Apresentou correlação estatisticamente significativa com as escalas de função executiva mais comumente utilizadas na literatura. Estes resultados estão de acordo com as outras validações, que utilizaram escala semelhantes: (1) versão americana: correlação estatisticamente significativa com o Teste de Extensão dos Dígitos Diretos e Teste de Fluência Semântica Verbal; (2) versão coreana: também apresentou correlação estatisticamente significativa com Teste de Extensão dos Dígitos Diretos.

As correlações com os testes que avaliam a função executiva foram estatisticamente significativas quando comparados com o total do TDFE: Teste de Fluência verbal Semântica Verbal, Teste do Desenho do Relógio, Teste de Extensão dos Dígitos Diretos, Teste de Extensão dos Dígitos Inversos, sub teste do Mapa do Zoológico (BADS) e o sub teste Modificado dos 6 Elementos (BADS). Estes resultados mostram que de fato o TDFE é uma ferramenta confiável e apropriada para avaliar a função executiva. Os testes selecionados para a validade de constructo são instrumentos reconhecidos por avaliar a função executiva em pesquisas e na prática clínica, porém se diferenciam do TDFE, pois o sujeito não conhecidas por ele (a).

O Teste de Stroop não apresentou correlação estatisticamente significativa com o TDFE, apesar de ambos avaliarem função executiva, são avaliados componentes diferentes: o Teste de Stroop avalia atenção seletiva, inibição de elemento distrator, impulsividade, velocidade de pensamento (Kulaif e Valle, 2008), enquanto que TDFE avalia iniciativa, sequenciamento, organização, julgamento e segurança e finalização (Baum et al, 2008). 
Não apenas a pontuação total do TDFE apresentou correlação estatisticamente significativa, mas quando avaliado em separado por tarefa, também houve correlação com outras medidas de função executiva. A tarefa que apresentou melhor resultado foi a das contas a pagar que mostrou correlação estatisticamente significativa com todos os testes de função executiva, com exceção do Teste de Stroop. Por outro lado, a tarefa da culinária apresentou correlação apenas com os Testes Fluência Verbal Semântica, Desenho do Relógio e sub teste do Mapa do Zoológico (BADS). A versão coreana (Kim et al, 2017) apresentou resultado semelhante, onde a tarefa de contas a pagar apresentou o melhor resultado, seguido do preparo de mingau de arroz (oposto da versão brasileira).

A tarefa de contas a pagar de fato se mostrou a mais complexa para os sujeitos, foi a que apresentou mais elementos de função executiva para serem avaliados. Já a tarefa de preparo do café foi considerada mais simples e mais conhecida pelos sujeitos. Possivelmente por este motivo, o resultado tenha apresentado uma correlação melhor com a tarefa de contas a pagar, ou seja, nesta tarefa é possível avaliar com mais propriedade a função executiva. Como na versão coreana (Kim et al, 2017), a tarefa de culinária é diferente (mingau de arroz), esta atividade se mostra mais complexa e com maior número de etapas a serem seguidas, envolvendo mais elementos da função executiva.

O principal componente avaliado no TDFE é a função executiva, porém indiretamente também avaliamos a funcionalidade nas atividades rotineiras. Possivelmente por este motivo que houve correlação estatisticamente significativa entre a pontuação total do TDFE e as escalas de Barthel, Questionário de Pfeffer e Escala de Lawton \& Brody. Estes três instrumentos são compostos de perguntas diretas para o paciente e suas famílias sobre a capacidade de realizar determinadas 
tarefas do dia a dia, sendo que as escalas Questionário de Pfeffer e Escala de Lawton \& Brody apresentam questões semelhantes as tarefas apresentadas no TDFE. Quando analisamos por tarefas, apenas a tarefa da medicação apresentou uma correlação estatisticamente significativa com as três escalas. As demais versões não descreveram o uso destas escalas, porém a versão americana (Baum et al, 2008) utilizou a escala de Medida de Independência Funcional, a qual apresentou uma correção estatisticamente significativa com a pontuação total do TDFE.

Quando observamos as características demográficas do estudo, nos surpreendeu, pois, a grande maioria da amostra é composta por homens (51/86), com idade média de 62 anos e uma média de escolaridade de 7,4 anos. Inicialmente acreditávamos que seria o oposto, com a maioria de mulheres e uma média de escolaridade mais baixa. Por outro lado, esta amostra esta semelhante as amostras dos estudos da Coreia do Sul (24/34 homens) (Kim et al., 2017) e o estudo da Suécia (16/23 homens) (Cenderfeldt et al., 2011), nos quais os sujeitos do sexo masculino predominaram. Já no estudo americano (Baum et al., 2008), houve um predomínio de mulheres. Quando comparado os anos de estudo, neste estudo a amostra apresentou menor nível de escolaridade, seguido pelo estudo da Suécia (9,5 anos), Coréia do Sul (10, 82 anos) e Estados Unidos (12 anos). Quanto a faixa etária dos sujeitos, o estudo coreano foi composto por sujeitos mais novos (54,4 anos), seguido por este estudo (62 anos), estudo americano (64 anos) e a amostra com sujeitos mais velhos, 72 anos, foi a amostra do estudo sueco.

\subsection{Vantagens e desvantagens do teste}

Este é um teste em que o indivíduo deve executar uma tarefa habitual do dia a dia e o terapeuta avalia o desempenho; para nós terapeutas ocupacionais que 
avaliamos a funcionalidade, se torna uma ferramenta com riqueza de detalhes para compreender melhor as dificuldades e habilidades do paciente. Outro fator importante é o fato de avaliar a função executiva observando o desempenho do sujeito em uma tarefa cotidiana, o sujeito executa uma tarefa (comum ao seu dia a dia) e assim é possível observar como ele (a) se comporta, lida com a situação, resolve um problema.

Durante a execução de uma tarefa cotidiana o terapeuta ocupacional tem mais propriedade para avaliar e julgar o sujeito, deste modo, ele será capaz de conhecer melhor os limites e potencialidades. A partir desta avaliação, o terapeuta ocupacional será capaz de compreender como o sujeito é capaz de realizar determinada tarefa, e que ajustes serão necessários para que consiga realizar de maneira mais independente. Avaliar e observar um sujeito executando uma tarefa é um modo rico de conhecê-lo, apesar do teste focar apenas nas funções executivas é possível observar outros aspectos, como função motora, cognitiva e emocional.

São tarefas simples, mas que em muitos casos o sujeito deve reaprender a executá-las de maneira adaptada. TDFE é bastante rico para a avalição do sujeito como um todo, dentro de tarefas cotidianas. O teste pode ser aplicado como uma avaliação no início e ao término do tratamento de reabilitação. O teste pode apresentar o aprendizado da tarefa pela repetição, mas ao mesmo tempo demonstrará o quanto houve de melhora em seu desempenho.

Este é um teste gratuito e de fácil aplicação, com a possibilidade de leitura do manual para compreender como utiliza-lo, não requer nenhum curso nem treinamento preparatório. O material necessário para administrar o teste é de fácil acesso ao terapeuta ocupacional, adquirindo nas lojas e/ou supermercados. O material utilizado 
para o TDFE deve ser separado em uma caixa, onde conterá também itens distratores. Este material permanece misturado e o sujeito deve ser capaz de distinguir o que faz parte da tarefa e o que não faz parte.

Por ser um teste de observação (subjetivo), pode gerar diferenças entre os examinadores, devido a diferentes percepções. Tem regras rígidas e uma hierarquia para aplicar as dicas/pistas, o que torna o teste confiável e possível de ser aplicado em momentos diferentes no mesmo sujeito.

Como uma desvantagem do teste, a tarefa da culinária (preparo de um café) que se mostrou muito fácil e pobre para avaliar a função executiva gerando assim a um efeito teto. Em um próximo estudo sugerimos a discussão e desenvolvimento de uma nova tarefa de culinária que possa substituir o preparo de um café. Outra desvantagem observada sujeitos com sequelas muito leves não se beneficiariam deste teste, pois ele não foi sensível a ponto de avaliar déficits sutis.

\subsection{Limitações do estudo}

Apesar de o estudo apresentar uma amostra grande e critérios de inclusão amplos, a amostra se tornou mais homogênea, com sujeitos independentes e disfunção executiva pouco significativa. A condição de locomoção do sujeito até o hospital para as avaliações foi um fator bastante limitante.

Antes de iniciar este estudo, foram considerados os possíveis locais para a aplicação dos testes dentro do hospital, porém não houve opções e consequentemente a sala de avaliação não foi a mais adequada. Apesar de o espaço ser silencioso e comportar todos os materiais necessários para as avaliações, o espaço não se parecia com uma cozinha (para a tarefa de preparo de café). A pia e o micro-ondas ficavam em espaços distintos. Com isso o sujeito necessitava de uma 
circulação maior e consequentemente um tempo maior de execução da tarefa. Embora o espaço não tenha sido o mais adequado, isto não se mostrou um empecilho, nem um fator destrator para os sujeitos executarem as tarefas do TDFE. Na pratica clínica, nem sempre o terapeuta ocupacional terá a chance de administrar o TDFE em uma cozinha ou algo semelhante a uma cozinha, portanto é importante que o teste de esta flexibilidade ao terapeuta.

Outro fator limitante deste projeto foi o fato de não oferecer nenhum tipo de tratamento após as avaliações e nem uma ajuda de custo para que o sujeito venha até o hospital. Em alguns casos, foi possível conciliar as avaliações com outras consultas ou exames no hospital. Outros sujeitos utilizaram o benefício do transporte público gratuito. Tiveram também os casos de sujeitos que compareceram com recursos próprios simplesmente para participar da pesquisa. Entretanto, muitos sujeitos optaram em não participar por falta de condição financeira de vir até o hospital. 
7. CONCLUSÃO

7. CONCLUSÃO 
Os resultados mostraram que TDFE é um instrumento valido e confiável para avaliar a função executiva de pacientes com AVC no Brasil. Considerado ainda, um instrumento para investigar os déficits de função executiva dos sujeitos, durante a fase aguda (hospitalar) e fase crônica (centro de reabilitação). Este instrumento, além de avaliar a função executiva, avalia também a independência nas atividades rotineiras. 
8. REFERÊNCIAS BIBLIOGRÁFICAS 


\section{REFERÊNCIAS BIBLIOGRÁFICAS}

1. Abend I, Vere F, Louisburg R, Ladder J, Honing A. Validity of the beck depression inventory, hospital anxiety and depression scale, SCL-90, and Hamilton depression rating scale as screening instruments for depression in stroke patients. Psychosomatics. 2002; 43(5):386-93.

2. Alexopoulos GS, Kiosses DN, Heo M, Murphy CF, Shanmugham B, Gunning-Dixon F. Executive Dysfunction and the Course of Geriatric Depression. Biol Psychiatric. 2005; 58:204-210.

3. Alvarez JA, Emory E. Executive function and the frontal lobes: a metaanalytic review. Neuropsychol Rev. 2006; 16 (1):17-42.

4. Alves CEO, Lanna ME, Moreira DM, Engelhardt E, Laks J. Subcortical ischemic vascular disease and cognition: A systematic review. Dement Neuropsychol. 2008; 2(2):82-90

5. American Psychiatric Association. Diagnostic and statistical manual of mental disorders. 4. Ed.1994. Washington: APA.

6. Andrade SP, Brucki SM, Bueno OF, Siqueira Neto JI. Neuropsychological performance in patients with subcortical stroke. Arq Neuropsiquiatr. 2012;70(5):3417.

7. Anjos SM, Cohen LG, Sterr A, Andrade KNF, Conforto AB. Translational neurorehabilitation research in the third world: what barriers to trial participation can teach us. Stroke. $2014 ;$ 45(5): 1495-1497.

8. Apfelbaum EP, Krendl AC, Ambady N. Age-related decline in executive function predicts better advice-giving in uncomfortable social contexts. J Exp Social Psychology. 2010; 46.1074-1077. 
9. Armentano CGC. Estudo do desempenho da Bateria de Avaliação Comportamental da Sindrome Diexecutiva (BADS) no espectro de indivíduos saudáveis, comprometimento cognitivo leve e Doença de Alzheimer. [Dissertação]. São Paulo: Faculdade de Medicina da Universidade de São Paulo, 2011.

10. Armentano, CGC; Porto, CS; Brucki, SMD; Nitrini, R. Study on the Behavioural Assessment of the Dysexecutive Syndrome (BADS) performance in healthy individuals, mild Cognitive impairment and Alzheimer's disease: a preliminary study. Dementia \& Neuropsychologia. 2009; v.3n.2p101-107.

11. Atalaia-Silva KC, Lourenço RA. Tradução, adaptação e validação de construto do Teste do Relógio aplicado entre idosos no Brasil. Rev. Saúde Pública. 2008; 42 (5).

12. Barker-Collo S, Feigin VL, Parag V, Lawes CM, Senior H. Auckland Stroke Outcomes Study. Part 2: Cognition and functional outcomes 5 years poststroke. Neurology. 2010; 75(18):1608-16.

13. Baum CM, Connor LT, Morrison T, Hahn M, Dromerick AW, Edwards DF. Reliability, validity, and clinical utility of the Executive Function Performance Test: a measure of executive function in a sample of people with stroke. Am J Occup Ther. 2008; 62(4):446-55.

14. Beaton DE, Bombardier C, Guillemin F, Ferraz MB. Guidelines for the Process of Cross-Cultural Adaptation of Self-Report Measures. Spine. 2000; 25 (24).

15. Bensenor IM, Goulart AC, Szwarcwald CL, Vieira MLFP, Malta DC, Lotufo PA. Prevalence of stroke and associated disabilityin Brazil: National Health Survey - 2013. Arq Neuropsiquiatr 2015;73(9):746-750 
16. Bettcher BM, Mungas D, Patel N, Elofson J, Dutt S, Wynn M, et al. Neuroanatomical substrates of executive functions: Beyond prefrontal structures. Neuropsychologia. 2016 May; 85:100-9.

17. Bolandzadeh N, Davis JC, Tam R, Handy TC, Liu-Ambrose T. The association between cognitive function and white matter lesion location in older adults: a systematic review. BMC Neurol. 2012; 12:126.

18. Bonelli RM, Cummings JL. Frontal-subcortical circuitry and behaviour. Dialogues Clin Neurosci. 2007;9(2):141-51.

19. Botega NJ, Bio MR, Zomignani MA, Garcia C, Pereira WA. Mood disorders among inpatients in ambulatory and validation of the anxiety and depression scale HAD. Rev Saude Publica. 1995; 29(5):355-63.

20. Bour A, Rasquin S, Limburg M, Verhey F. Depressive symptoms and executive functioning in stroke patients: a follow-up study. Int J Geriatr Psychiatry. 2011; 26(7):679-86.

21. Brito RG, Lins LCRF, Almeida CDA, Ramos Neto ES, Araújo DP, Franco CIF. Instrumentos de Avaliação Funcional Específicos Para o Acidente Vascular Cerebral Specific Functional Assessments For Stroke. Rev Neurocienc 2013;21(4):593-599.

22. Brott T, Adams HP Jr, Olinger CP, Marler JR, Barsan WG, Biller J, et al. Measurements of acute cerebral infarction: a clinical examination scale.1989; 20(7):864-70.

23. Brucki

SMD, Machado

MF, Rocha

MSG.

Vascular Cognitive Impairment ( $\mathrm{VCl})$ after nonembolic ischemic stroke during a 12month follow-up in Brazil. Dement Neuropsychol. 2012; 6(3):164-169. 
24. Brucki SMD, Malheiros SMF, Okamoto IH, Bertolucci PHF. Dados normativos para o teste de fluência verbal categoria animais em nosso meio. Arq Neuropsquiatr. 1997; 55(1):56-61.

25. Brucki SMD, Nitrini R, Caramelli P, Bertolucci PHF, Okamoto IH. Sugestões para o uso do mini-exame do estado mental no Brasil. Arq Neuropsiquiatr 2003;61: $777-781$

26. Burgess PW, Simons JS. Theories of frontal lobe executive function: clinical applications. In: Halligan PW, Wade DT. Effectiveness of rehabilitation for cognitive deficits. Oxford, Oxford University Press. 2009. p.211-231.

27. Cabral NL, Gonçalves AR, Longo AL, Moro CH, Costa G, Amaral CH, et al. Trends in stroke incidence, mortality and case fatality rates in Joinville, Brazil: 1995-2006. J Neurol Neurosurg Psychiatry. 2009; 80(7):749-54.

28. Cabral NL, Freire AT, Conforto AB, Santos N, Reis FI, Nagel V, et al. Increase of Stroke Incidence in Young Adults in a Middle-Income Country. Stroke. 2017; 48: 2925-2930.

29. Canali F, Bertolucci PH, Bueno OF. Reliability study of the Behavioral Assessment of the Dysexecutive Syndrome adapted for a Brazilian sample of olderadult controls and probable early Alzheimer's disease patients. Rev Bras Psiquiatr. 2011; 33(4):338-46.

30. Caneda MAG, Fernandes JG, Almeida AG, Mugnol FE. Confiabilidade de escalas de comprometimento neurológico em pacientes com acidente vascular cerebral. Arq. Neuro-Psiquiatr. 2006; 64 (3).

31. Canon MBF, Novelli MMPC. Estudo dos instrumentos de avaliação funcional em demência comumente utilizados no Brasil. Rev. Ter. Ocup. Univ. São Paulo, 2012: 23 (3), p. 253-62, 2012. 
32. Capovilla AGS, Montiel JM, Macedo EC, Charin S. Computerized Stroop Test. Itatiba, São Paulo: University São Francisco; 2005.

33. Caramelli P, Carthery MT, Charchat-Fichman H, Porto CS, Nitrini R. Teste de fluência verbal no diagnóstico da doença de Alzheimer leve: notas de corte em função da escolaridade. Arq Neuropsiquiatr 2003; 61(Supl 2): S32

34. Carod-Artal FJ, Coral LF, Trizotto DS, Moreira CM. The stroke impact scale 3.0: evaluation of acceptability, reliability, and validity of the Brazilian version. Stroke. 2008; 39(9):2477-84.

35. Carvalho JJ, Alves MB, Viana GÁ, Machado CB, dos Santos BF, et al. Stroke epidemiology, patterns of management, and outcomes in Fortaleza, Brazil: a hospital-based multicentre prospective study. Stroke. 2011; 42(12):3341-6.

36. Cederfeldt M, Widell Y, Anderson EE, Dahlin-Ivanoff S, Gosman-Hedström G. Concurrent validity of the Executive Function Performance Test in people with mild stroke. Br J Occup The 2011; 74(9).

37. Chiu EC, Wu WC, Hung JW, Tseng YH. Validity of the Wisconsin Card Sorting Test in patients with stroke. Disabil Rehabil. 2017, 11:1-5

38. Cincura C, Pontes-Neto OM, Neville IS, Mendes HF, Menezes DF, Mariano DC, et al. Validation of the National Institutes of Health Stroke Scale, modified Rankin Scale and Barthel Index in Brazil: the role of cultural adaptation and structured interviewing. Cerebrovasc Dis. 2009; 27(2):119-22.

39. Conselho Federal de Psicologia, SATEPSI. http://satepsi.cfp.org.br/listalnstrumento.cfm?status= acesso em 09/08/1

40. Conti J, Sterr A, Brucki SM, Conforto AB. Diversity of approaches in assessment of executive functions in stroke: limited evidence? eNeurologicalSci. $2015 ; 1(1): 12-20$. 
41. Cramm HÁ, Krupa TM, Missiuna TA, Lysaght RM e Parker KH. Executive Functioning: a scope review of Occupational Therapy literature. Canadian Jour Occup Ther. 2013; 80 (3).

42. Cumming TB, Churilov L, Linden T, Bernhardt J. Montreal Cognitive Assessment and Mini-Mental State Examination are both valid cognitive tools in stroke. Acta Neurol Scand. 2013;128 (2):122-9.

43. Cunha JA. As Escalas Wechsler. Em J. A. Cunha (Org.), PsicodiagnósticoR. 1993. (pp. 278-354). Porto Alegre: Artes Médicas.

44. Di Carlo A, Baldereschi M, Amaducci L, Maggi S, Grigoletto F, Scarlato G, et al. Cognitive impairment without dementia in older people: prevalence, vascular risk factors, impact on disability. The Italian Longitudinal Study on Aging. J Am Geriatr Soc. 2000; 48(7):775-82.

45. Edmans J, Champion A, Hill L, Ridley M, Skelly F, Jackson T, et al. Occupational Therapy and Stroke. Whurr Publishers 2001. Chaper 6. 107-11

46. Elliott R. Executive functions and their disorders. Br Med Bull. 2003; 65:4959

47. Farias N, Buchalla CM. A classificação internacional de funcionalidade, incapacidade e saúde da organização mundial da saúde: conceitos, usos e perspectivas. Rev. bras. epidemiol. 2005; 8 (2).

48. Fernandes TG, Goulart AC, Campos TF, Lucena NMG, Freitas KLA, Trevisan $\mathrm{CM}$, et al. Early stroke case-fatality rates in three hospital registries in the Northeast and Southeast of Brazil. Arq Neuropsiquiatr 2012; 70(11):869-873

49. Fazekas F, Wardlaw JM. The origin of white matter lesions: a further piece to the puzzle. Stroke. $2013 ; 44(4): 951-2$. 
50. Feigin VL, Forouzanfar MH, Krishnamurthi R, Mensah GA, Connor M, Bennett DA, et al. Global and regional burden of stroke during 1990-2010: findings from the Global Burden of Disease Study 2010. Lancet. 2014; 383(9913):245-54.

51. Figueiredo VLM, Nascimento E. Desempenhos nas duas tarefas do subteste dígitos do WISC-III e do WAIS-III. Psic. Teor. e Pesq. 200723 (3) 7.

52. Folstein MF, Folstein SE, McHugh PR. "'Mini-mental status". A practical method for grading the cognitive state of patients for the clinician". Journal of Psychiatric Research. 1975. 12 (3): 189-98.

53. Furukawa TA, Akechi T, Azuma H, Okuyama T, Higuchi T. Evidence-based guidelines for interpretation of the Hamilton Rating Scale for Depression. J Clin Psychopharmacol. 2007; 27(5):531-4.

54. Gallucci Neto J, Campos Júnior MS, Hübner CK. Escala de Depressão de Hamilton (HAM-D): revisão dos 40 anos de sua utilização. Rev Fac Ciênc Méd. 2001; $3(1): 10-4$

55. Godefroy O, Stuss D. Dysexecutive syndromes in The Behavioral and Cognitive Neurology of Stroke. Olivier Godefroy \& Julien Bogousslavsky. Capitulo 19. Cambridge University Press 2007. 369-406.

56. Gregoire SM, Smith K, Jäger HR, Benjamin M, Kallis C, Brown MM, et al. Cerebral microbleeds and long-term cognitive outcome: longitudinal cohort study of stroke clinic patients. Cerebrovasc Dis. 2012; 33(5):430-5.

57. Grieve J, Gnanasekaran L. Neuropsychology for occupational therapists: cognition in occupational performance. 3ạ. Edição. Blackwell PublishingLta.Cap1.p.01-19.2008.

58. Guillemin F. Cross-cultural adaptation and validation of health status measures. Scand J Rheumatol. 1995; 24(2):61-3. 
59. Guillemin F, Bombardier C, Beaton D. Cross-cultural adaptation of healthrelated quality of life measures: literature review and proposed guidelines. $\mathrm{J}$ Clin Epidemiol. 1993; 46(12):1417-32.

60. Hahn B, Baum C, Moore J, Ehrlich-Jones L, Spoeri S, Doherty M, et al. Development of additional tasks for the executive function performance test. Am J Occup Ther. 2014; 68(6):e241-6.

61. Hamdan AC, Hamdan EML. Effects of age and education level on the Trail Making Test in a healthy Brazilian sample. Psychology \& Neuroscience. 2009; 2(2), 199-203.

62. Hamilton M. A rating scale for depression. J Neurol Neurosurg Psychiatry. 1960; 23: 56-62.

63. Hamilton J, Radlak B, Morris PG, Phillips LH Theory of Mind and Executive Functioning Following Stroke. Arch Clin Neuropsychol. 2017;32(5):507-518.

64. Hayes S, Donnellan C, Stokes E. Executive dysfunction and balance function post-stroke: A cross-sectional study. Physiotherapy. 2015.

65. Jankowska AM, Klimkiewicz R, Kubsik A, Klimkiewicz P, Śmigielski J, Woldańska-Okońska M. Location of the ischemic focus in rehabilitated stroke patients with impairment of executive functions. Adv Clin Exp Med. 2017; 26(5):767-776.

66. Jensen EA, Panitch H, Moore PE, Schmidt B. Interobserver Reliability of the Respiratory Physical Examination in Premature Infants: A Multicenter Study. J Pediatr. 2016; 178:87-92.

67. Jodzio K, Biechowska D. Wisconsin card sorting test as a measure of executive function impairments in stroke patients. Appl Neuropsychol. 2010;17(4):267-77. 
68. Josman N, Kizony R, Hof E, Goldenberg K, Weiss PL, Klinger E. Using the virtual action planning-supermarket for evaluating executive functions in people with stroke. J Stroke Cerebrovasc Dis. 2014; 23(5):879-87.

69. Katz N, Tadmor I, Felzen B, Hartman-Maeir A. Validity of the Executive Function Performance Test in individuals with schizophrenia. OTJR: Occupation, Participationand Health. 2007; 27, 1-8.

70. Kegel J, Dux M, Macko R. Executive function and coping in stroke survivors. Neuro Rehabilitation. 2014; 34(1):55-63.

71. Kim H, Lee YN, Jo EM, Lee EY. Reliability and Validity of Culturally Adapted Executive Function Performance Test for Koreans with Stroke. J Stroke Cerebrovasc Dis. 2017; 26(5):1033-1040.

72. Kirova AM, Bays RB, Lagalwar S. Working memory and executive function decline across normal aging, mild cognitive impairment, and Alzheimer's disease. Biomed Res Int. 2015.

73. Kirkwood BR, Sterne, JAC. Essential medical statistics. 2nd ed. Blackwell Science: Massachusetts, USA. 2006, 502.

74. Kluding PM, Tseng BY, Billinger SA. Exercise and executive function in individuals with chronic stroke: a pilot study. J Neurol Phys Ther. 2011; 35(1):11-7.

75. Koo TK, Li MY. A guideline of selecting and reporting Intraclass Correlation Coefficients for Reliability Research. J. Chiropractic Med. 2016. 15: 155-163.

76. Kramer JH, Reed BR, Mungas D, Weiner MW, Chui HC. Executive dysfunction in subcortical ischaemic vascular disease. J Neurol Neurosurg Psychiatry. 2002; 72(2):217-20.

77. Kulaif T. O teste de cores e palavras de Stroop modificado para analfabetos. Dissertação (Mestrado - Programa de Pós-Graduação em Psicologia. 
Área de Concentração: Neurociências e Comportamento) - Instituto de Psicologia da Universidade de São Paulo. 2005.

78. Kulaif T, Valle LE. Alternative to the Stroop Color-Word Test for illiterate individuals. Clin Neuropsychol. 2008; 22(1):73-83.

79. Langhorne P, Bernhardt J, Kwakkel G. Stroke rehabilitation. Lancet. 2011; 377(9778):1693-702.

80. Larson BA. Calculating disability-adjusted-life-years lost (DALYs) in discrete-time. Cost Eff Resour Alloc. 2013; 11(1):18.

81. Lawton MP, Brody EM. Assessment of older people: self-maintaining and instrumental activities of daily living. Gerontologist. 1969;9(3):179-86.

82. Lawton RI, Kurosaki TT, Harrah $\mathrm{CH}$, Chance JM, Filos S. Measurement of functional activities in older adults in the community. J Gerontol. 1982; 37(3):323-9.

83. Leeds L, Meara RJ, Woods R, Hobson JP. A comparison of the new executive functioning domains of the CAMCOG-R with existing tests of executive function in elderly stroke survivors. Age Ageing. 2001;30(3):251-4.

84. Lees R; Fearon P; Harrison JK; Broomfield NM; Quinn TJ. Cognitive and mood assessment in Stroke research. Focused review in contemporary studies. Stroke. 2012; 43. 1678-1680.

85. Leskelä M, Hietanen M, Kalska H, Ylikoski R, Pohjasvaara T, Mäntylä R, et al. Executive functions and speed of mental processing in elderly patients with frontal or nonfrontal ischemic stroke. Eur J Neurol. 1999; 6(6):653-61.

86. Leśniak M, Bak T, Czepiel W, Seniów J, Członkowska A. Frequency and prognostic value of cognitive disorders in stroke patients. Dement Geriatr Cogn Disord. 2008; 26(4):356-63. 
87. Lezak, M. D. Neuropsychological assessment (3 $3^{\underline{a}}$ ed.). New York: Oxford University Press.1995.

88. Liu-Ambrose T, Eng JJ. Exercise training and recreational activities to promote executive functions in chronic stroke a proof-of-concept study. J Stroke Cerebrovasc Dis. 2015; 24(1):130-7.

89. Liu-Ambrose T, Pang MY, Eng JJ. Executive function is independently associated with performances of balance and mobility in community-dwelling older adults after mild stroke: implications for falls prevention. Cerebrovasc Dis. 2007;23 $(2-3): 203-10$.

90. Lourenço RA, Veras RP. Mini-Exame do Estado Mental: características psicométricas em idosos ambulatoriais. Rev Saúde Pública 2006;40(4):712-9.

91. Machado MF, Brucki SM, Nogueira CF, Rocha MS. Infectious disease is the most common cause of death among stroke patients: two-years of follow-up. Arq Neuropsiquiatr. 2013; 71(6):371-5.

92. Mahoney FI, Barthel DW. Functional Evaluation: The Barthel Index. Md State Med J. 1965; 14: 61-5.

93. Maroco J, Garcia -Marques T. Qual a fiabilidade do alfa de Cronbach? Questões antigas e soluções modernas? Laboratório de Psicologia, 2006; 4(1): 6590.

94. Martins GA. Sobre Confiabilidade e Validade. RBGN. 2006; 8 (20). 1-12.

95. Matioli MNPS, Caramelli P. NEUROPSI battery subtest profile in subcortical vascular dementia and Alzheimer' s disease. Dement Neuropsychol. 2012;6(3):170-174

96. Matos EG, Matos TMG, Matos GMG. A importância e as limitações do uso do DSM-IV na prática clínica. Rev. psiquiatr. Rio Gd. Sul. 2005; 27(3). 
97. Markowitsch HJ. The neuroanatomy of memory. In: Halligan PW and Wade DT. Effectiveness of Rehabilitation for cognitive deficits. Oxford University Press. 2005. Chapter 10, 105-114.

98. McDowell I. Measuring Health: A Guide to Rating Scales and Questionnaires, Third Edition 2006. Chapter 2, 30-36.

99. Melkas S, Vataja R, Oksala NK, Jokinen H, Pohjasvaara T, Oksala A, et al. Depression-executive dysfunction syndrome relates to poor poststroke survival. Am J Geriatr Psychiatry. 2010; 18(11):1007-16.

100. Menezes PR, Nascimento AF. Validade e confiabilidade das escalas de avaliação em psiquiatria. In: Gorestein C, Andrade LHSG, Zuarde SW (Eds). Escalas de avaliação em psiquiatria e psicofarmacologia. São Paulo. Lemos editorial. 2000, 22-28.

101. Minelli C, Fen LF, Minelli DP. Stroke incidence, prognosis, 30-day, and 1year case fatality rates in Matão, Brazil: a population-based prospective study. Stroke. 2007; 38(11):2906-11.

102. Miyake A, Friedman NP, Emerson MJ, Witzki AH, Howerter A, Wager TD. The Unity and Diversity of Executive Functions and Their Contributions to Complex "Frontal Lobe" Tasks: A Latent Variable Analysis. Cognitive Psychology. 2000; $41: 49-100$.

103. Mohammad AH, Al-Sadat N, Siew Yim L, Chinna K. Reliability and validity of the Nigerian (Hausa) version of the Stroke Impact Scale (SIS) 3.0 index. Biomed Res Int. 2014; 2014:302097.

104. Mok VC, Wong A, Yim P, Fu M, Lam WW, Hui AC, et al. The validity and reliability of Chinese frontal assessment battery in evaluating executive dysfunction 
among Chinese patients with small subcortical infarct. Alzheimer Dis Assoc Disord. 2004; 18(2):68-74.

105. Montiel J, Seabra AG. Teste de Trilhas - partes A e B. In: A. G. Seabra \& N. M Dias (Orgs.), Avaliação Neuropsicológica cognitiva: atenção e funções executivas. São Paulo: Memnon. 2012; 1, 79-85.

106. Moreno RA, Moreno DH. Escalas de depressão de Montgomery \& Asberg (MADRS) e de Hamilton (HAM-D). Rev Psiquiatr Clin. 1998; 25: 262-72

107. Moreno RA, Moreno DH, Soares MBM. Psicofarmacologia dos antidepressivos. Rev. Bras. Psiquiatr. 1999, 21 (1).

108. Morrison MT, Edwards DF, Giles GM. Performance-based testing in mild stroke: identification of unmet opportunity for occupational therapy. Am J Occup Ther. 2015; 69(1).

109. Motta K, Lee H, Falkmer T. Post-stroke driving: examining the effect of executive dysfunction. J Safety Res. 2014; 49:33-8.

110. Naghavi M, Abajobir AA, Abbafati C, Abbas KM, Abd-Allah F, Abera SF. Global, regional and national age sex specific mortality for 264 causes of death, 1980-2016: a systematic analysis for the Global Burden of Disease Study 2016. Lancet. 2017; 390 (10100): 1151-1210.

111. Narushima K, Paradiso S, Moser DJ, Jorge R, Robinson RG. Effect of antidepressant therapy on executive function after stroke. Br J Psychiatry. 2007; 190: 260-5.

112. Nichtweiss M, Weidauer S, Treusch N, Hattingen E. White matter lesions and vascular cognitive impairment: part 1: typical and unusual causes. Clin Neuroradiol. 2012; 22(3):193-210. 
113. Nitrini R, Lefèvre BH, Mathias SC, Caramelli P, Carrilho PEM, Sauaia N, et al. Testes neuropsicológicos de aplicação simples para o diagnóstico de demência. Arq Neuropsiq 1994; 52: 457-465. 10.

114. Nitrini R, Caramelli P, Herrera Jr E, Porto CS, Charchat-Fichman $\mathrm{H}$, Carthery MT et al. Performance of illiterate and literate non demented elderly subjects in two tests of long-term memory. J Int Neuropsychol Soc 2004; 10: 634638.

115. Norris G, Tate RL. The Behavioural Assessment of the Dysexecutive Syndrome (BADS): Ecological, Concurrent and Construct Validity. Journal Neuropsy Rehab. 2000, 10 (1): 33-45.

116. Nys GM, van Zandvoort MJ, de Kort PL, Jansen BP, de Haan EH, Kappelle LJ. Cognitive disorders in acute stroke: prevalence and clinical determinants. Cerebrovasc Dis. 2007; 23(5-6):408-16.

117. Ojagbemi A, Akinyemi R, Baiyewu O. Cognitive dysfunction and functional limitations are associated with major depression in stroke survivors attending rehabilitation in Nigeria. NeuroRehabilitation. 2014; 34(3):455-61.

118. Oldfield RC. The assessment and analysis of handedness: the Edinburgh inventory. Neuropsychologia. 1971; 9(1):97-113.

119. Ownsworth T, Shum D. Relationship between executive functions and productivity outcomes following stroke. Disabil Rehabil. 2008; 30(7):531-40.

120. Organização Pan -America de Saúde. Enfoque passo a passo da OMS para a vigilância de acidentes vascular cerebrais. O Manual STEPS de Acidentes Vascular Cerebrais da OMS: enfoque passo a passo para a vigilância de acidentes vascular cerebrais/doenças não-transmissíveis e saúde mental, Organização Mundial da Saúde. Organização Mundial da Saúde 2005 
121. Paixão Jr. CM, Reichenheim ME. Uma revisão sobre instrumentos de avaliação do estado funcional do idoso. Cad. Saúde Pública, Rio de Janeiro, 2005; 21(1):7-19.

122. Patel MD, Coshall C, Rudd AG, Wolfe CD. Cognitive impairment after stroke: clinical determinants and its associations with long-term stroke outcomes. J Am Geriatr Soc. 2002; 50(4):700-6.

123. Park KC, Yoon SS, Rhee HY. Executive dysfunction associated with stroke in the posterior cerebral artery territory. J Clin Neurosci. 2011;18(2):203-8.

124. Park YH, Jang JW, Park SY, Wang MJ, Lim JS, Baek MJ, et al. Executive function as a strong predictor of recovery from disability in patients with acute stroke: a preliminary study. J Stroke Cerebrovasc Dis. 2015; 24(3):554-61.

125. Partridge JS, Dhesi JK, Cross JD, Lo JW, Taylor PR, Bell R, et al. The prevalence and impact of undiagnosed cognitive impairment in older vascular surgical patients. J Vasc Surg. 2014.

126. Passos VM, Ishitani LH, Franco GC, Lana GC, Abreu DM, Marinho M, et al. Consistent declining trends in stroke mortality in Brazil: mission accomplished? Arq Neuropsiquiatr. 2016; 74(5):376-81.

127. Pendlebury ST, Rothwell PM. Prevalence, incidence, and factors associated with pre-stroke and post-stroke dementia: a systematic review and metaanalysis. Lancet Neurol. 2009; 8(11):1006-18.

128. Pfeffer RI, Kurosaki TT, Harrah CH Jr, Chance JM, Filos S. Measurement of functional activities in older adults in the community. J Gerontol 1982; 37:323-329.

129. Pohjasvaara T, Leskelä M, Vataja R, Kalska H, Ylikoski R, Hietanen M, et al. Post-stroke depression, executive dysfunction and functional outcome. Eur J Neurol. 2002; 9(3):269-75. 
130. Poulin V, Korner-Bitensky N, Bherer L, Lussier M, Dawson DR. Comparison of two cognitive interventions for adults experiencing executive dysfunction poststroke: a pilot study. Disabil Rehabil. 2017; 39(1):1-13.

131. Poulin V, Korner-Bitensky N, Dawson DR, Bherer L. Efficacy of executive function interventions after stroke: a systematic review. Top Stroke Rehabil. 2012; 19(2):158-71.

132. Rand D, Eng JJ, Liu-Ambrose T, Tawashy AE. Feasibility of a 6-month exercise and recreation program to improve executive functioning and memory in individuals with chronic stroke. Neurorehabil Neural Repair. 2010; 24(8):722-9.

133. Rankin J. Cerebral vascular accidents in patients over the age of 60 . III. Diagnosis and treatment. Scott Med J. 1957; 2(6):254-68.

134. Reitan RM. Trail making test results for normal and brain-damaged children Percept Mot Skills. 1971; 33(2):575-81.

135. Richards LG, Latham NK, Jette DU, Rosenberg L, Smout RJ, DeJong G. Characterizing occupational therapy practice in stroke rehabilitation. Arch Phys Med Rehabil. 2005; 86 (12 Suppl 2):S51-S60.

136. Rocha MS, Almeida AC, Abath Neto O, Porto MP, Brucki SM. Impact of stroke unit ina public hospital on length of hospitalization and rate of early mort ality of ischemic stroke patients. Arq Neuropsiquiatr. 2013; 71(10):774-9.

137. Rockwood K, Wentzel C, Hachinski V, Hogan DB, MacKnight C, McDowell I. Prevalence and outcomes of vascular cognitive impairment. Vascular Cognitive Impairment Investigators of the Canadian Study of Health and Aging. Neurology. $2000 ; 54(2): 447-51$. 
138. Roussel M, Dujardin K, Hénon H, Godefroy O. Is the frontal dysexecutive syndrome due to a working memory deficit? Evidence from patients with stroke. Brain. 2012; 135 (Pt 7):2192-201.

139. Roussel M, Martinaud O, Hénon H, Vercelletto M, Bindschadler C, Joseph PA, et al. The Behavioral and Cognitive Executive Disorders of Stroke: The GREFEX Study. PLoS One. 2016; 29; 11(1): e0147602.

140. Rozental-Iluz C, Zeilig G, Weingarden H, Rand D. Improving executive function deficits by playing interactive video games: secondary analysis of a randomized controlled trial for individuals with chronic stroke. Eur J Phys Rehabil Med. 2016; 52(4):508-15. Epub 2016 Jan 13.

141. Saa JP, Doherty M, Young A, Spiers M, Leary E, Wolf TJ. Development and alternate form reliability of the Complex Task Performance Assessment (CTPA) for people with mild stroke. American Journal of Occupational Therapy. 2017. 71

142. Sainani KL. Statistically Speaking. Reliability Statistics. PM R 9. 2017. 622628.

143. Santos CS, Cerchiari EAN, Alvarenga MRM, Faccenda O, Oliveira MAC. Avaliação da confiabilidade do Mini Exame do Estado Mental em idosos e associação com as variáveis sócio demográficas. Cogitar e Enferm. 2010; $15(3): 406-12$

144. Sibolt G, Curtze S, Melkas S, Pohjasvaara T, Kaste M, Karhunen PJ, et al. Post-stroke depression and depression-executive dysfunction syndrome are associated with recurrence of ischaemic stroke. Cerebrovasc Dis. 2013; 36(5-6):33643.

145. Siegrist M. Reliability of the Stroop test with single-stimulus presentation. Percept Mot Skills. 1995; 81(3 Pt 2):1295-8. 
146. Silva-Filho JH, Pasian SR, Barboza LL. Potencial informativo e desafios técnicos do Teste Wisconsin de classificação de cartas. Rev. SPAGESP. 2013; 14 (2) .

147. Simon SS, Ribeiro MPO. Comprometimento cognitivo leve e reabilitação neuropsicológica: uma revisão bibliográfica. Psic. Rev. São Paulo. 2011; 20 (1), 93122.

148. Sobreiro MF, Miotto EC, Terroni L, Tinone G, losifescu DV, de Lucia MC, et al. Executive function and depressive symptoms of retardation in nonelderly stroke patients. J Clin Exp Neuropsychol. 2014; 36(6):636-47.

149. Stuart AL, Ware JE: Measuring functioning and well-being: the Medical Outcomes Study approach. Durham, North Carolina. Duke University Press, 1992: 375-376.

150. Sunderland T, Hill JL, Mellow AM, Lawlor BA, Gundersheimer J, Newhouse PA, et al. Clock drawing in Alzheimer's disease. A novel measure of dementia severity. J Am Geriatr Soc. 1989; 37(8):725-9.

151. Sudo FK, Amado P, Alves, GS, Laks J, Engelhardt E. A continuum of executive function deficits in early subcortical vascular cognitive impairment: A systematic review and meta-analysis. Dement. neuropsychol. 2017, 11 (4), 371380.

152. Tamez E, Myerson J, Morris L, White DA, Baum C, Connor LT. Assessing executive abilities following acute stroke with the trail making test and digit span. Behav Neurol. 2011; 24(3):177-85.

153. Tang WK, Chen Y, Lam WW, Mok V, Wong A, Ungvari GS, et al. Emotional incontinence and executive function in ischemic stroke: a case-controlled study. J Int Neuropsychol Soc. 2009; 15(1):62-8. 
154. Taylor-Piliae RE, Hepworth JT, Coull BM. Predictors of depressive symptoms among community-dwelling stroke survivors. J Cardiovasc Nurs. 2013; 28(5): 460-7.

155. Terroni L, Sobreiro MFM, Conforto AB, Adda CC, Guajardo VD, Lucia MC, et al. Association among depression, cognitive impairment and executive dysfunction after stroke. Dement Neuropsychol. 2012; 6(3):152-157

156. Toglia J, Askin G, Gerber LM, Taub MC, Mastrogiovanni AR, O'Dell MW. Association Between 2 Measures of Cognitive Instrumental Activities of Daily Living and Their Relation to the Montreal Cognitive Assessment in Persons With Stroke. Arch Phys Med Rehabil. 2017; 4.

157. Turunen KE, Laari SP, Kauranen TV, Mustanoja S, Tatlisumak T, Poutiainen E. Executive Impairment Is Associated with Impaired Memory Performance in Working-Aged Stroke Patients. J Int Neuropsychol Soc. 2016; 22(5):551-60 .

158. Van Geldorp B, Kesselsa RPC, Hendriks MPH. Single-item working memory in stroke patients. Behavioural Neurology. 2013; 26:199-201.

159. Van de Port IG, Kwakkel G, Schepers VP, Heinemans CT, Lindeman E. Is fatigue an independent factor associated with activities of daily living, instrumental activities of daily living and health-related quality of life in chronic stroke? Cerebrovasc Dis. 2007; 23(1):40-5.

160. Van der Werf YD, Scheltens P, Lindeboomc J, Witter MP, Uylings HMB, Jolles J. Deficits of memory, executive functioning and attention following infarction in the thalamus; a study of 22 cases with localised lesions. Neuropsychologia. 2003; $41: 1330-1344$. 
161. Vataja R, Pohjasvaara T, Mäntylä R, Ylikoski R, Leppävuori A, Leskelä M, et al. MRI correlates of executive dysfunction in patients with ischaemic stroke. Eur J Neurol. 2003; 10(6):625-31.

162. Vataja R, Pohjasvaara $T$, Mäntylä R, Ylikoski R, Leskelä M, Kalska $H$, et al. Depression-executive dysfunction syndrome in stroke patients. Am J Geriatr Psychiatry. 2005; 13(2):99-107.

163. Vellone E, Savini S, Fida R, Dickson VV, Melkus GDE, Carod-Artal FJ, et al. Psychometric Evaluation of the Stroke Impact Scale 3.0. Journal of Cardiovascular Nursing. 2015, 30 (3), 229Y241

164. Vernooij MW, van der Lugt A, Ikram MA, Wielopolski PA, Niessen WJ, Hofman A, et al. Prevalence and risk factors of cerebral microbleeds: the Rotterdam Scan Study. Neurology. 2008; 70(14):1208-14.

165. Vitiello APP, Ciríaco JGM, Takahashi DY, Nitrini R, Caramelli P. Avaliação Cognitiva Breve de pacientes atendidos em ambulatório de neurologia geral. Arq Neuropsiquiatr 2007; 652-A: 299-303.

166. Vos T, Abajobir AA, Abate KH, Abbafati C, Abbas KM, Abd-Allah F, et al. Global, regional, and national incidence, prevalence, and years lived with disability for 328 diseases and injuries for 195 countries, 1990-2016: a systematic analysis for the Global Burden of Disease Study 2016. Lancet. 2017; 16; 390(10100):12111259.

167. Wechsler D. Wechsler. Bellevue intelligence scale. New York: The Psychological Corporation. 1939.

168. Williamson, T. Can cognition be factorized into internal and external components? In Contemporary debates in cognitive science. Malden MA: Blackwell Publishing. R. J. Stainton (Ed.). 2006. 
169. Wilson BA, Alderman N, Burgess P, Emslie H, Evans J. Behavioural Asse ssment of theDysexecutive Syndrome. Bury St Edmunds Suffolk: Thames Valley Test Company.1996.

170. Wolf TJ, Barbee AR, White D. Executive dysfunction immediately after mild stroke. OTJR (Thorofare N J). 2011; 31(1):S23-9.

171. Wolf TJ, Dahl A, Auen C, Doherty M. The reliability and validity of the Complex Task Performance Assessment: A performance-based assessment of executive function. Neuropsychol Rehabil. 2015:1-15.

172. Wolf TJ, Morrison T, Matheson L. Initial development of a work-related assessment of dysexecutive syndrome: the Complex Task Performance Assessment. Work. 2008; 31(2):221-8.

173. Wolf TJ, Stift S, Connor LT, Baum C. Cognitive Rehabilitation Research Group. Feasibility of using the EFPT to detect executive function deficits at the acute stage of stroke. Work. 2010; 36(4):405-12.

174. World Health Organization. 2014 http://www.who.int/topics/cerebrovascular_accident/en/. Acesso em 05/08/2016.

175. Worthington A. Rehabilitation of Executive Deficits: effective treatment of related disabilities. In: Halligan PW and Wade DT. Effectiveness of Rehabilitation for cognitive deficits. Oxford University Press. 2005. Chapter 21, 257-270.

176. Yang $Y$, Wang $Y$, Zhou $Y$, Chen C, Xing D. Reliability of functional gait assessment in patients with Parkinson disease: Interrater and intrarater reliability and internal consistency. 2016; 95(34):e4545

177. Zigmond AS, Snaith RP. The hospital anxiety and depression scale. Acta Psychiatr Scand. 1983; 67(6):361-70. 
178. Zinn S, Bosworth HB, Hoenig HM, Swartzwelder HS. Executive function deficits in acute stroke. Arch Phys Med Rehabil. 2007; 88(2):173-80.

179. Zuverza-Chavarria V, Tsanadis J. Measurement properties of the CLOX Executive Clock Drawing Task in an inpatient stroke rehabilitation setting. Rehabil Psychol. 2011; 56(2):138-44. 
9. ANEXOS 


\section{ANEXOS}

\section{Anexo I: autorização da autora para a tradução}

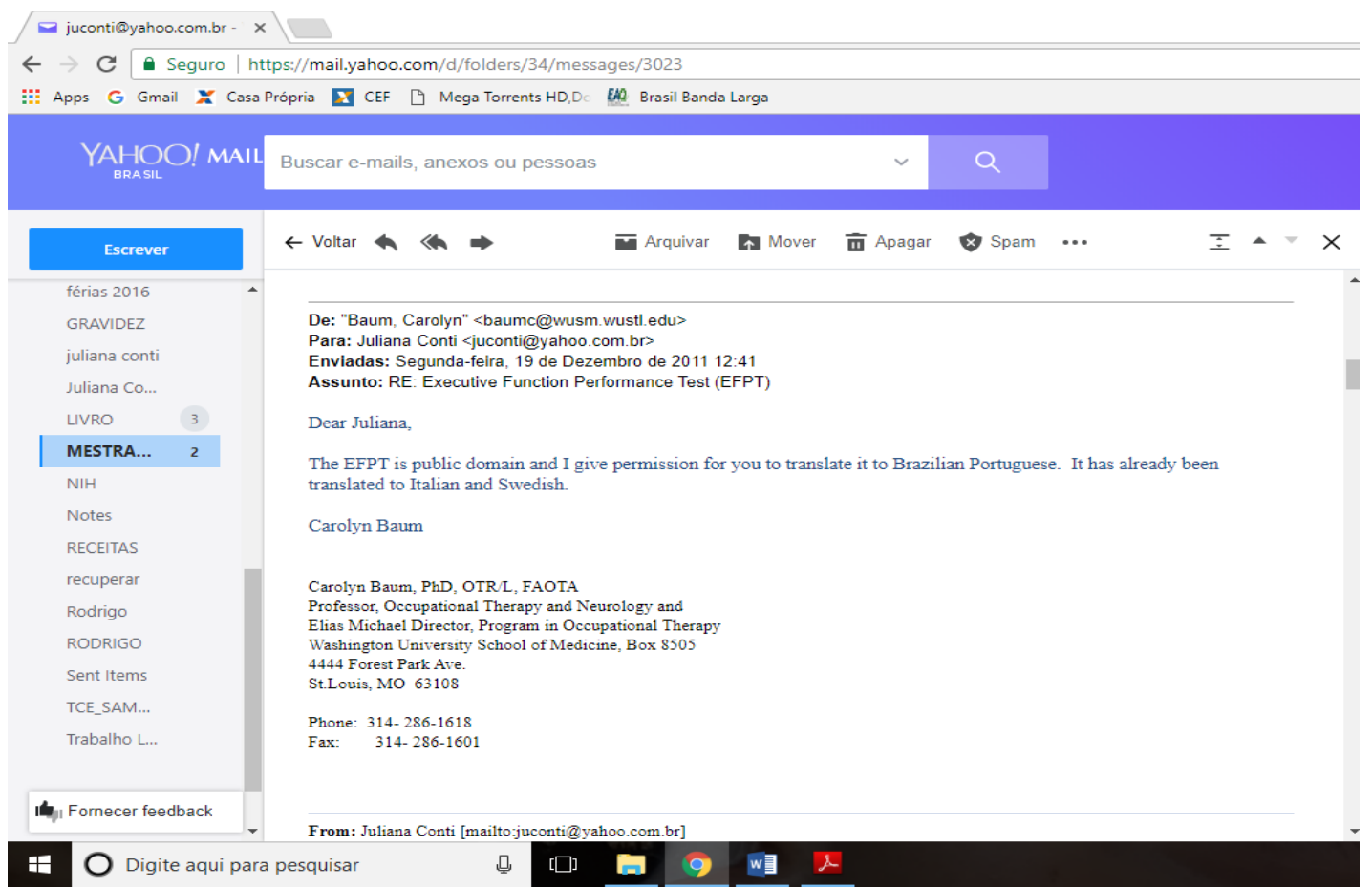




\title{
Anexo II: Aprovação CAPPesq
}

\author{
Hospital das Clínicas da FMUSP
}

Comissão de Ética para Análise de Projetos de Pesquisa - CAPPesq

\section{PROJETO DE PESQUISA}

Título: TESTE DE DESEMPENHO DA FUNÇÃO EXECUTIVA: TRADUÇÃO E VALIDAÇÃO DA

VERSÃO BRASILEIRA PARA PACIENTES COM ACIDENTE VASCULAR ENCEFÁLICO

Pesquisador Responsável: Profa.Dra. Adriana Bastos Versão: 2

Conforto

Pesquisador Executante: Juliana Conti

CAAE: 08438913.0 .0000 .0068

Finalidade Acadêmica Mestrado

Instituição: HCFMUSP

Departamento: NEUROLOGIA

\section{PARECER CONSUBSTANCIADO DO CEP}

Registro on-line: 9936

Número do Parecer: 214.265

Data da Relatoria: 06/03/13

Apresentação do Projeto: As sequelas cognitivas dos Acidentes Vasculares Encefálicos (AVE) são por vezes mais incapacitantes que as sequelas motoras. A avaliação precisa destas sequelas cognitivas, entre as quais as relacionadas às funções executivas é o primeiro passo para encaminhar de forma adequada a reabilitação cognitiva. 0 projeto em análise está apresentado de forma detalhada e clara tem como proposta a traduzir e validar o Teste de Desempenho da Função Executiva (Executive Function Performance Test) para a língua portuguesa, para aplicação em pacientes com AVE.

Objetivo da Pesquisa: Os objetivos estão definidos de forma adequada.

Avaliação dos Riscos e Benefícios: Os riscos envolvidos são mínimos e os autores se cercaram dos devidos cuidados quanto aos mesmos. O benefício será a disponibilização de uma escala para o nosso meio que será de utilidade para a avaliação de pacientes com AVE.

Comentários e Considerações sobre a Pesquisa: 0 estudo foi elaborado de forma adequada dentro de normas éticas.

Considerações sobre os Termos de apresentação obrigatória: Os termos obrigatórios requeridos foram apresentados.

Rua Dr, Ovídio Pires de Campos, 225 - Prédio da Administração - 5 andar CEP 05403-010 - São Paulo - SP.

5511 2661-7585 - 5511 2661-6442 ramais: 16, 17, 18 | marcia.carvalho@hc.fm.usp.br 


\title{
Anexo III: Manual para uso da escala
}

\section{Executive Function Performance Test (EFPT)}

\author{
Carolyn M. Baum, PhD, OTR/L \\ Program in Occupational Therapy \\ Washington University School of Medicine \\ St. Louis, MO \\ USA
}

Teste de Desempenho da Funcão Executiva (TDFE)

Manual para uso da escala:

- Por que a TDFE foi desenvolvida? O Teste de Desempenho da Função Executiva foi desenvolvido para criar uma avaliação padronizada e baseada no desempenho da função cognitiva.

- Como o TDFE se difere de outros testes neuropsicológicos tradicionais? Geralmente os demais testes neuropsicológicos reúnem informações específicas sobre aspectos da cognição, como a memória, atenção, ou planejamento. O TDFE alcança um nível mais elevado, ou seja, tem uma visão mais global da cognição: a funcionalidade do indivíduo é avaliada por completo durante toda a tarefa.

- O que o TDFE mensura? O TDFE foi desenvolvido para avaliar a integração entre a cognição e a funcionalidade do indivíduo em um contexto ambiental.

- Os três objetivos do TDFE:

1. Determinar qual função executiva esta alterada

2. Determinar a capacidade funcional do individuo

3. Determinar a quantidade de assistência necessária para completar a tarefa.

- Como que o TDFE se relaciona com outros instrumentos que avaliam as Atividades Instrumentais de Vida Diária (AIVD)? Diferente das escalas que avaliam as AIVD, o TDFE não avalia as tarefas que o indivíduo não é capaz de realizar. O Teste avalia o que o indivíduo é capaz de realizar e/ou a quantidade de assistência necessária para executar uma tarefa. $O$ TDFE não diferencia os indivíduos que conseguem realizar o teste daqueles que não conseguem realiza-lo. Pode ser utilizado um sistema de dicas para auxiliar aqueles indivíduos que apresentam mais dificuldades e se mostravam incapazes de serem testados. Este sistema de dicas é padronizado e está de acordo com o grau de prejuízo cognitivo do indivíduo. Este sistema de pistas/dicas permite que o avaliador avalie de maneira mais adequada, proporcionando a assistência que o indivíduo necessita para desempenhar de maneira segura e adequada as tarefas propostas pelo teste. Sendo assim, este é um teste muito utilizado clinicamente e para pesquisa.

- Quais são as tarefas do TDFE? O TDFE examina quatro tarefas básicas que são essenciais para auto-manutenção e independência: preparo de algum alimento simples na cozinha, uso do telefone, uso adequado do medicamento prescrito, pagamento de contas. O TDFE avalia a habilidade individual de completar a os componentes da tarefa. (Quadro com as definições está logo abaixo).

- Quais constructos cognitivos são observados durante o TDFE? Iniciar, completar e executar uma tarefa é a base para guiar o desenvolvimento do teste. Utilizando esta definição, o avaliador será capaz de avaliar as funções executivas em cada etapa da tarefa. O TDFE permite que o avaliador observe o quando a função executiva esta alterada e qual a quantidade de assistência este indivíduo necessitará para suas tarefas de básicas de autossuficiência. Esta informação valiosa pode ser compartilhada com os cuidadores. 


\begin{tabular}{|c|c|c|}
\hline $\begin{array}{l}\text { Componente da } \\
\text { Função Executiva }\end{array}$ & Definição & Comportamento esperado \\
\hline Iniciação & $\begin{array}{l}\text { Movimento inicial para } \\
\text { começar a tarefa }\end{array}$ & $\begin{array}{l}\text { Participante se movimentar } \\
\text { para alcançar e pegar os } \\
\text { objetos necessários para } \\
\text { executar a tarefa. }\end{array}$ \\
\hline Execução & $\begin{array}{l}\text { Realização propriamente } \\
\text { dita da tarefa, paço a paço. } \\
\text { Considerando os seguintes } \\
\text { aspectos fundamentais: } \\
\text { organização, sequência e } \\
\text { julgamento e segurança. }\end{array}$ & $\begin{array}{l}\text { Participante realizar o paço a } \\
\text { paço da tarefa. }\end{array}$ \\
\hline Organização & $\begin{array}{l}\text { A organização do } \\
\text { ambiente, materiais e } \\
\text { ferramentas utilizadas } \\
\text { para a execução da } \\
\text { tarefa de maneira mais } \\
\text { eficiente e efetiva de } \\
\text { cada etapa da tarefa. }\end{array}$ & $\begin{array}{l}\text { Participante relembre e use de } \\
\text { maneira adequada as } \\
\text { ferramentas para a execução } \\
\text { da tarefa. }\end{array}$ \\
\hline Sequenciamento & $\begin{array}{l}\text { Coordenar as diferentes } \\
\text { etapas da tarefa, } \\
\text { realizando as etapas na } \\
\text { ordem correta, } \\
\text { requerendo uma } \\
\text { distribuição e atenção } \\
\text { adequadas durante a } \\
\text { execução. }\end{array}$ & $\begin{array}{l}\text { Participante realiza as etapas } \\
\text { da tarefa na ordem correta, } \\
\text { executando cada etapa de } \\
\text { maneira adequada e dividindo a } \\
\text { atenção entre as diferentes } \\
\text { etapas. }\end{array}$ \\
\hline $\begin{array}{l}\text { Julgamento } \\
\text { segurança }\end{array}$ & $\begin{array}{l}\text { Uso adequado da razão e } \\
\text { tomado de decisões, além } \\
\text { da capacidade de evitar } \\
\text { riscos (situações } \\
\text { perigosas) físicos, } \\
\text { emocionais ou financeiros. }\end{array}$ & $\begin{array}{l}\text { Participante } \\
\text { consciência quanto a sua } \\
\text { segurança para evitar e } \\
\text { prevenir situações que o } \\
\text { coloque em risco. }\end{array}$ \\
\hline Finalização & $\begin{array}{l}\text { Finalizar as ações } \\
\text { motoras, pois há o } \\
\text { entendimento de que a } \\
\text { tarefa finalizou. O } \\
\text { participante não } \\
\text { persevera na tarefa. }\end{array}$ & $\begin{array}{l}\text { Participante indica que ele/ela } \\
\text { finalizou a tarefa. Ou se afasta } \\
\text { do local de execução ao } \\
\text { finalizar a tarefa. }\end{array}$ \\
\hline
\end{tabular}

A tabela a seguir descreve como as funções cognitivas são utilizadas no TDFE. O avaliador auxiliará o indivíduo que necessita de pista/dicas para executar a tarefa com sucesso. É necessário que o avaliador registre fielmente as pistas/dicas fornecidas para o indivíduo nas diferentes categorias cognitivas do teste. As categorias são:

- Iniciação

- Organização

- Sequencia

- Julgamento

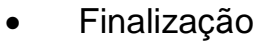




\begin{tabular}{|c|c|c|}
\hline Tarefa: & & $\begin{array}{l}\text { Exemplos de ações } \\
\text { específicas do participante, } \\
\text { que o avaliador utilizará } \\
\text { para a pontuação do teste. }\end{array}$ \\
\hline $\begin{array}{l}\text { Iniciação: início da } \\
\text { tarefa }\end{array}$ & $\begin{array}{lr}\text { A partir } & \text { do } \\
\text { comando } & \text { do } \\
\text { avaliador, } & \text { o } \\
\text { participante } & \text { inicia } \\
\text { a tarefa se se } \\
\text { dirigindo para } & \\
\text { local adequado. }\end{array}$ & $\begin{array}{l}\text { Somente observe o participante } \\
\text { iniciando a tarefa. }\end{array}$ \\
\hline \multirow[t]{4}{*}{$\begin{array}{lr}\text { Execução: realização } & \text { da } \\
\text { tarefa, considerando } & \mathrm{a} \\
\text { organização, } & \\
\text { sequenciamento } & \mathrm{e} \\
\text { julgamento. } & \end{array}$} & & \\
\hline & $\begin{array}{l}\text { Organização: } \\
\text { organização das } \\
\text { ferramentas } \\
\text { materiais } \\
\text { necessários para a } \\
\text { execução da tarefa. } \\
\text { O indivíduo deve ser } \\
\text { capaz de relembrar } \\
\text { como executar a } \\
\text { tarefa. }\end{array}$ & $\begin{array}{l}\text { Participante reúne os materiais e } \\
\text { ferramentas necessários para a } \\
\text { execução da tarefa. Os itens } \\
\text { podem ser reunidos no início da } \\
\text { tarefa ou durante a tarefa. Apenas } \\
\text { registre se o indivíduo necessitar } \\
\text { de alguma pista/dica para reunir } \\
\text { os materiais e ferramentas. }\end{array}$ \\
\hline & $\begin{array}{l}\text { Sequência: executar } \\
\text { a tarefa obedecendo } \\
\text { à ordem correta das } \\
\text { etapas. }\end{array}$ & $\begin{array}{l}\text { Avaliador se concentra na } \\
\text { execução da tarefa. } \\
\text { O participante segue as direções } \\
\text { (aveia) ou se movimenta entre } \\
\text { uma etapa e outra da tarefa para } \\
\text { alcança os objetivos (telefone, } \\
\text { pagar a conta, uso do } \\
\text { medicamento). }\end{array}$ \\
\hline & $\begin{array}{l}\text { Julgamento } \\
\text { segurança: evitar } \\
\text { situações perigosas. } \\
\text { O participante deve } \\
\text { evitar e prevenir } \\
\text { situações de perigo. } \\
\text { Exemplos: jogar a } \\
\text { água fora, não } \\
\text { colocar objetos } \\
\text { próximos de locais } \\
\text { quentes para evitar } \\
\text { queimaduras, } \\
\text { desligar o acendedor } \\
\text { do fogão quando } \\
\text { finalizada a etapa, } \\
\text { utilizar um pegador } \\
\text { próprio para panelas } \\
\text { quentes. }\end{array}$ & $\begin{array}{l}\text { Este item está apenas relacionado à } \\
\text { segurança. } \\
\text { A aveia não queima o indivíduo nem } \\
\text { aos outros, coloca o jarro na mesa de } \\
\text { maneira que não caia. } \\
\text { Pega o telefone, disca o número e } \\
\text { coloca no gancho novamente para } \\
\text { que outra pessoa possa utiliza-lo } \\
\text { novamente. } \\
\text { Não toma o medicamento errado. } \\
\text { Não come o biscoito. } \\
\text { Não reconhecem que não podem } \\
\text { pagar as duas contas. }\end{array}$ \\
\hline $\begin{array}{l}\text { Finalização } \\
\text { Tarefa: finalizar a } \\
\text { tarefa. }\end{array}$ & $\begin{array}{l}\text { Participante sabe } \\
\text { que a tarefa } \\
\text { terminou. }\end{array}$ & $\begin{array}{l}\text { Participante finaliza a tarefa. } \\
\text { Participante não persevera na } \\
\text { tarefa. }\end{array}$ \\
\hline
\end{tabular}

Nota: Esta avaliação é desenvolvida para demonstrar qual o número de pista/dicas o participante necessita para executar as tarefas com sucesso. O participante pode levar um tempo maior para processar a informação, mas não pode cometer erros. O objetivo é manter o participante executando a tarefa. O número de dicas fornecidas para a realização da tarefa indica a quantidade de assistência que o participante necessitará. Você deve 
fornecer as dicas necessárias para o participante desempenhar a tarefa, porém não deverá ser fornecida até que o participante demonstre a necessidade desta pista/dica para executar a tarefa. Não de dicas além do necessário, mas não o deixem cometer erros. Até mesmo indivíduos com severos déficits cognitivos são capazes de desempenhar as tarefas por causa do auxílio do avaliador. "Proporcione o auxílio necessário para que o indivíduo continue a tarefa. "

\section{Descrição das dicas:}

\begin{tabular}{|c|c|}
\hline Não necessita de dicas & $\begin{array}{l}\text { Participante não necessita de auxilio nem } \\
\text { confirmação, não faz perguntas para } \\
\text { esclarecer a tarefa. Simplesmente completa a } \\
\text { tarefa. Autoajuda é aceitável, exemplo: falar } \\
\text { com sigo próprio. }\end{array}$ \\
\hline Orientação verbal indireta & $\begin{array}{l}\text { Participante necessita de um alerta verbal, tais } \\
\text { como, uma pergunta aberta ou afirmação que } \\
\text { o ajudará a continuar na tarefa. A orientação } \\
\text { verbal indireta deve vir como uma pergunta e } \\
\text { não como uma instrução para continuar a } \\
\text { tarefa. Exemplos: "O que você deve fazer } \\
\text { agora?"ou "Qual a próxima etapa?" ou "O que } \\
\text { mais você precisa?". Evite frases diretas como } \\
\text { "leia as instruções" ou "acenda o fogo". }\end{array}$ \\
\hline Orientação com gesto & $\begin{array}{l}\text { O participante necessita de uma orientação com } \\
\text { gesto. Neste nível você não está envolvida } \\
\text { fisicamente com nenhuma parte da tarefa. Você } \\
\text { deve fazer gestos que imitem a ação necessária } \\
\text { para completar a etapa da tarefa ou fazer um } \\
\text { movimento para guiar o participante. Exemplos: } \\
\text { você pode mover seus braços como se estivesse } \\
\text { mexendo, apontar onde o participante encontrará } \\
\text { o item, aponte para a posição adequada, aponte } \\
\text { para a medida certa do copo. Você não deve } \\
\text { participar fisicamente da tarefa, tal como entregar } \\
\text { o item para o participante. }\end{array}$ \\
\hline Assistência verbal direta & $\begin{array}{l}\text { Você deve falar uma ação que o participante } \\
\text { deve realizar, ou seja, você está fornecendo a } \\
\text { pista/dica para o participante realizar a tarefa. } \\
\text { Exemplos: "pegue a caneta", "coloque água na } \\
\text { panela". }\end{array}$ \\
\hline Assistência física & $\begin{array}{l}\text { Você auxilia fisicamente o participante, mas } \\
\text { você não realiza por ele/ela. Você pode segurar } \\
\text { o copo enquanto o participante derrama, segura } \\
\text { o talão de cheques enquanto ele/ela preenche, } \\
\text { separa o medicamento do container, porém o } \\
\text { participante continua participando ativamente da } \\
\text { tarefa. }\end{array}$ \\
\hline Realiza pelo individuo & Você realizará a etapa para o participante. \\
\hline
\end{tabular}

\section{Diretrizes das dicas:}

O Avaliador fornece as dicas necessárias para auxiliar a evitar os erros e completar a tarefa. Não espere a pessoa cometer um erro para fornecer a pista/dica.

- A menos que o participante esteja em perigo (exemplos: participante colocando a jarra de água na mesa onde pode cair e quebrar, colocar a panela quente na boca do fogão, verificar com a mão se a boca do fogão ou forno está quente, colocar a manga da camisa no fogo). Não intervenha até que o participante mostre que ele/ela não está processando qual é a próxima etapa. 
- Se a pessoa tem dificuldade com qualquer aspecto da tarefa, você deve dar tempo maior para que ele/ela processe antes de fornecer uma dica. Não espere muito para permitir que ele/ela cometa

erros.

- De duas (2) dicas de cada tipo antes de prosseguir para o próximo nível de pistas/dicas.

- Forneça as dicas progressivas (veja abaixo) a partir da: orientação verbal $\rightarrow$ orientação gestual $\rightarrow$ assistência verbal direta $\rightarrow$ assistência física. Se o participante continuar incapaz de desempenhar a etapa da tarefa, o avaliador deverá realizar a etapa por ele/ela e depois o participante deverá receber novas pistas/dicas para prosseguir na próxima etapa da tarefa.

- Uma vez que você determinou que a pessoa necessita de orientação verbal, as pistas/dicas devem prosseguir para fornecer a assistência verbal para completar a tarefa sem dificuldades.

- Você pode ser ver dando diferentes níveis de dicas (várias orientações verbais, gestos, uma direção específica, ou assistência). A pontuação relacionada ao nível de assistência deverá corresponder ao nível mais elevado de dicas fornecidos para que a tarefa seja concluída.

- Não inicie nenhum tipo de conversa durante o teste e não comente sobre a tarefa, ou seja, não forneça um parecer positivo nem negativo.

0 que deve ser observado e registrado durante o teste? $O$ avaliador observa 0 participante realizando a tarefa, com o foco nas cinco (5) funções executivas (iniciação, organização, sequencia finalização e julgamento e segurança). $O$ avaliador registra o nível de dicas necessárias para que 0 participante realize a tarefa. O nível mais elevado de dicas fornecidas será pontuado e não o número de dicas fornecidas. (veja um exemplo abaixo).

\begin{tabular}{|c|c|c|c|c|c|c|c|}
\hline $\begin{array}{l}\text { Tarefa: } \\
\text { Cozinhar }\end{array}$ & $\begin{array}{l}\text { Inde } \\
\text { pend } \\
\text { ente } \\
\\
\\
0\end{array}$ & $\begin{array}{l}\text { Orie } \\
\text { ntaç } \\
\text { ão } \\
\text { verb } \\
\text { al } \\
\\
\\
1\end{array}$ & $\begin{array}{l}\text { Orie } \\
\text { ntaç } \\
\text { ão } \\
\text { com } \\
\text { gest } \\
0 \\
\\
2\end{array}$ & $\begin{array}{l}\text { Instruç } \\
\text { ão } \\
\text { verbal } \\
\text { direta } \\
\qquad 3\end{array}$ & $\begin{array}{l}\text { Assistê } \\
\text { ncia } \\
\text { física } \\
\\
\\
\\
4\end{array}$ & $\begin{array}{l}\text { Realizar } \\
\text { pelo } \\
\text { participan } \\
\text { te } \\
\qquad 5\end{array}$ & Pontuação \\
\hline $\begin{array}{l}\text { Iniciação: início } \\
\text { da tarefa }\end{array}$ & & & & & & & \\
\hline $\begin{array}{lr}\text { A partir } & \text { do } \\
\text { comando } & \text { do } \\
\text { avaliador, } & \text { o } \\
\text { participante } & \text { inicia } \\
\text { a tarefa r se } \\
\text { dirigindo para } \\
\text { local adequado. }\end{array}$ & $\mathbf{X}$ & & & & & & 0 \\
\hline $\begin{array}{l}\text { Execução: } \\
\text { realização da } \\
\text { tarefa a partir da } \\
\text { organização, } \\
\text { sequenciamento e } \\
\text { julgamento. }\end{array}$ & & & & & & & \\
\hline $\begin{array}{lr}\text { Organização: } & \\
\text { organização das } \\
\text { ferramentas } \\
\text { materiais } \\
\text { necessários } & \\
& \text { para }\end{array}$ & & $\mathbf{X}$ & $\mathbf{X}$ & $\mathbf{X}$ & & & 3 \\
\hline
\end{tabular}




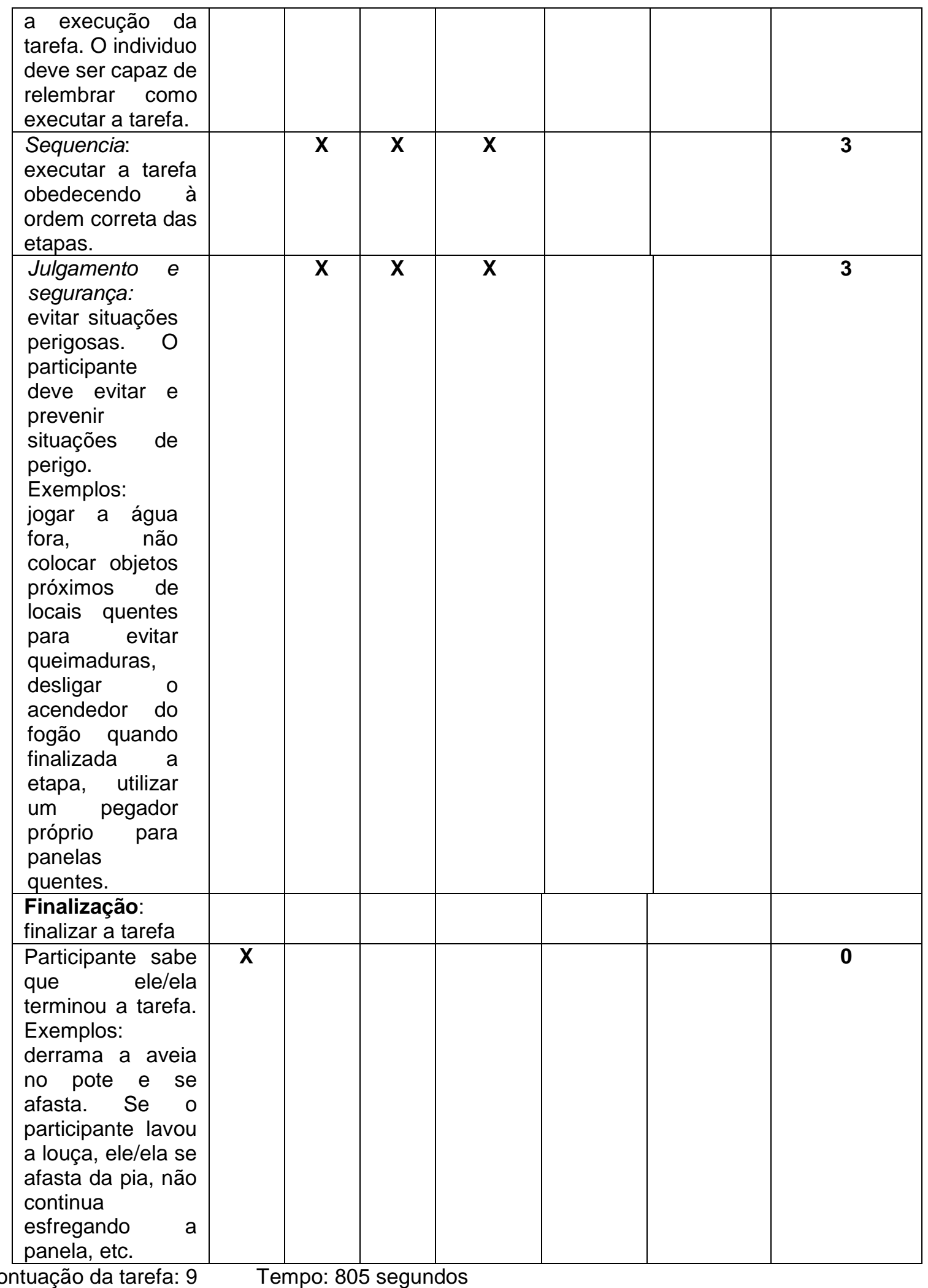

Pontuação da tarefa: 9

Eu posso modificar as instruções? O TDFE é um teste cognitivo formal que deve seguir rigorosamente as normas do protocolo. Não deve ocorrer de maneira nenhuma as modificações das instruções. Qualquer modificação na maneira do padrão do teste causará uma perda na validade do teste. Para evitar influencias negativas, o avaliador não deve ter preconceitos sobre a capacidade do participante. Todos os testes devem ser realizados independente das preferências e experiências do participante com os itens da tarefa. O TDFE foi desenvolvido para todos os níveis de funcionalidade para estabelecer o nível de assistência necessária para as tarefas. 
Portanto todos os participantes podem ser pontuados com esta medida, especialmente por ser possível pontuar quando a assistência física é fornecida e quando a pessoa não é capaz de cumprir a tarefa.

\section{Perguntas Frequentes:}

Como você pontua se o cliente não quer realizar uma dos subtestes? Você disse no início do teste que isto é um teste e que pode ser que realize ou não estas tarefas no dia-a-dia. Leve um tempo maior para explicar que é importante que tenha todas as informações utilizadas nestes testes e tente convence (a) a continuar na tarefa. Pergunte se ele/ela quer realizar outro subtesteque ele/ela não esteja tão ansioso e depois retornar para este subteste.

$E$ se a pessoa nunca utilizou um talão de cheques? Você utilizará a pergunta no pré-teste: você já utilizou um talão de cheques? E depois perguntará: você sabe como utilizar um talão de cheques? Se ele/ela não souber como utilizar um talão de cheques pule este teste como se você estivesse pontuando por falta de conhecimento e não por desempenho cognitivo.

Como eu diferencio a assistência física devido ao déficit motor e a assistência física devido ao déficit cognitivo? Você dirá para a pessoa antes de começaro teste que ele/ela poderá solicitar assistência quando necessário. Se a pessoa solicitar que você realize a tarefa for ele/ela, você deverá pontuar como 0. Desta forma, ele/ela saberá. Vocêestá pontuando o desempenho cognitivo e não o desempenho motor.

\section{Preparando os itens para o teste:}

("os itens devem ser armazenados em uma caixa limpa de 27"x16"x12" de profundidade)

- Sabonete na saboneteira (igual aos encontrados em casa)

- Papel toalha (se você utilizar a toalha deverá lava-la após cada uso)

- Panela (com cabo que esquente para que possa utilizar o pegador)

- Pegador de panela quente

- Descanso de panela quente para colocar a panela ao lado da pia quando finalizar a tarefa (deixe no local antes de começar a tarefa).

- Apoio para a colher

- Um copo medidor

- Copos secos de medida

- Colher para mexer

- Espátula de borracha

- Aveia

- Cumbuca

- Colher para comer

- Saleiro

- Cronometro (que possa ser utilizado por 2 minutos)

- Papel e lápis

- Caderno de telefones

- Lente de aumento

- Frasco de remédios com instruções e o nome da pessoa dentro (coloque balinhas sem açúcar dentro)

- Frasco de remédios com instruções e o nome de outra pessoa dentro (coloque balinhas sem açúcar dentro)

- Bolachas água-sal

- Outro frasco (sem medicamento) para ser usado como distrator (coloque balinhas sem açúcar dentro)

- Copo para beber

- Duas contas (TV a cabo - vencimento em 30 dias; telefone - vencimento imediato) em envelopes pré-endereçados. Misture com outras cinco correspondências (conta do cartão de 
crédito, cartão postal, panfleto, carta em envelope em branco, catalogo do correio) em um saquinho plástico.

- Talão de cheques com o nome da pessoa

- Recibo do saldo bancário (exemplo: extrato bancário) com um saldo de $\mathrm{R} \$ 15$, menor que o valor das contas.

- Caneta

- Calculadora

- Alguns itens para confundir

- Pinça

- Pimenteira

- Receita para cozinhar como aquelas que vêm na caixa de aveia (pode ser que eles não consigam ler as letras miúdas). Exceção: diga para cozinhar por 2 minutos (então terá o tempo que eles devem seguir e usar o cronometro, se necessário de a pista/dica).

- $\quad$ Cronometro (você pode usar o seu celular como cronometro)

- $\quad$ Prepare um cartão resposta para o pré-teste.

- Coloque as contas e as demais correspondências no saco plástico

- Coloque os medicamentos em um saco plástico.

\section{Checklist do pré-teste}

- Verifique o container da aveia (deve estar pela metade e nunca menos de um copo)

- Coloque o nome do paciente no rotulo do frasco de medicamento e coloque no saco de medicamentos

- No frasco do medicamento incorreto (que servirá com distração) deve ter outro nome no rotulo

- Certifique-se que o frasco de medicamentos tem quantidade suficiente de falso medicamento

- Coloque o nome e endereço do participante e lacre o envelope

- Remova qualquer envelope velho do saco das correspondências

- Não coloque o talão de cheques no saco de correspondências e certifique-se que os envelopes endereçados ao participante estejam misturados com aqueles que servirão para confundi-lo.

- Coloque a data de vencimento na conta da TV a cabo aproximadamente três semanas após a data do teste

- Papel tolha na caixa do teste

- Coloque o nome do participante em 2 folhas de cheques do talão de cheques

- Perforate the bills so they can be torn to return in the envelop

- Saldo do talão de cheques deve ser registrado como está abaixo:

\begin{tabular}{|l|r|r|l|l|l|l|l|l|l|l|}
\hline $\begin{array}{l}\text { Nú } \\
\text { mer } \\
\text { o }\end{array}$ & Data & $\begin{array}{l}\text { Desc } \\
\text { rição } \\
\text { da } \\
\text { Tran } \\
\text { saçã } \\
\text { o }\end{array}$ & $\begin{array}{l}\text { Pagam } \\
\text { ento/ } \\
(-)\end{array}$ & $\begin{array}{l}\text { Cóbito } \\
\text { dig } \\
\text { ( }\end{array}$ & $\begin{array}{l}\text { Taxa } \\
\mathrm{s}\end{array}$ & $\begin{array}{l}\text { Deposi } \\
\text { to/ } \\
\text { Pagam } \\
\text { ento } \\
(+)\end{array}$ & $\begin{array}{l}\text { Saldo } \\
\mathrm{R} \$\end{array}$ & & \\
\hline & & & & & & & & 123 & & \\
\hline & $\begin{array}{r}05 / 0 \\
1\end{array}$ & $\begin{array}{r}\text { Comi } \\
\text { da }\end{array}$ & 33 & 24 & & & & 89 & & 76 \\
\hline
\end{tabular}

\section{Orientações para o teste TDFE}

As tarefas devem ser realizadas na seguinte ordem:

- Preparação de uma refeição simples (folha de pontuação B)

- Telefone (folha de pontuação C)

- Administrando a medicação (folha de pontuação D) 
- $\quad$ Pagar as contas (folha de pontuação E)

- Certifique-se de que a área de trabalho está limpa e organizada para o participante trabalhar.

\section{Administrando a Avaliação:}

1. Inicie o TDFE com as instruções e as questões do pré-teste

2. Deixe todos os itens necessários para a avaliação na caixa ou em cima da mesa ("mesa dos materiais"). Deixe em um banco ou mesa mais baixa se a pessoa estiver na cadeira de rodas. (contas e correspondências devem estar misturadas no saco; o talão de cheques deve conter as folhas de cheque dentro; os outros itens devem estar soltos na caixa).

3. Peça para a pessoa iniciar a tarefa (use o texto de procedimentos).

4. Ofereça assistência apenas depois que o participante tenha feito uma boa tentativa para proceder na tarefa.

5. Complete as tabelas de comportamento e pistas/dicas para cada uma das tarefas.

6. Cronometre e registre o tempo em minutos e segundos de cada tarefa na folha de pontuação (respectiva de cada tarefa).

7. Complete a folha de pontuação com informações de cada tarefa.

Quando realizar o teste em um local tipo cozinha do serviço de Terapia Ocupacional/ hospital / Centro de reabilitação, certifique-se que o participante possa alcançar os acendedores das bocas do fogão, que o jarro de água esteja pela metade e que ele/ela possa alcançar e olhar.

\section{Script - Texto de Procedimentos}

\section{(Peça para a pessoa desligar ou deixar no silencioso o celular)}

- "Hoje eu pedirei para você fazer um mingau de aveia, usar o telefone, tomar um medicamento falso e pagar algumas contas falsas. Pode ser que você não realiza uma dessas tarefas em casa, mas elas foram selecionadas como as tarefas mais realizadas no dia-a-dia. Se você necessitar da minha ajuda em qualquer momento da tarefa, me avise."

- "Esta é uma avaliação e eu responderei as perguntas que você me fizer, mas nós não teremos uma conversa durante este teste, quero avisa-lo para você não achar que eu não sou amigável.

- "Todos os itens necessários para a realização da tarefa estão dentro desta caixa (mostre a caixa). Quero saber algumas coisas sobre você, antes que eu comece a avaliação, então te farei algumas perguntas. Por favor, responda da melhor maneira que você puder. Este cartão deve guiar as suas respostas. " (Mostre para o participante o cartão de respostas e pergunte direto dele).

\section{Questões Pré-teste:}

- Você cozinha? 1=Sim 2=não

- Você usa o fogão para cozinhar? 1=Sim 2=não

- Você fez recentemente um mingau de aveia? 1=Sim 2=não

- Você será capaz de preparar um mingau de aveia:

$0=$ independente

$1=$ com orientação verbal

$2=$ com assistência física

$3=$ você não será capaz de realizar esta tarefa

- Normalmente você usa o telefone? 1=Sim 2=não

- Quantas vezes por semana você usa o telefone?

- Qual o número de telefone você liga em caso de emergência?

1=correto 2=incorreto

- Você será capaz de fazer uma ligação telefônica:

$0=$ independente

$1=$ com orientação verbal

$2=$ com assistência física 
$3=$ você não será capaz de realizar esta tarefa

- Você toma algum medicamento? 1=Sim 2=não

- Você pode me dizer onde você guarda a sua medicação?

$1=\operatorname{Sim} 2=$ não

- Quando você toma sua medicação?

$1=$ manhã

$2=$ tarde

$3=$ noite

$4=$ antes de dormir

$5=$ mais de uma vez por dia (ou vezes, exemplo 2 vezes por semana).

- Você será capaz de tomar sua medicação adequadamente:

$0=$ independente

$1=$ com orientação verbal

$2=$ com assistência física

$3=$ você não será capaz de realizar esta tarefa

- Você paga as suas contas? $1=\operatorname{Sim} 2=$ não

- Alguém paga as suas contas para você? $1=\operatorname{Sim} 2=$ não

- Você alguma vez usou um talão de cheques? 1=Sim 2=não

- Você sabe como usar um talão de cheques? 1=Sim 2=não

Nota: Se a pessoa nunca viu nem usou um talão de cheques, não realize a tarefa do pagamento de contas (folha de pontuação $\mathrm{E}$ ), pois você estará fornecendo pistas/dicas devido à falta de conhecimento e não pela alteração de processamento.

- Você será capaz de pagar uma conta:

$0=$ independente

$1=$ com orientação verbal

$2=$ com assistência física

$3=$ você não será capaz de realizar esta tarefa

\section{Teste de Desempenho da Função Executiva (TDFE)}

Tarefa: preparar uma refeição simples

Itens necessários para esta tarefa:

- Panela (com cabo que esquente para que possa utilizar o pegador)

- Pegador de panela quente

- Um copo medidor

- Copos secos de medida

- Colher para mexer

- Espátula de borracha

- Aveia instantânea (2 minutos para cozinhar)

- Uma cópia grande da receita (instruções) de como prepara a o mingau no fogão em 2 minutos.

- Cumbuca

- Colher para comer

- Saleiro

- Cronometro (que possa ser utilizado por 2 minutos)

Inicie a Tarefa:

"Eu quero que você prepare um mingau de aveia. As instruções estão na embalagem. Aqui em uma cópia maior caso você necessite (entregue para o participante). Por favor, leia para mim para eu ter certeza que você sabe o que deve ser feito. Siga esta receita e quando você terminar coloque o mingau nesta cumbuca. Os itens que você necessita estão nesta caixa."

Caso eles não tenham todos os itens necessários antes de começar, pergunte (primeira pista/dica) se eles precisarão de mais algum material; depois (segunda pista/dica) aponte para a caixa; depois 
(terceira pista/dica) Ihe mostre (pista/dica direta) o item necessário ou auxilie o participante. Caso o participante tenha uma alteração motora ele/ela pode solicitar que você pegue o item da caixa, neste caso não pontue como uma pista/dica de assistência física. Nota: o participante não deve ser penalizado caso não lave/limpe a cumbuca e/ou a panela.

Teste de Desempenho para Função Executiva: folha de pontuação B

\begin{tabular}{|c|c|c|c|c|c|c|c|}
\hline Tarefa: Cozinhar & $\begin{array}{l}\text { Ind } \\
\text { epe } \\
\text { nd } \\
\text { ent } \\
\text { e } \\
\\
0\end{array}$ & $\begin{array}{l}\text { Ori } \\
\text { ent } \\
\text { açã } \\
0 \\
\text { ver } \\
\text { bal } \\
\\
\\
1\end{array}$ & $\begin{array}{c}\text { Orien } \\
\text { tação } \\
\text { com } \\
\text { gesto } \\
\\
2\end{array}$ & $\begin{array}{l}\text { Instru } \\
\text { ção } \\
\text { verbal } \\
\text { direta } \\
\qquad 3\end{array}$ & $\begin{array}{l}\text { Assi } \\
\text { stên } \\
\text { cia } \\
\text { físic } \\
\text { a } \\
\\
4\end{array}$ & \begin{tabular}{l} 
Reali \\
zar \\
pelo \\
partic \\
ipant \\
e \\
\multicolumn{1}{|l}{5}
\end{tabular} & $\begin{array}{l}\text { Pontua } \\
\text { ção }\end{array}$ \\
\hline $\begin{array}{l}\text { Iniciação: início da } \\
\text { tarefa }\end{array}$ & & & & & & & \\
\hline $\begin{array}{l}\text { A partir do comando } \\
\text { do avaliador, } \\
\text { participante inicia a } \\
\text { tarefa se dirigindo } \\
\text { para o loca } \\
\text { adequado. }\end{array}$ & & & & & & & \\
\hline $\begin{array}{l}\text { Execução: } \\
\text { realização da tarefa } \\
\text { a partir da } \\
\text { organização, } \\
\text { sequenciamento } \\
\text { julgamento. }\end{array}$ & & & & & & & \\
\hline $\begin{array}{l}\text { Organização: } \\
\text { organização das } \\
\text { ferramentas } \\
\text { materiais } \\
\text { necessários para a } \\
\text { execução da tarefa. } \\
\text { O individuo deve ser } \\
\text { capaz de relembrar } \\
\text { como executar a } \\
\text { tarefa (panela, } \\
\text { pegador, aveia, } \\
\text { receita, copo para } \\
\text { medir, colher). }\end{array}$ & & & & & & & \\
\hline $\begin{array}{l}\text { Sequencia: executar } \\
\text { a tarefa obedecendo } \\
\text { à ordem correta das } \\
\text { etapas. Participante } \\
\text { executa as etapas } \\
\text { tarefa conforme a } \\
\text { receita. } \\
\text { participante coloca a } \\
\text { água na panela, } \\
\text { acende a boca do } \\
\text { fogão, deixa a } \\
\text { temperatura do } \\
\text { fogão adequada, } \\
\text { ferve a água, mede a } \\
\text { aveia, coloca a aveia }\end{array}$ & & & & & & & \\
\hline
\end{tabular}




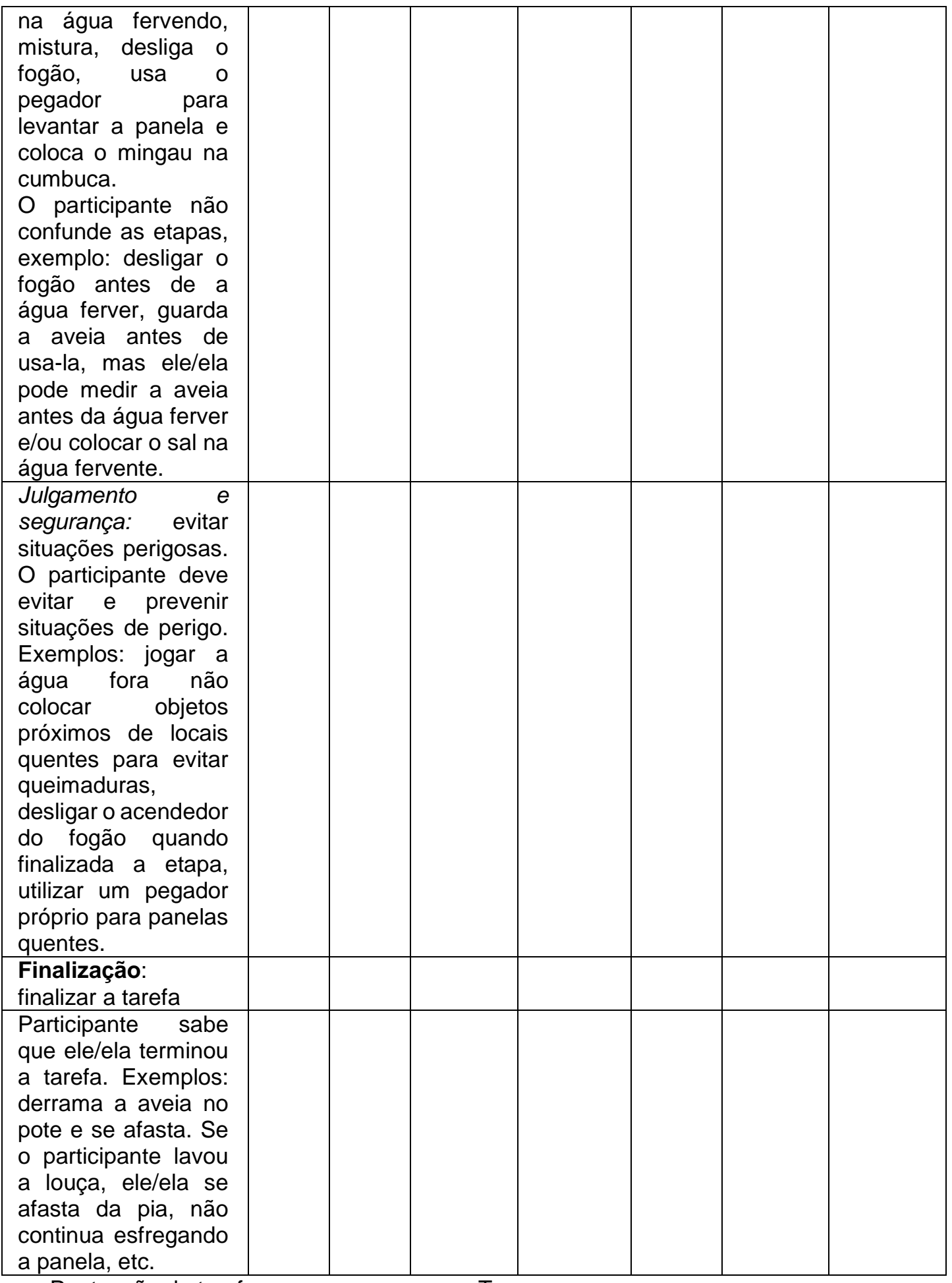

Pontuação da tarefa:

Tempo:

Tarefa: uso do telefone Itens necessários:

- Lápis

- Papel

- Caderno de telefones

- Lente de aumento

- Um cartão que de instruções de como fazer uma ligação externa 
Inicie a tarefa:

"Eu quero que você encontre o telefone do mercado para comprar comida, mais próximo, ligue para eles e pergunte se entregam as compras. Avisa-me o que você achou. Os itens necessários estão na caixa.

(Deixe o telefone na viva voz, assim você saberá se o número foi discado e se você precisará dar pistas/dicas).

Caso eles não tenham todos os itens necessários antes de começar, pergunte (primeira pista/dica) se eles precisarão de mais algum material; depois (segunda pista/dica) aponte para a caixa; depois (terceira pista/dica) Ihe mostre (pista/dica direta) o item necessário ou auxilie o participante. Caso o participante tenha uma alteração motora ele/ela pode solicitar que você pegue o item da caixa, neste caso não pontue como uma pista/dica de assistência física.

Teste de Desempenho para Função Executiva: folha de pontuação C

\begin{tabular}{|c|c|c|c|c|c|c|c|}
\hline $\begin{array}{l}\text { Tarefa: uso do } \\
\text { telefone }\end{array}$ & $\begin{array}{c}\text { Inde } \\
\text { pend } \\
\text { ente } \\
\\
0\end{array}$ & $\begin{array}{l}\text { Orie } \\
\text { ntaç } \\
\text { ão } \\
\text { verb } \\
\text { al } \\
\\
\\
1\end{array}$ & $\begin{array}{l}\text { Orient } \\
\text { ação } \\
\text { com } \\
\text { gesto }\end{array}$ & $\begin{array}{l}\text { Instru } \\
\text { ção } \\
\text { verbal } \\
\text { direta } \\
\qquad 3\end{array}$ & 4 & $\begin{array}{l}\text { Realiz } \\
\text { ar } \\
\text { pelo } \\
\text { partici } \\
\text { pante } \\
\qquad 5\end{array}$ & Pontuação \\
\hline $\begin{array}{l}\text { Iniciação: início da } \\
\text { tarefa }\end{array}$ & & & & & & & \\
\hline $\begin{array}{l}\text { A partir do comando } \\
\text { do avaliador, o } \\
\text { participante inicia a } \\
\text { tarefa se dirigindo } \\
\text { para o local } \\
\text { adequada e pega o } \\
\text { material necessário } \\
\text { para fazer uma } \\
\text { ligação telefônica. }\end{array}$ & & & & & & & \\
\hline $\begin{array}{l}\text { Execução: } \\
\text { realização da tarefa } \\
\text { a partir da } \\
\text { organização, } \\
\text { sequenciamento e } \\
\text { julgamento. }\end{array}$ & & & & & & & \\
\hline $\begin{array}{l}\text { Organização: } \\
\text { organização } \\
\text { ferramentas } \\
\text { materiais } \\
\text { necessários para a } \\
\text { execução da tarefa. } \\
\text { O indivíduo deve } \\
\text { ser capaz de } \\
\text { relembrar como } \\
\text { executar a tarefa e } \\
\text { materiais } \\
\text { necessários } \\
\text { (caderno } \\
\text { (c) de }\end{array}$ & & & & & & & \\
\hline
\end{tabular}




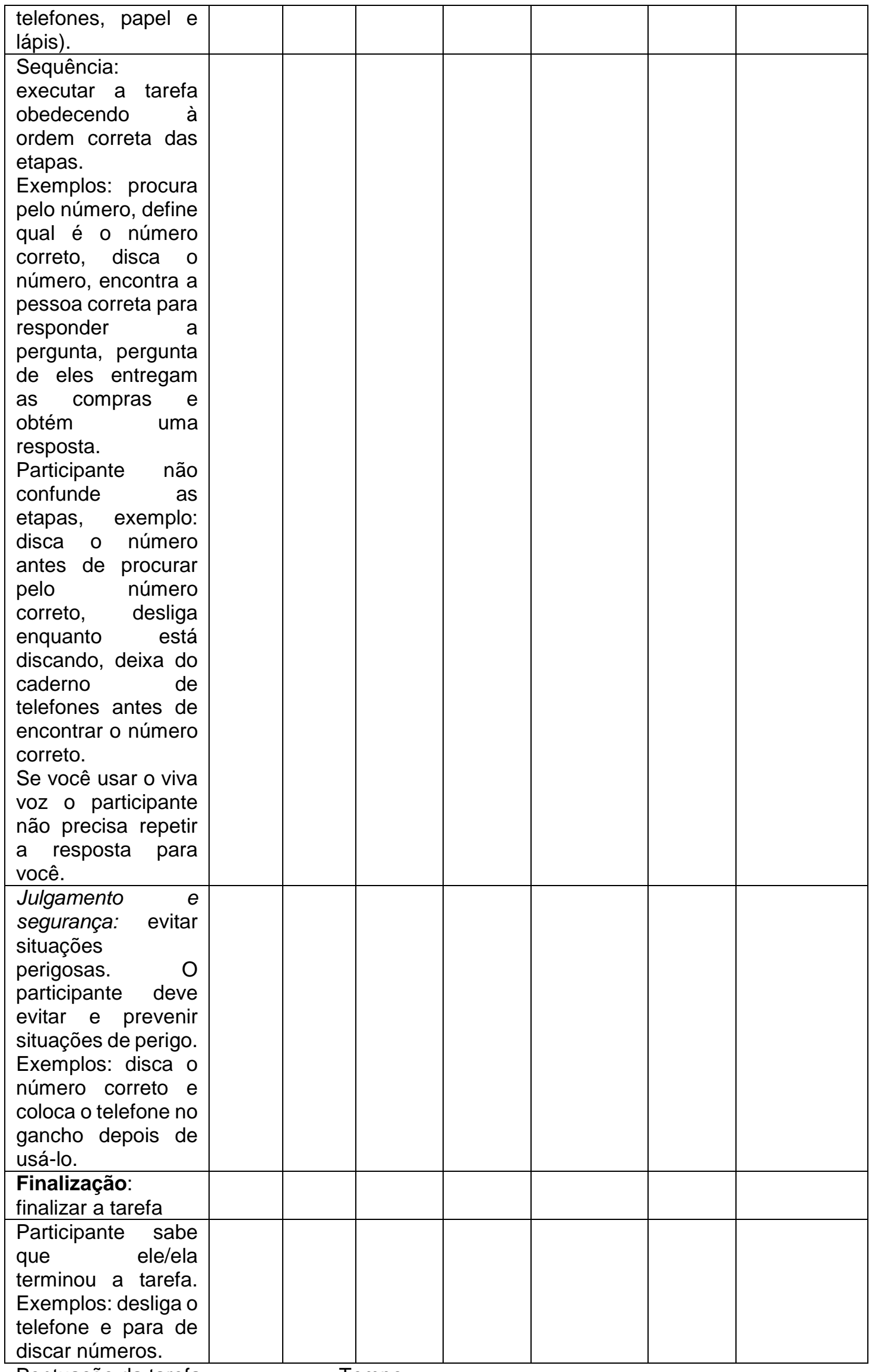

Pontuação da tarefa:

Tempo: 
Tarefa: administrar o medicamento

Itens necessários:

- Frasco de remédios com instruções e o nome da pessoa dentro (coloque balinhas sem açúcar dentro)

- Frasco de remédios com instruções e o nome de outra pessoa dentro (coloque balinhas sem açúcar dentro)

- Outro frasco (sem medicamento) para ser usado como distrator (coloque balinhas sem açúcar dentro)

- Copo para beber

- Lentes de aumento

- Bolachas água e sal, assim o participante poderá comer depois do remédio.

Inicie a tarefa:

"Eu preciso que você faça de conta que a receita dos seus medicamentos está nesta caixa. Encontre a sua receita medica e faça o que está escrito para você fazer. As pílulas dentro dos frascos são seguras, são balinhas sem açúcar."

Caso eles não tenham todos os itens necessários antes de começar, pergunte (primeira dica) se eles precisarão de mais algum material; depois (segunda dica) aponte para a caixa; depois (terceira dica) Ihe mostre (dica direta) o item necessário ou auxilie o participante. Caso o participante tenha uma alteração motora ele/ela pode solicitar que você pegue o item da caixa, neste caso não pontue como uma pista/dica de assistência física.

Depois que eles tomarem a medicação faça as seguintes perguntas, para pontuar a capacidade de julgamento e segurança:

"Que parte do dia você deveria tomar este medicamento?"

"O que você deveria tomar com este medicamento?"

"Que cuidado você deve ter ao tomar este medicamento? 'Nota: não há problema se o participante mastigar o "falso - medicamento".

Teste de Desempenho para Função Executiva: folha de pontuação D

\begin{tabular}{|c|c|c|c|c|c|c|c|}
\hline $\begin{array}{l}\text { Tarefa: administrar } \\
\text { o medicamento }\end{array}$ & $\begin{array}{l}\text { Indep } \\
\text { enden } \\
\text { te } \\
\quad 0\end{array}$ & $\begin{array}{l}\text { Orient } \\
\text { ação } \\
\text { verbal } \\
\\
1\end{array}$ & $\begin{array}{l}\text { Orienta } \\
\text { ção } \\
\text { com } \\
\text { gesto } \\
\\
\qquad 2\end{array}$ & $\begin{array}{l}\text { Instrução } \\
\text { verbal } \\
\text { direta } \\
\\
3\end{array}$ & $\begin{array}{c}\text { Assist } \\
\text { ência } \\
\text { física } \\
\\
4\end{array}$ & 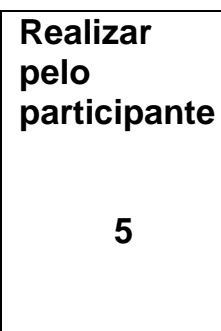 & $\begin{array}{l}\text { Pontuaçã } \\
\text { o }\end{array}$ \\
\hline $\begin{array}{l}\text { Iniciação: início da } \\
\text { tarefa }\end{array}$ & & & & & & & \\
\hline $\begin{array}{l}\text { A partir do comando } \\
\text { do avaliador, o } \\
\text { participante inicia a } \\
\text { tarefa se dirigindo } \\
\text { para o local } \\
\text { adequado para tomar } \\
\text { sua medicação. }\end{array}$ & & & & & & & \\
\hline $\begin{array}{l}\text { Execução: } \\
\text { realização da tarefa a } \\
\text { partir da } \\
\text { organização, }\end{array}$ & & & & & & & \\
\hline
\end{tabular}




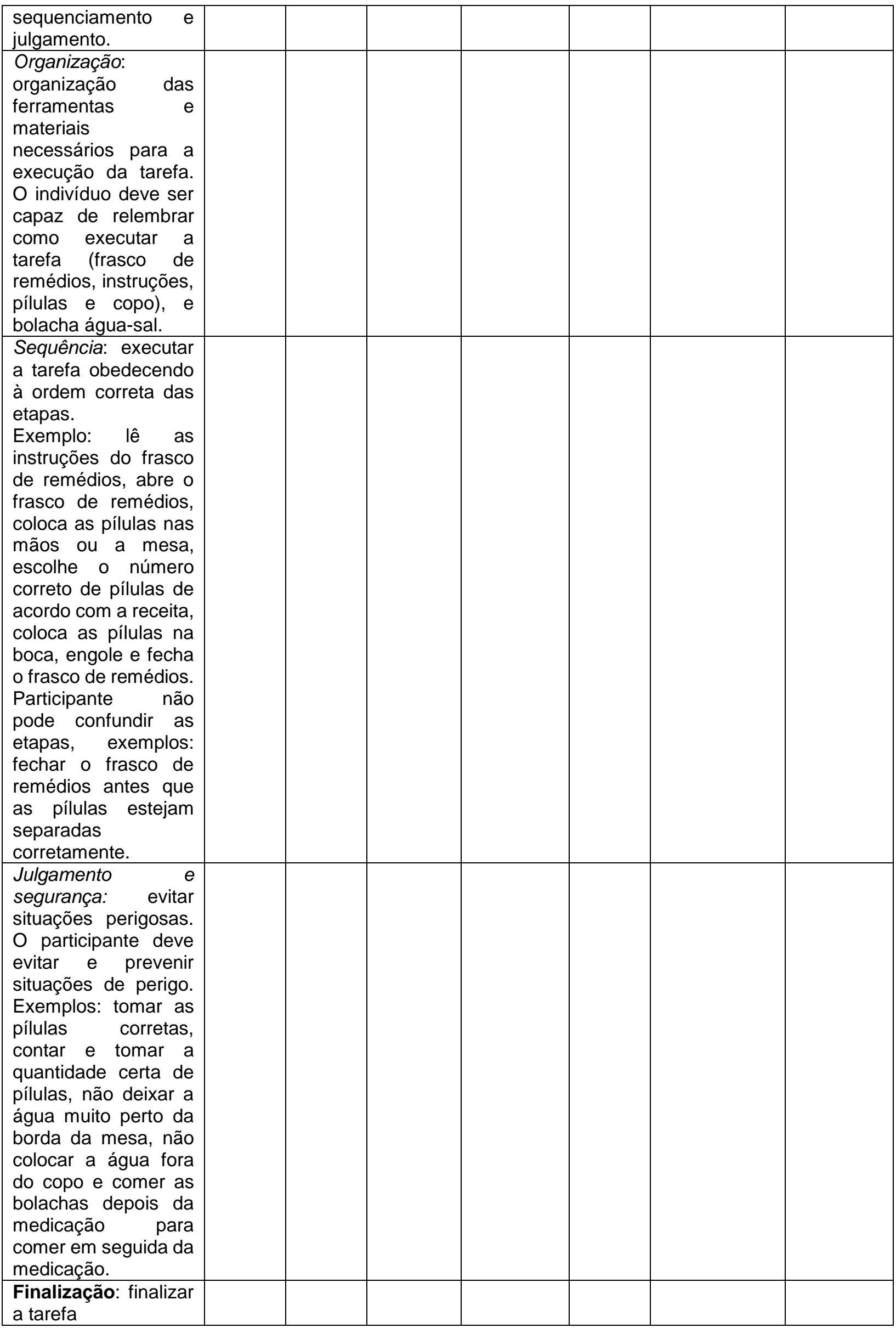




\begin{tabular}{|l|l|l|l|l|l|l|}
\hline Participante sabe & & & & & \\
que ele/ela terminou & & & & & & \\
a tarefa. Exemplos: & & & & & & \\
não abre o frasco de & & & & & & \\
remédios e brinca \\
com as pílulas.
\end{tabular}

Pontuação da tarefa:

Tempo:

Tarefa: Pagar as contas

Itens necessários:

- Duas contas (TV a cabo - vencimento em 30 dias; telefone - vencimento imediato) em envelopes pré-endereçados. Misture com outras cinco correspondências (conta do cartão de crédito, cartão postal, panfleto, carta em envelope em branco, catalogo do correio) em um saquinho plástico.

- Talão de cheques com o nome da pessoa

- Recibo do saldo bancário (exemplo: extrato bancário) com um saldo de $\mathrm{R} \$ 15$, menor que o valor das contas.

- Caneta

- Calculadora

Nota: uma das contas este vencida, a outra vence de acordo com o recibo da conta, ou seja, eles precisam revisar as duas contas antes de pagar. Pode ser que o participante necessite de uma dica.

Inicie a tarefa:

"Eu quero que você pegue o que for necessário para pagar as suas contas que estão nesta sacola, encontre as contas, abra as contas, pague as contas e compute o valor no seu saldo. Essas são contas falsas e esta não é a sua conta, mas eu preciso que você finja que estas são as suas contas e essa é a sua conta bancaria, pois isto é parte da sua avaliação."

Caso eles não tenham todos os itens necessários antes de começar, pergunte (primeira dica) se eles precisarão de mais algum material; depois (segunda dica) aponte para a caixa; depois (terceira dica) Ihe mostre (dica direta) o item necessário ou auxilie o participante. Caso o participante tenha uma alteração motora ele/ela pode solicitar que você pegue o item da caixa, neste caso não pontue como uma pista/dica de assistência física.

Nota: o uso da calculadora não é obrigatório.

Tenha certeza de qual conta vencerá imediatamente, para que você auxilie o participante a pagar a conta correta, caso ele esteja pagando a conta errada. Quando o participante estiver pagando a conta e te parecer que ele/ela não está atento aos detalhes e decide pagar primeiro a conta de telefone, pergunte: "O que te fez escolher a conta de telefone para pagar primeiro? " Esta resposta determinará se você precisará fornecer a pista/dica, pois eles precisão fazer uma escolha consciente e pagar a conta de telefone que vence primeiro do que a conta da TV a cabo.

Teste de Desempenho para Função Executiva: folha de pontuação $E$

\begin{tabular}{|l|l|l|l|l|l|l|l|}
\hline $\begin{array}{l}\text { Tarefa: } \\
\text { Pagar } \\
\text { contas }\end{array}$ & $\begin{array}{l}\text { Inde } \\
\text { pend } \\
\text { ente }\end{array}$ & $\begin{array}{l}\text { Orienta } \\
\text { ção } \\
\text { verbal }\end{array}$ & $\begin{array}{l}\text { Orienta } \\
\text { ção } \\
\text { com } \\
\text { gesto }\end{array}$ & $\begin{array}{l}\text { Instrução } \\
\text { verbal } \\
\text { direta }\end{array}$ & $\begin{array}{l}\text { Assistênci } \\
\text { a física }\end{array}$ & $\begin{array}{l}\text { Realizar } \\
\text { pelo } \\
\text { participa } \\
\text { nte }\end{array}$ & Pontuação \\
& & & & & \\
\hline
\end{tabular}




\begin{tabular}{|c|c|c|c|c|c|c|}
\hline & 0 & 1 & 2 & 3 & 4 & 5 \\
\hline $\begin{array}{l}\text { Iniciação: } \\
\text { início da } \\
\text { tarefa }\end{array}$ & & & & & & \\
\hline $\begin{array}{l}\text { A partir do } \\
\text { comando do } \\
\text { avaliador, o } \\
\text { participante } \\
\text { inicia a tarefa } \\
\text { se dirigindo } \\
\text { para o local } \\
\text { adequado } \\
\text { para pagar } \\
\text { as duas } \\
\text { contas. }\end{array}$ & & & & & & \\
\hline $\begin{array}{l}\text { Execução: } \\
\text { realização da } \\
\text { tarefa a partir } \\
\text { da } \\
\text { organização, } \\
\text { seqüenciame } \\
\text { nto julgamento. } \\
\text { jula }\end{array}$ & & & & & & \\
\hline $\begin{array}{l}\text { Organização: } \\
\text { organização } \\
\text { das } \\
\text { ferramentas } \\
\text { e materiais } \\
\text { necessários } \\
\text { para a } \\
\text { execução da } \\
\text { tarefa. O } \\
\text { indivíduo } \\
\text { deve ser } \\
\text { capaz de } \\
\text { relembrar } \\
\text { como } \\
\text { executar a } \\
\text { tarefa } \\
\text { (caneta, } \\
\text { talão } \\
\text { cheques, de } \\
\text { contas, } \\
\text { envelopes e } \\
\text { selos). }\end{array}$ & & & & & & \\
\hline $\begin{array}{l}\text { Sequência: } \\
\text { executar a } \\
\text { tarefa } \\
\text { obedecendo } \\
\text { à ordem } \\
\text { correta das } \\
\text { etapas. } \\
\text { Exemplos: } \\
\text { encontra a } \\
\text { conta que } \\
\text { tem o }\end{array}$ & & & & & & \\
\hline
\end{tabular}




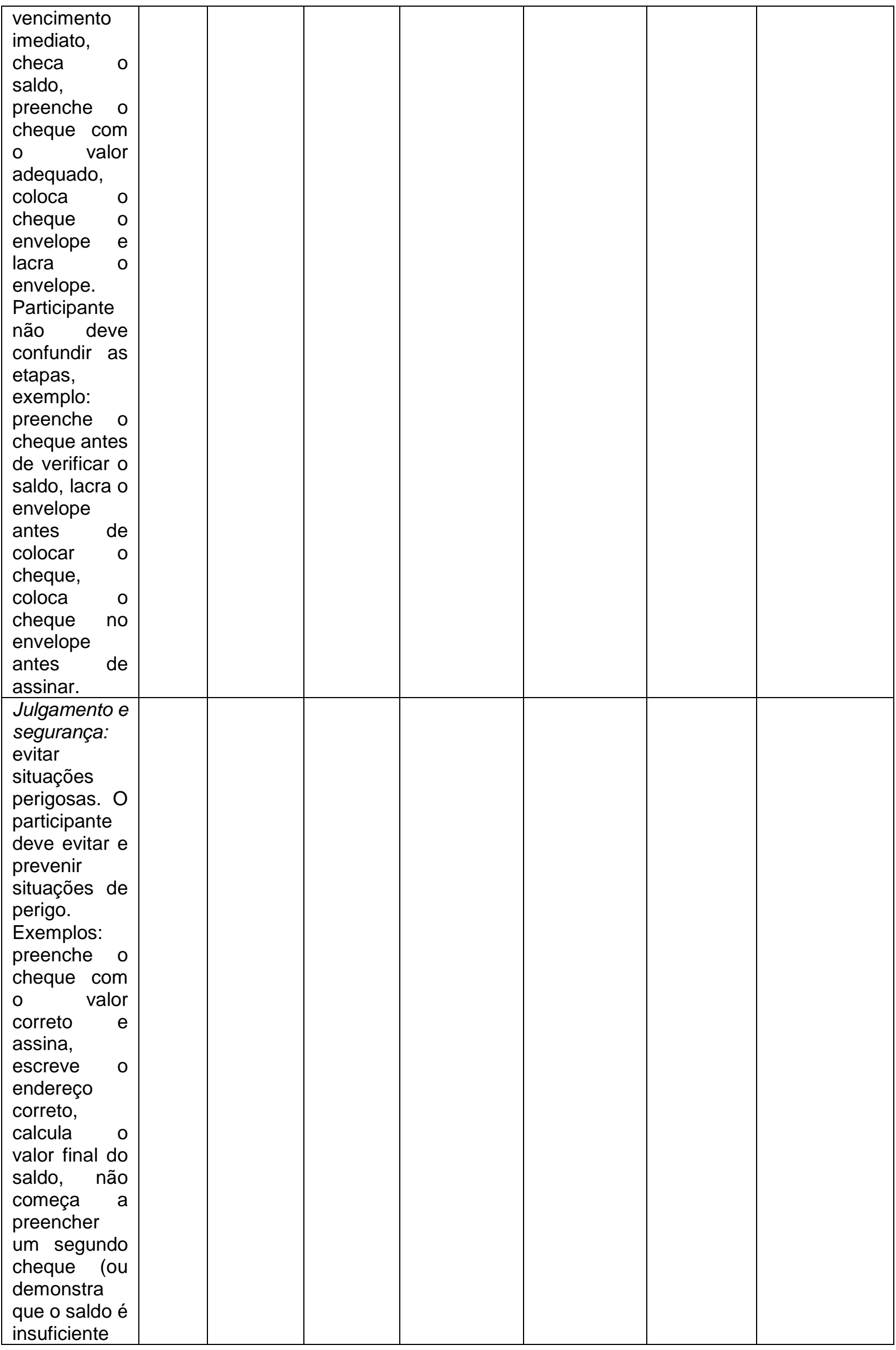




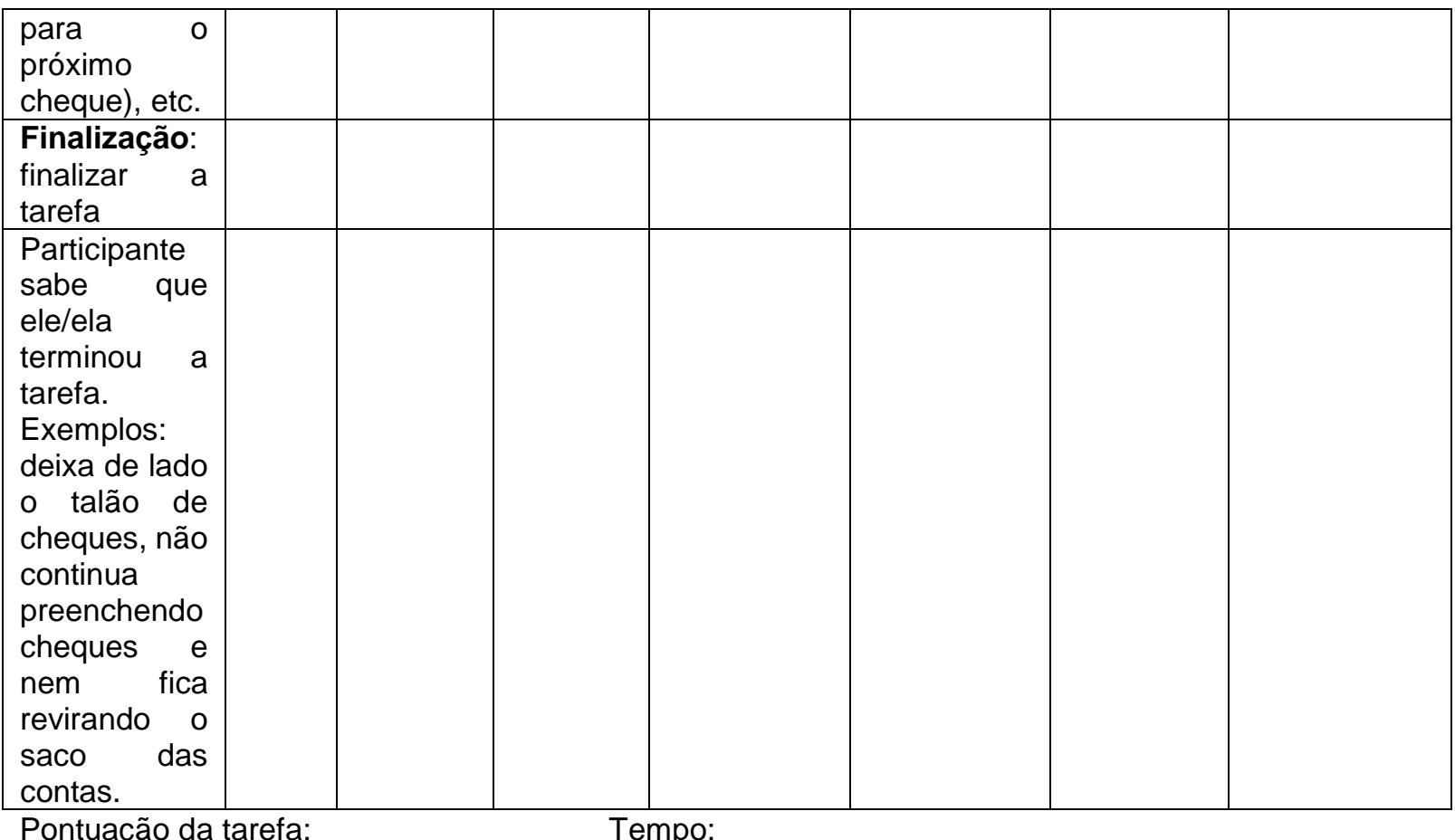

Pontuação da tarefa:

Tempo:

TDFE Resumo das Folhas da Pontuação:

\begin{tabular}{|l|l|l|}
\hline \multicolumn{2}{|c|}{ Adicione o total de cada folha de pontuação } \\
\hline Cozinhar & & \\
\hline Usar o telefone & & \\
\hline Administrar a medicação & & \\
\hline Pagar as contas & & \\
\hline Total & \\
\hline
\end{tabular}

\begin{tabular}{|c|c|c|c|c|c|}
\hline \multicolumn{6}{|c|}{$\begin{array}{l}\text { Categorias cognitivas } \\
\text { Melhor revisar as } 4 \text { folhas de pontuação para contar o total, o mais } \\
\text { alto valor de cada categoria vai neste formulário. }\end{array}$} \\
\hline $\begin{array}{l}\text { Categoria } \\
\text { Cognitiva }\end{array}$ & Cozinhar & $\begin{array}{l}\text { Usar o } \\
\text { Telefo } \\
\text { ne }\end{array}$ & $\begin{array}{c}\text { Administrar } \\
0 \\
\text { medicament } \\
0\end{array}$ & $\begin{array}{c}\text { Pagar } \\
\text { as } \\
\text { conta } \\
\text { s }\end{array}$ & $\begin{array}{c}\text { Pontuaçã } \\
\text { o total }\end{array}$ \\
\hline \multicolumn{6}{|l|}{ Iniciar } \\
\hline \multicolumn{6}{|l|}{ Organizar } \\
\hline \multicolumn{6}{|l|}{ Sequencia } \\
\hline \multicolumn{6}{|l|}{$\begin{array}{l}\text { Julgament } \\
\text { o \& } \\
\text { segurança }\end{array}$} \\
\hline Finalizar & & & & & \\
\hline
\end{tabular}

\begin{tabular}{|l|l|l|l|}
\hline \multicolumn{5}{|c|}{$\begin{array}{l}\text { Questões Pré - teste } \\
\text { Respostas do participante }\end{array}$} \\
\hline & Sem ajuda & Com ajuda & $\begin{array}{l}\text { Não é capaz de } \\
\text { realizar }\end{array}$ \\
\hline Cozinhar & 0 & 1 & 2 \\
\hline
\end{tabular}




\begin{tabular}{|l|l|l|l|}
\hline Usar o Telefone & 0 & 1 & 2 \\
\hline $\begin{array}{l}\text { Administrar } \\
\text { medicamento }\end{array}$ & 0 & 1 & 2 \\
\hline Pagar as contas & 0 & 1 & 2 \\
\hline
\end{tabular}

\begin{tabular}{|l|l|l|l|}
\hline \multicolumn{5}{|c|}{$\begin{array}{c}\text { Desempenho atual/real } \\
\text { Experiências do avaliador }\end{array}$} \\
\hline & Sem ajuda & Com ajuda & $\begin{array}{l}\text { Não é capaz de } \\
\text { realizar }\end{array}$ \\
\hline Cozinhar & 0 & 1 & 2 \\
\hline Usar o Telefone & 0 & 1 & 2 \\
\hline $\begin{array}{l}\text { Administrar } \\
\text { medicamento }\end{array}$ & 0 & 1 & 2 \\
\hline Pagar as contas & 0 & 1 & 2 \\
\hline
\end{tabular}

\begin{tabular}{|l|l|l|}
\hline \multicolumn{4}{|c|}{ Potencial para alteração na percepção de suas } \\
dificuldades \\
\hline A quantidade de ajuda & Sim & Não \\
\hline necessária para realizar as & & \\
tarefas estimada pelo \\
participante e pelo avaliador foi à \\
mesma. (Caso não seja, por \\
favor especifique) & \\
\hline A quantidade de ajuda & \\
necessária para realizar as & \\
tarefas estimada pelo & \\
participante e pelo avaliador foi & \\
maior do que esperado ado ada & \\
\hline A quantidade de ajuda & \\
necessária para realizar as & \\
tarefas estimada pelo & \\
participante e pelo avaliador foi & \\
menor do que esperado & \\
\hline
\end{tabular}

\begin{tabular}{|c|c|}
\hline & $\begin{array}{l}\text { Estimativa incorreta: } \\
\text { a estimativa incorreta seja maior do que em } 4 \text { (caso } 1 \text { das } \\
4 \text { tarefas, marcar sim na pergunta abaixo) }\end{array}$ \\
\hline & 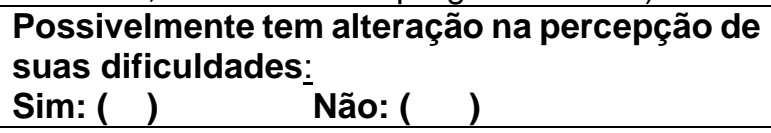 \\
\hline
\end{tabular}




\section{Anexo IV: Artigo publicado - Diversity of approaches in} assessment of executive functions in stroke: limited evidence? (DOI: http://dx.doi.org/10.1016/j.ensci.2015.08.002)

\begin{tabular}{lcc}
\hline & Contents lists available at ScienceDirect & eNS \\
ELSEVIER & eNeurologicalSci & eNeurologicasci \\
\hline
\end{tabular}

Review article

Diversity of approaches in assessment of executive functions in stroke:

Limited evidence?

Juliana Conti ${ }^{\mathrm{a}, *}$, Annette Sterr ${ }^{\mathrm{a}, \mathrm{b}}$, Sônia Maria Dozzi Brucki ${ }^{\mathrm{a}}$, Adriana B. Conforto ${ }^{\mathrm{a}, \mathrm{c}}$

a Neurostimulation Laboratory, Neurology Clinical Division, Hospital das Clinicas/Sao Paulo University, Brazil

School of Psychology, University of Surrey, Guildford, UK

' Hospital Isroelita Albert Einstein, São Paulo, Brazil

\section{A R T I C L E I N F O}

Article history:

Received 11 August 2015

Accepted 12 August 2015

\section{Keywords:}

Stroke

Executive function

Evaluation methodology

Cognition

\section{A B S T R A C T}

Stroke is a leading cause of disability worldwide. Cognitive functions and, in particular, executive function, are commonly affected after stroke, leading to impairments in performance of daily activities, decrease in social participation and in quality of life. Appropriate assessment and understanding of executive dysfunction are important, firstly to develop better rehabilitation strategies for executive functions per se and secondly to consider executive function abilities on rehabilitation strategies in general. The purpose of this review was to identify the most widely used assessment tools of executive dysfunction for patients with stroke, and their psychometric properties.

We systematically reviewed manuscripts published in English in databases from 1999 to 2015. We identified 35 publications. The most frequently used instruments were the Stroop. Digit Span and Trail making tests. Psychometric properties were described for the Executive Function Performance Test, Executive Clock Drawing Task, Chinese Frontal Assessment Battery and Virtual Action Planning - Supermarket, and two subtests Drawing Task, Chinese Frontal Assessment Battery and

of the Cambridge Cognitive Examination - Revised.
There is a paucity of tools to reliably measure executive dysfunction after stroke, despite the fact that executive dysfunction is frequent. Identification of the best tools for executive dysfunction assessment is necessary to address important gaps in research and in clinical practice.

Q 2015 Published by Elsevier B.V. 
